AUTARQUIA ASSOCIADA À UNIVERSIDADE DE SÃO PAULO

\title{
PREPARAÇÃO, IRRADIAÇÃO E CARACTERIZAÇÃO DE BLENDAS PEAD RECICLADO/EPDM
}

LEANDRO GABRIEL

Dissertação apresentada como parte dos requisitos para obtenção do Grau de Mestre em Ciências na Área de Tecnologia Nuclear - Aplicações

Orientadora:

Profa. Dra. Áurea Beatriz Cerqueira Geraldo 
INSTITUTO DE PESQUISAS ENERGÉTICAS E NUCLEARES

Autarquia associada à Universidade de São Paulo

\section{PREPARAÇÃO, IRRADIAÇÃO E CARACTERIZAÇÃO DE BLENDAS \\ PEAD RECICLADO/EPDM}

LEANDRO GABRIEL

Dissertação apresentada como parte dos requisitos para obtenção do Grau de Mestre em Ciências na Área de Tecnologia Nuclear - Aplicações

Orientadora:

Profa. Dra. Áurea Beatriz Cerqueira Geraldo

Versão Corrigida

Versão Original disponível no IPEN

São Paulo

2016 
À Deus, pelo amor e atenção.

À minha mãe, Vera Lúcia de Oliveira, pelo exemplo de dedicação, persistência e todo apoio e confiança.

A minha esposa, Vanessa Gomes, pela paciência, compreensão e carinho.

À minha filha Cecília, um presente de Deus. 


\section{AGRADECIMENTOS}

Desejo agradecer a todos que ajudaram na realização deste trabalho, em especial: À Dra. Áurea Beatriz Cerqueira Geraldo, pela oportunidade, parceria e especial atenção no desenvolvimento deste trabalho.

Ao Dr. Cláudio Geraldo Shön, pelas inúmeras contribuições e sugestões.

Ao IPEN, em proporcionar as instalações para desenvolver a pesquisa.

Ao meu grupo de pesquisa Eduardo, Maiara e Jéssica pelo companheirismo, apoio e luta no objetivo e compromisso nas atividades.

Ao CTR, pelo apoio e condições em disponibilizar seus colaboradores, técnicos e professores para o desenvolvimento deste trabalho.

Ao Luis Roberto Santos Kretly pela gentileza de disponibilizar recursos e maquinário na confecção das amostras.

Ao Reginaldo Barbosa, pela disposição em colaborar na doação do material da pesquisa, necessária para a realização deste trabalho.

À Universidade Mackenzie por disponibilizar o equipamento de ensaio de impacto.

À NZ Cooperpolymer pela colaboração em processar as blendas. 
Entregue o teu caminho ao senhor, confie nele, e ele o fará.

Salmos 37:5. 


\title{
PREPARAÇÃO, IRRADIAÇÃO E CARACTERIZAÇÃO DE BLENDAS PEAD RECICLADO/EPDM
}

\author{
Leandro Gabriel
}

\section{RESUMO}

A reciclagem de refugos é um processo estratégico que viabiliza a expansão do mercado de plásticos, podendo gerar novos produtos. A obtenção de blendas poliméricas é uma alternativa nesse processo, já que é conhecida a perda de propriedades mecânicas dos termoplásticos nas etapas de reprocessamento. Neste trabalho, o polietileno de alta densidade (PEAD) reciclado teve adições de borracha do monômero etileno-propileno-dieno (EPDM) puro em baixos teores ( $1 \%$, $5 \%$ e $10 \%$ ), cujo objetivo foi formar blendas miscíveis e um produto final mais resistente ao impacto. O PEAD foi submetido a quatro ciclos de moagem, extrusão e injeção (reprocessamento) e misturado ao EPDM puro por extrusão sem o uso de qualquer aditivo. Os grânulos da blenda formada foram usados para confeccionar os corpos-de-prova por injeção para seu uso nas distintas metodologias analíticas. O processo de irradiação gama foi aplicado nas doses de 50 kGy e 100 kGy e os parâmetros físico-químicos e mecânicos dessas amostras foram comparados aos das não irradiadas. Tanto as blendas irradiadas como as não irradiadas mostraramse visualmente e microscopicamente homogêneas, indicando a compatibilidade da mistura, que também é verificada por seu comportamento térmico. Os parâmetros mecânicos provenientes dos ensaios de tração e flexão, foram semelhantes nas amostras do termoplástico virgem e do reciclado; o processo de irradiação nas blendas gerou sua reticulação, sendo esta verificada não só pelo aumento dos valores desses parâmetros como também pelo aumento da fração gel. A resistência ao impacto aumentou cerca de duas vezes e meia nas amostras com maior teor de EPDM e cerca de 6 a 7 vezes nestas mesmas amostras irradiadas a 50 kGy e 100 kGy respectivamente. O novo material obtido tem fortes indicativos para a sua utilização na pequena e média indústria de plástico, uma vez que já com $1 \%$ de EPDM apresentam melhores características mecânicas em relação ao termoplástico reciclado quatro vezes e essas características foram incrementadas após o processo de irradiação gama. 


\title{
PREPARATION, IRRADIATION AND CHARACTERIZATION OF RECYCLED HDPE/EPDM BLENDS
}

\author{
Leandro Gabriel
}

\begin{abstract}
Waste recycling is a process that allows for advances in plastics industry, particularly when new products are developed. Thus polymer blending is an alternative to recycling processes, since degradation of the mechanical properties of thermoplastics occurs during the reprocessing stages of the material. In this work, high density polyethylene (HDPE) was recycled and mixed to ethylene propylene diene pristine rubber (EPDM) in low concentrations (1\%, $5 \%$ and $10 \%)$ to obtain a miscible blend and a final product with high resistance to impact. Pristine HDPE was submitted to four cycles of milling, extrusion and injection (reprocessing) and then mixed with EPDM by extrusion, free of any additives whatsoever. The resulting material was then injected to obtain standard samples submitted to several analytical methods during this research. Also, gamma irradiation process was performed with $50 \mathrm{kGy}$ and $100 \mathrm{kGy}$ absorbed doses; the physical-chemical and the mechanical parameters of these samples were compared to non-irradiated samples. Irradiated and non-irradiated blends were visually and microscopically homogeneous. This indicates a compatible mixture, something which was also verified from analysis of their thermal behavior; mechanical parameters such as stress-strain and flexural curves were similar for pristine and recycled HDPE thermoplastic. On the other hand, the irradiation process on blends generates thermoplastic molecular cross-linking which is verified from increased strength values of mechanical and gel fraction tests. Impact resistance had a 2.5 fold increase with samples with higher EPDM content and about 6-7 fold increase on irradiated samples with 50-100 kGy respectively. These new materials are aimed to small and medium-scale industries, for adding as low as $1 \%$ EPDM to the blends sharply improves their mechanical characteristics when compared to recycled thermoplastic. Also, these characteristics improve even further when these materials are gamma irradiated.
\end{abstract}




\section{SUMÁRIO}

Página

1 INTRODUÇÃO

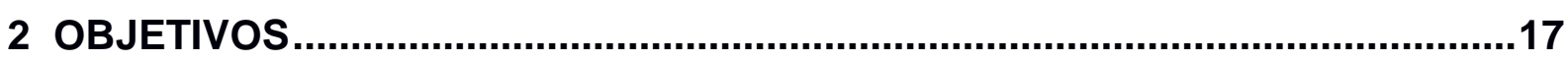

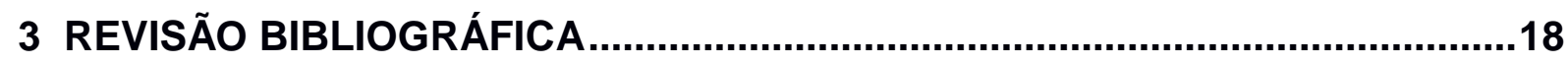

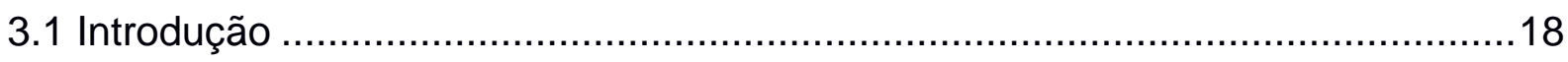

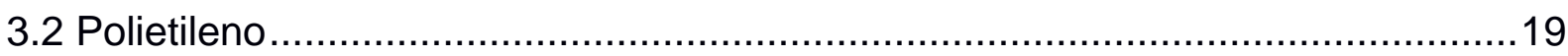

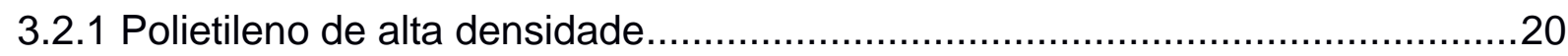

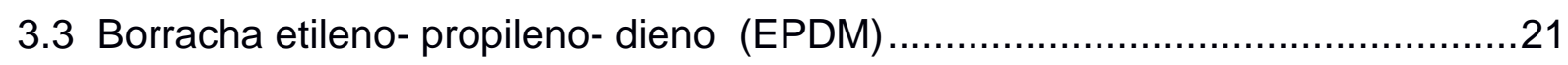

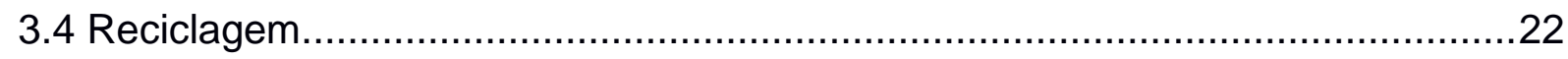

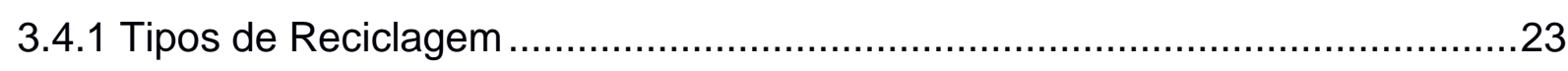

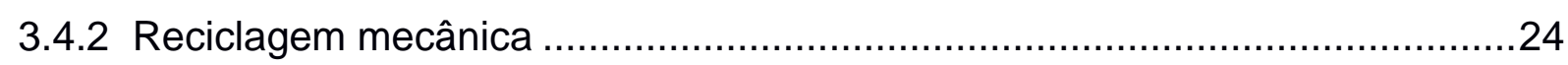

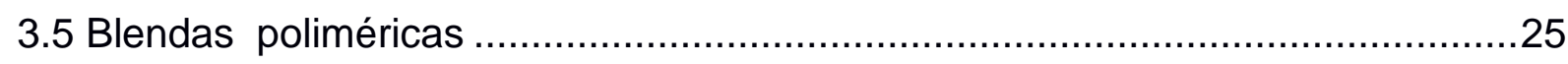

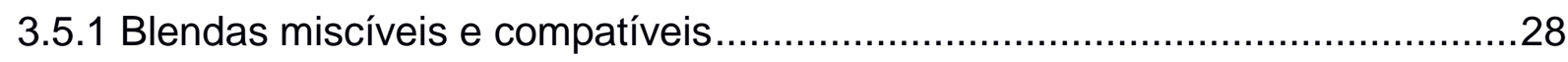

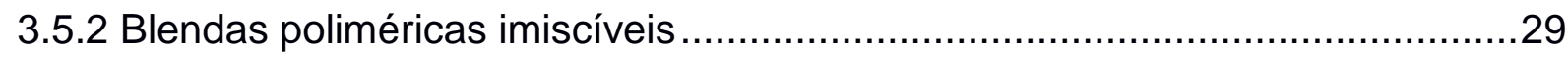

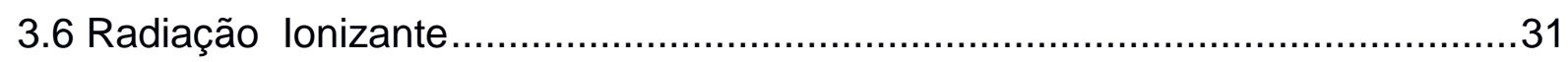

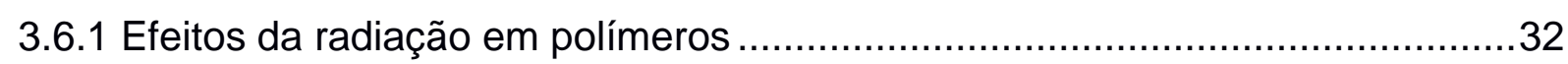

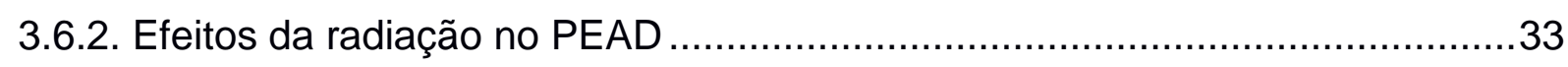

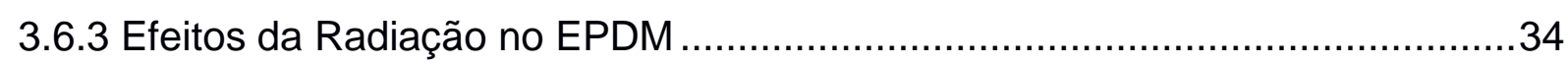

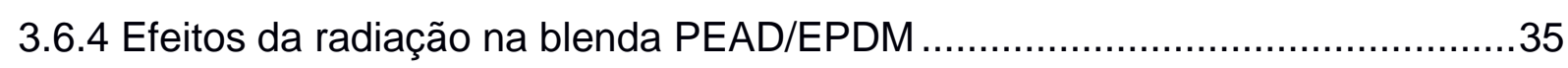

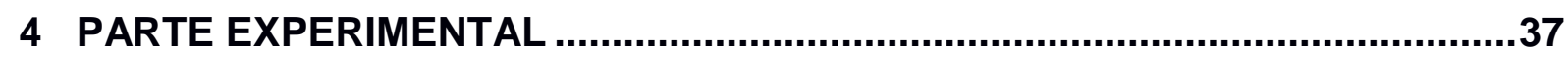

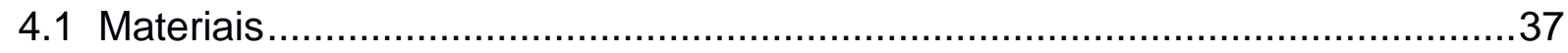

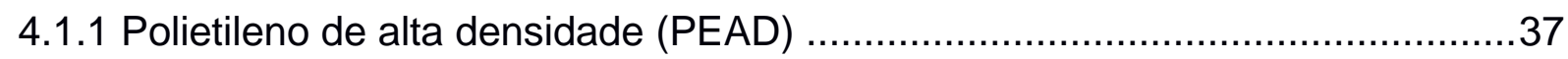

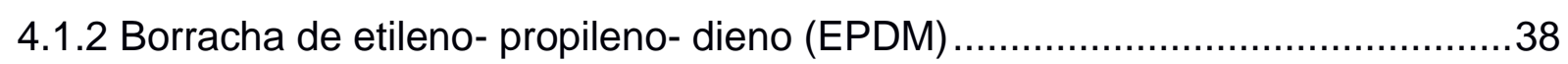

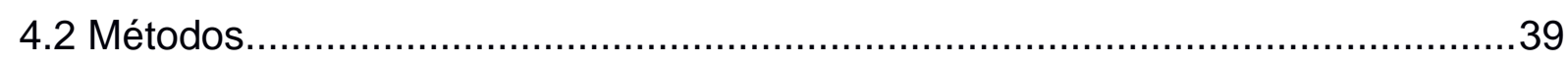

4.2.1 Processamento e reprocessamento do PEAD e de blendas de PEAD

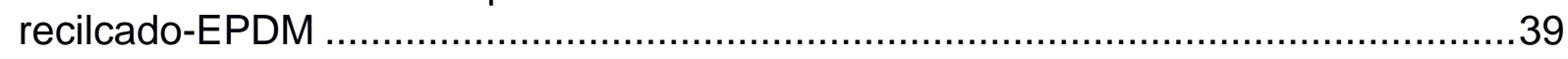

4.2.2 Formação das blendas de PEAD reciclado/EPDM puro ................................41

4.2.3 Processo de Irradiação gama dos corpos-de-prova .....................................42

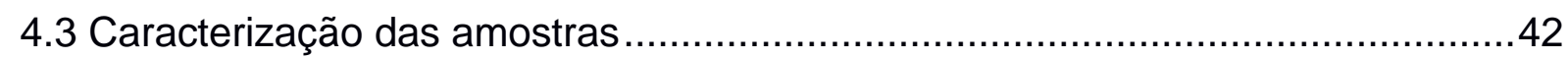

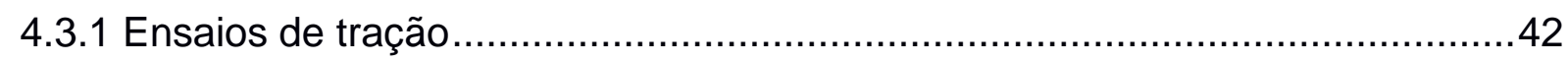

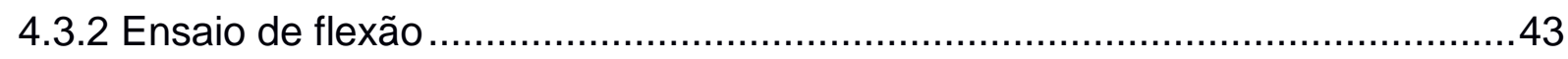

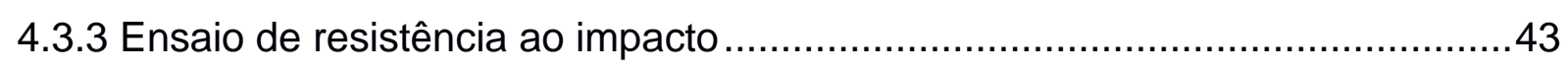

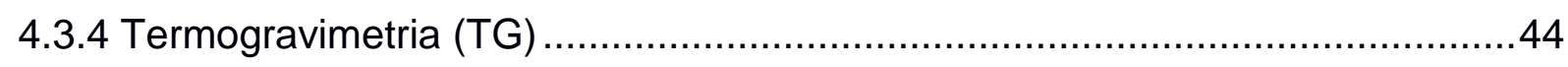




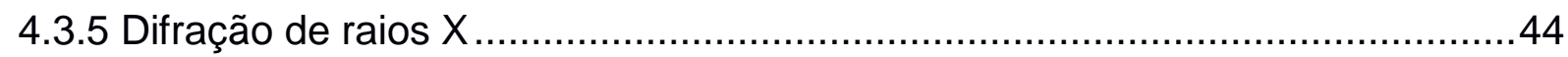

4.3.6 Calorimetria exploratória diferencial (DSC) ….......................................... 44

4.3.7 Espectrometria no infravermelho por transformada de Fourier (FTIR) ..........45

4.3.8 Determinação do grau de reticulação.......................................................46

4.3.9 Microscopia eletrônica de varredura (MEV) …............................................

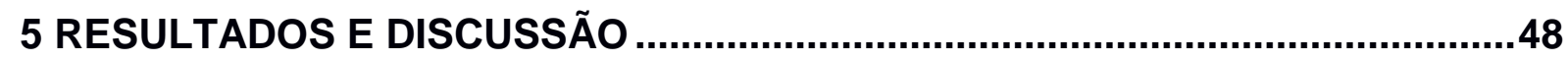

5.1 Espectrometria no infravermelho por transformada de Fourier (FTIR) ..............48



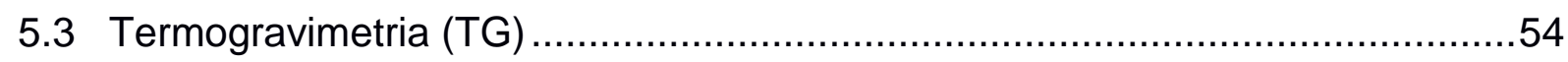

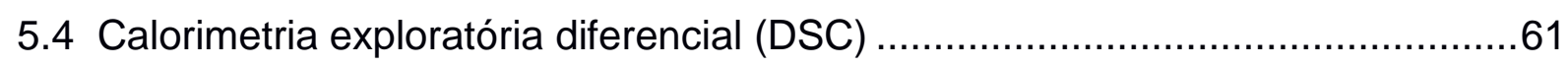

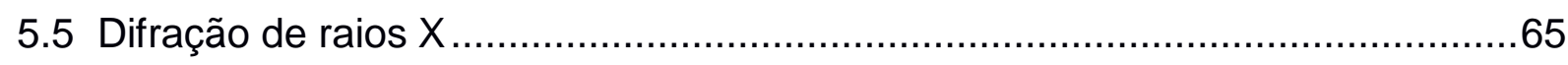

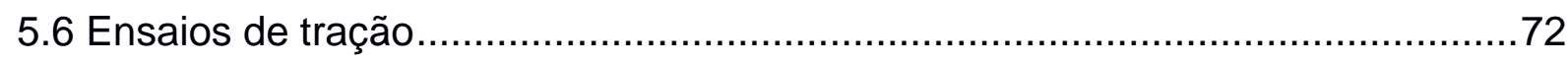

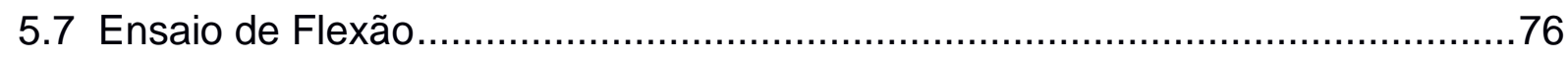

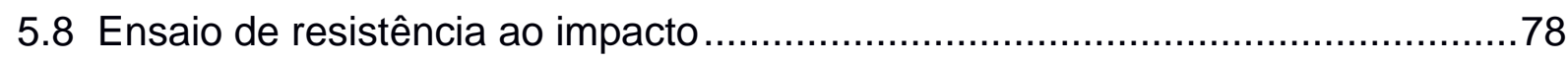



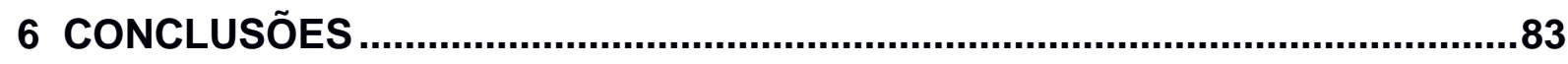

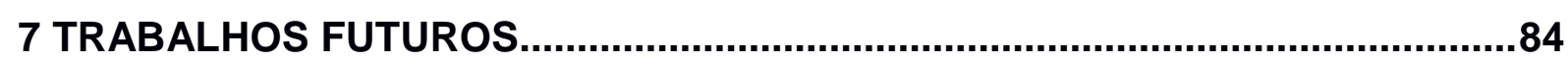

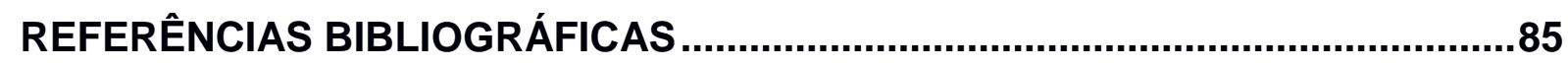




\section{ÍNDICE DE FIGURAS}

Página

FIGURA 1- Processo Logístico Reverso² .14

FIGURA 2 - Percentual das Resinas Consumidas no Brasil em $2014^{14}$. .18

FIGURA 3 - Representação esquemática da polimerização por adição do polietileno ${ }^{17}$

FIGURA 4 - Estrutura molecular: a) diferenças entre o polietileno de alta densidade (PEAD) e o polietileno de baixa densidade (PEBD) e b) disposição das cadeias no PEAD e PEBD ${ }^{20}$

FIGURA 5 - Estrutura química do terpolímero etileno-propileno-dieno $(E P D M)^{25} \ldots . .22$

FIGURA 6 - Processos de reciclagem mecânica do $P C^{30}$ .25

FIGURA 7 - Processo de obtenção de blendas poliméricas por extrusão ${ }^{34}$ .26

FIGURA 8 - Representação da morfologia da blenda miscível: polímero A (linha contínua) e polímero $B$ (linha tracejada) ${ }^{42}$.

FIGURA 9 - Representação da morfologia da blenda imiscível: polímero A (linha contínua) e polímero B (linha tracejada) ${ }^{42}$. .30

FIGURA 10 - Efeito da radiação em polímeros ${ }^{54}$... 33

FIGURA 11 - Polietileno de alta densidade (PEAD) JV060U .37

FIGURA 12 - Elastômero EPDM puro (Keltan 5470 - LANXESS) .38

FIGURA 13 - Injetora HAITIAN Série Saturno modelo AS 9000/6800 .40

FIGURA 14 - Moinho de facas rotativas .40

FIGURA 15 - Extrusora Dupla Rosca ${ }^{73}$ 41

FIGURA 16 - Equipamento de Impacto (a) e Entalhadora (b) .43

FIGURA 17- Determinação de fração gel. Sistema em refluxo (a); tipo de tela e amostra embalada para a extração (b). 46

FIGURA 18 - Espectros de FTIR do PEAD virgem e 4ํㅡㄹ reprocessamento 48

FIGURA 19 - Mecanismo da oxidação termomecânica em polímeros ${ }^{87}$ 50

FIGURA 20- Espectro ATR-FTIR do EPDM puro. .50

FIGURA 21 - Espectros FTIR das blendas de PEAD 4ํrep./EPDM não irradiados .51 FIGURA 22 - Espectros FTIR das blendas de PEAD 4ํㅏㄹ./EPDM irradiados sob radiação gama na dose de $50 \mathrm{kGy}$..... 
FIGURA 23 - Espectros de FTIR das blendas de PEAD 4ํrep./EPDM irradiados sob

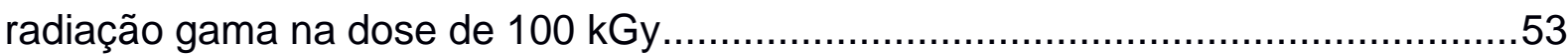

FIGURA 24 - Grau de reticulação das blendas irradiadas ..................................54

FIGURA 25 - Curva termogravimétrica das amostras (a) PEAD puro e (b) PEAD $4^{\circ}$ reprocessamento

FIGURA 26 - Curva termogravimétrica da amostra EPDM puro (a) e PEAD $4^{\circ}$ rep./

$1 \%$ EPDM puro (b).

FIGURA 27 - Curvas termogravimétricas das amostras PEAD $4^{\circ}$ Rep./ 5 \% de EPDM puro (a) e (b) com $10 \%$ de EPDM puro

FIGURA 28 - Curvas termogravimétricas das amostras de PEAD $4^{\circ}$ rep./ 1\% 5\% e 10\% de EPDM puro irradiados com 50kGy coluna (a) e $100 \mathrm{kGy}$ coluna( b) .......60 FIGURA 29 - Curvas de DSC do PEAD virgem e $4^{\circ}$ reprocessamento....................61 FIGURA 30 - Curva de DSC do EPDM puro ..............................................62 FIGURA 31 - Curvas de DSC das blendas não irradiadas de PEAD 4ํrep. com EPDM nas concentrações de $1 \%, 5 \%$ e $10 \%$

FIGURA 32 - Curvas de DSC das blendas irradiadas de PEAD 4ํrep. com EPDM nas concentrações de $1 \%, 5 \%$ e $10 \%$ nas doses de: 50 kGy (a) e 100 kGy (b) ...64 FIGURA 33- Difratogramas das amostras de PEAD virgem (a) e 4ํㅡㄹ. (b) .66 FIGURA 34 - Grau de cristalinidade por difração de raios X do PEAD virgem, 4ำ rep. e suas blendas PEAD 4rep./EPDM puro, não irradiadas e irradiadas 68 FIGURA 35 - Tamanho do cristalito no PEAD virgem, 4ํㅜㄹ. e suas blendas PEAD $4^{\circ}$ rep./EPDM puro não irradiadas e irradiadas 69

FIGURA 36 - Distância interplanar entre os cristalitos nas faces (a) 110 e (b) 200 no PEAD virgem, 4ํㅜㄹ. e suas blendas PEAD 4ํrep./EPDM puro, não irradiadas e irradiadas.

FIGURA 37 - Módulo de elasticidade do PEAD virgem, 4ํㅜㄹ. e das blendas de PEAD 4ํrep./EPDM puro, não irradiadas e irradiadas .73 FIGURA 38 - Tensão limite de escoamento do PEAD virgem, 4ํㅜㄹ. e das blendas de PEAD 4ำ rep./EPDM puro, não irradiadas e irradiadas .75

FIGURA 39 - Tensão em 100 \% de deformação do PEAD virgem, 4ํㅏㄹ. e das blendas de PEAD 4ºrep./EPDM puro, não irradiadas e irradiadas

FIGURA 40 - Módulo flexural de elasticidade do PEAD virgem, e 4ํㅜ rep. e das blendas de PEAD 4ํㅜㄹ.EPDM puro, não irradiadas e irradiadas 
FIGURA 41 - Tensão máxima de flexão do PEAD virgem, 4ํㅜㄹ. e das blendas de PEAD 4\%/EPDM puro, não irradiadas e irradiadas .78

FIGURA 42 - Resistência ao Impacto do PEAD virgem, 4ํㅜ rep. e das blendas PEAD $4^{\circ}$ rep./EPDM puro, não irradiadas e irradiadas .80

FIGURA 43 - Micrografias obtidas por microscopia eletrônica de varredura do PEAD virgem (a) e PEAD 4을 Reprocessamento (b)

FIGURA 44 - Micrografias obtidas por microscopia eletrônica de varredura para as blendas: (a,b,c) PEAD 4ํㅜㄹeciclagem / 1, 5 e 10 \% de EPDM não irradiada , (d,e,f) irradiadas com dose de $50 \mathrm{kGy},(\mathrm{g}, \mathrm{h}, \mathrm{i})$ irradiadas com dose de $100 \mathrm{kGy}$ 


\section{ÍNDICE DE TABELAS}

TABELA 1 - Propriedades do PEAD (JV060U-Braskem) ${ }^{66}$

TABELA 2 - Propriedades do EPDM puro (KELTAN 5470 - LANXESS) ${ }^{67}$. .38

TABELA 3 - Condições do processo de injeção. 40

TABELA 4 - Condições do processo de extrusão 42

TABELA 5 - Parâmetros obtidos das curvas termogravimétricas das amostras de PEAD e suas blendas com a borracha EPDM puro

TABELA 6 - Parâmetros de temperaturas de fusão e cristalização (Tf ) e $\left(T_{m}\right)$, entalpia de fusão ( $\triangle \mathrm{Hf}$ ) e grau de cristalização (Xc) obtidos pela técnica de DSC do EPDM puro, PEAD virgem e reciclado e suas blendas, irradiadas e não irradiadas 65 


\section{LISTA DE ABREVIAÇÃO E SIMBOLOS}

ABIPLAST Associação Brasileira da Indústria do Plástico.

ASTM American Society for Testing and Materials.

ATR Refletância Total Atenuada

DRX Difração de Raios $X$.

DSC Calorimetria exploratória diferencial.

EPDM Monômero de etileno propileno dieno.

FTIR Espectrometria no infravermelho com transformada de Fourier.

GTR Pó de borracha de pneus.

$\Delta \mathrm{H}_{\mathrm{f}} \quad$ Entalpia de fusão da amostra.

HDPE Polietileno de alta densidade.

ISO International Standart Organization.

IUPAC International Union of Pure na Applied Chemistry.

LDPE Polietileno de baixa densidade.

LLDPE Polietileno linear de baixa densidade.

MEV Microscopia eletrônica de varredura.

NBR Denominação de norma da Associação Brasileira de Normas Técnicas (ABNT)

PE Polietileno.

PEAD Polietileno de alta densidade.

PEBD Polietileno de baixa densidade.

PELBD Polietileno linear de baixa densidade.

PET Politereftalato de etileno.

PEUAPM Polietileno de ultra alto peso molecular.

PEUBD Polietileno de ultra baixa densidade.

phr concentração partes por cem de borracha (parts per hundred rubber)

PP Polipropileno.

PVC Policloreto de vinila.

$T_{m} \quad$ Temperatura de fusão .

$T_{c} \quad$ Temperatura de Cristalização. 
$T_{g} \quad$ Temperatura de transição vítrea.

TG Termogravimetria.

UHMWPE Polietileno de ultra alto peso molecular

ULDPE Polietileno de ultra baixa densidade 


\section{INTRODUÇÃO}

A coleta de resíduos plásticos e outros materiais pós-consumo e a sua utilização como matéria prima à produção industrial, chama-se logística reversa (FIG.1). Os procedimentos que vão desde o insumo básico até o reprocessamento de refugos para fabricação de novos produtos, são estratégicos para a expansão do mercado da reciclagem ${ }^{1}$.

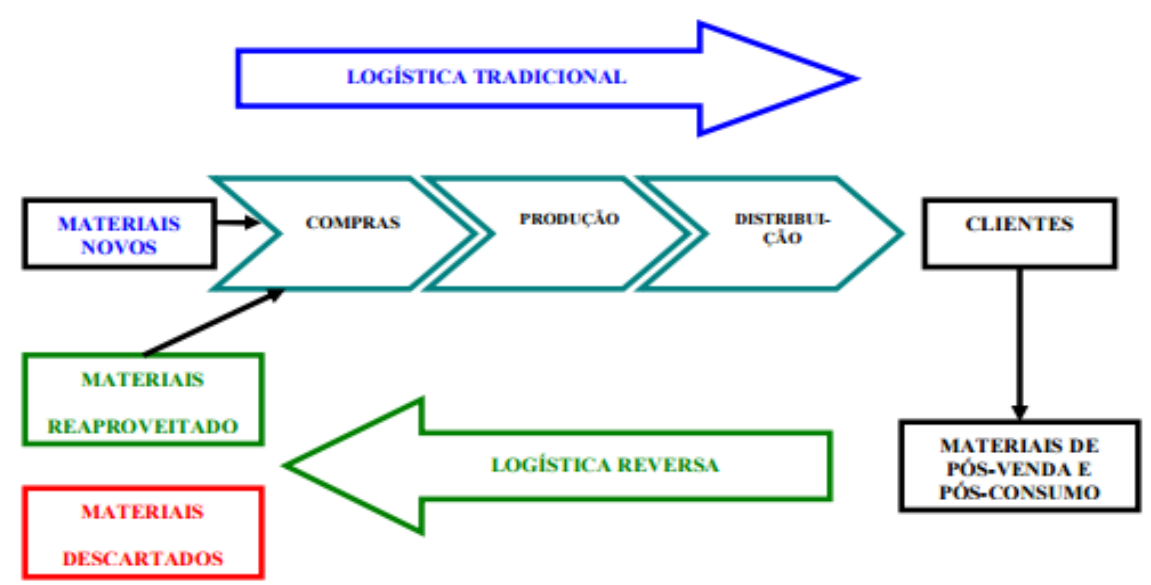

FIGURA 1- Processo Logístico Reverso²

Atualmente, uma grande parte dos resíduos descartados é composta por material plástico como polietileno de alta densidade (PEAD), polietileno de baixa densidade (PEBD), polipropileno (PP) e o poli(tereftalato de etileno) (PET) que são as classes de termoplásticos mais consumidas e consequentemente, as que geram grandes quantidades de resíduos ao término da vida útil dos produtos por eles constituídos ${ }^{3,4}$.

Estima-se que até 2019 ocorra um aumento de capacidade na ordem de 46 milhões de toneladas impulsionada principalmente pelo crescimento de polietilenos (PE), principalmente no Oriente Médio, na China e nos EUA ${ }^{5}$.

Além disso, elastômeros termoestáveis como a borracha do monômero etileno-propileno-dieno (EPDM), muito utilizada na indústria automobilística, é um importante passivo ambiental. No Brasil estima-se que a produção de EPDM convencional está em torno de 40.000 toneladas $^{6}$. 
Devido ao aumento expressivo do volume de resíduos disponíveis para reciclagem, é necessário práticas eficazes no reaproveitamento dos insumos.

No Brasil, a regulamentação da geração, manuseio e reaproveitamento de resíduos está baseada em leis federais, estaduais e municipais, fiscalizadas pelos órgãos governamentais. As normas ambientais estão previstas na ISO 14.000 e a disposição dos resíduos sólidos voltados aos plásticos na NBR 10.004 (anexo $\mathrm{H} \mathrm{A007)}{ }^{7}$.

Além disso, no reaproveitamento dos materiais deve ser considerada a relação direta da perda de propriedades mecânicas e consequente processo de degradação do material polimérico durante os diferentes estágios de seu ciclo de vida (síntese, processamento, estocagem e uso final) ${ }^{8}$.

A perda de propriedades mecânicas pode também ocorrer pela ação da mistura de plásticos devido aos efeitos de incompatibilidade entre os componentes poliméricos o que reflete na morfologia da mistura.

Segundo Canevarolo Junior ${ }^{9}$, o processo de degradação em polímeros conduz à mudanças na estrutura molecular do material, promovendo alterações nas propriedades físicas e químicas.

Para obter melhores propriedades, busca-se obter mistura de materiais como plásticos e elastômeros para a produção de blendas. Segundo a IUPAC ${ }^{10}$, define-se blenda como uma mistura macroscópica, na escala maior que várias vezes o comprimento de onda da luz visível, de dois ou mais tipos diferentes de polímeros.

No sentido de obter controle, soma e até sinergia de propriedades, blendas binárias e ternárias têm sido amplamente pesquisadas utilizando-se diferentes aditivos e métodos de compatibilização ${ }^{11}$.

Os principais processos de mistura dos materiais poliméricos são:

a) fluidificação da massa polimérica à quente método mais difundido na indústria;

b) dissolução por solvente com posterior evaporação, o que permite a formação de filme polimérico, técnica usada em escala micro.

Independentemente do processo utilizado, uma mistura de polímeros resulta em heterogeneidades que conduzem à condições de imiscibilidade. Nesse caso, a imiscibilidade leva à baixa adesão interfacial entre os componentes, 
necessitando de compatibilização a partir do uso de aditivos ou modificações químicas dos polímeros, ou ainda por meio de misturas reativas ${ }^{12,13}$.

O uso da radiação gama em polímeros pode provocar modificação das estruturas moleculares das cadeias poliméricas e consequentemente, modificação de suas propriedades devido à ocorrência dos seguintes processos concorrentes e simultâneos:

a) geração de ligações cruzadas: com o surgimento de novas ligações por meio do mecanismo de geração de radicais em distintos sítios nas cadeias poliméricas; a nível molecular a estrutura apresenta aspecto de rede. $O$ aumento da massa molar é um dos efeitos macroscópicos observados;

b) cisão de cadeia ou degradação: há o predomínio de quebra de ligações; a nível molecular as cadeias ficam mais curtas e como consequência, há a diminuição da massa molar.

Esta dissertação está apresentada da seguinte forma: no primeiro capítulo, a introdução apresenta os aspectos gerais do tema, o segundo capítulo apresenta os objetivos do trabalho; o terceiro capítulo mostra a revisão da bibliográfica necessária para embasar este trabalho. A metodologia experimental e os ensaios de caracterização dos materiais utilizados até a obtenção do produto final estão apresentados no quarto capítulo. Os resultados e sua discussão estão descritos no quinto capítulo. O sexto capítulo apresenta as conclusões do trabalho e no último capítulo, as perspectivas para desenvolvimentos futuros. A lista de referências bibliográficas usadas é apresentada no final desta dissertação. 


\section{OBJETIVOS}

Neste trabalho os objetivos principais foram obter blendas a partir do polietileno de alta densidade (PEAD) reciclado e da borracha do monômero etileno-propileno-dieno (EPDM) puro, de forma a compensar a degradação resultante do reprocessamento do termoplástico e avaliar em termos experimentais a compatibilidade, a miscibilidade e os efeitos do processo de irradiação aplicado para incrementar as propriedades mecânicas do produto final.

Em termos específicos, os objetivos foram:

- Avaliar e comparar o comportamento físico-químico das blendas não irradiadas com as blendas irradiadas com radiação gama nas doses de 50 kGy e 100 kGy ;

- Caracterizar os materiais segundo propriedades mecânicas, térmicas, morfológicas e espectroscópicas. 


\section{REVISÃO BIBLIOGRÁFICA}

\subsection{Introdução}

O polietileno (PE) e a borracha do monômero etileno-propileno-dieno (EPDM) são polímeros produzidos em larga escala e têm seu uso amplamente disseminado nos setores da economia relativa à produção de bens e serviços (FIG. 2).

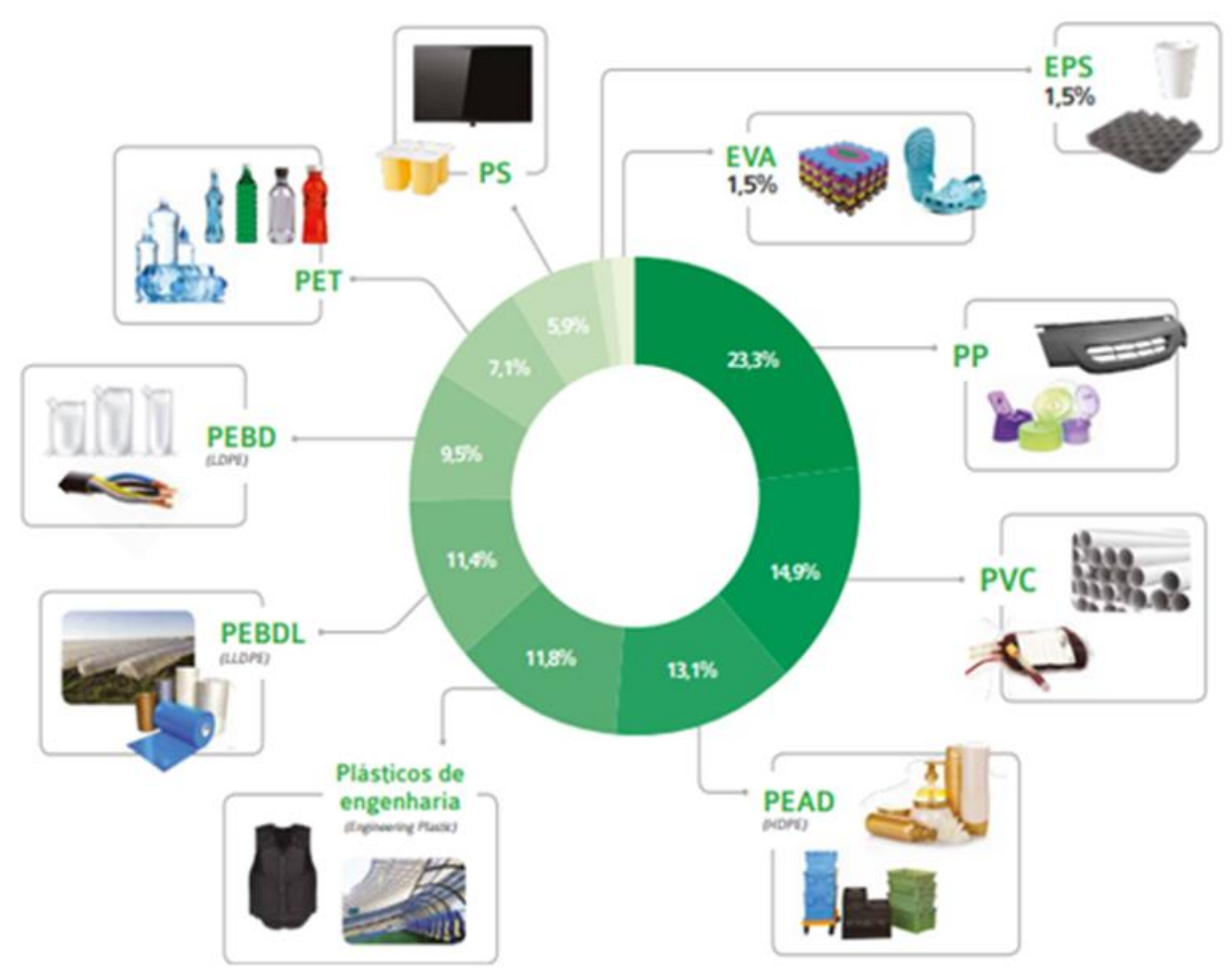

FIGURA 2 - Percentual das Resinas Consumidas no Brasil em $2014^{14}$

A grande problemática apresenta-se ao término da sua vida útil, já que também é grande $\mathrm{o}$ volume de passivos ambientais desses dois tipos de polímeros.

$\mathrm{Na}$ tecnologia de polímeros algumas soluções de processo podem ser aplicadas no reprocessamento desse material refugado. Alguns dos aspectos 
dessa tecnologia de processo e seus desenvolvimentos estão descritas neste capítulo e servirão para embasar essa dissertação.

\subsection{Polietileno}

O polietileno é um polímero parcialmente cristalino, flexível, suas propriedades são influenciadas pela quantidade relativa das fases amorfa e cristalina ${ }^{15}$. Em termos de morfologia de cadeia, as menores unidades cristalinas, as lamelas, são perpendiculares ao plano da cadeia principal e dobradas em zigzag, com pouca frequência de defeitos morfológicos.

Essa morfologia influencia na massa molar e na cristalinidade do PE. Possui composição simples, constituída por uma cadeia longa de átomos de carbono e átomos de hidrogênio a eles ligados ${ }^{16}$, possui baixa reatividade, daí a inércia deste tipo de termoplástico face à maioria dos produtos químicos e também atoxicidade, o que permite seu uso e contato com produtos alimentícios e farmacêuticos, descartando-se obviamente a presença de alguns tipos de aditivos que podem ser agressivos à saúde humana.

A reação de polimerização ocorre pela união de diversas moléculas do monômero etileno a partir de um mecanismo de geração radicalar como mostra a FIG. 3, sendo o processo chamado de polimerização por adição.

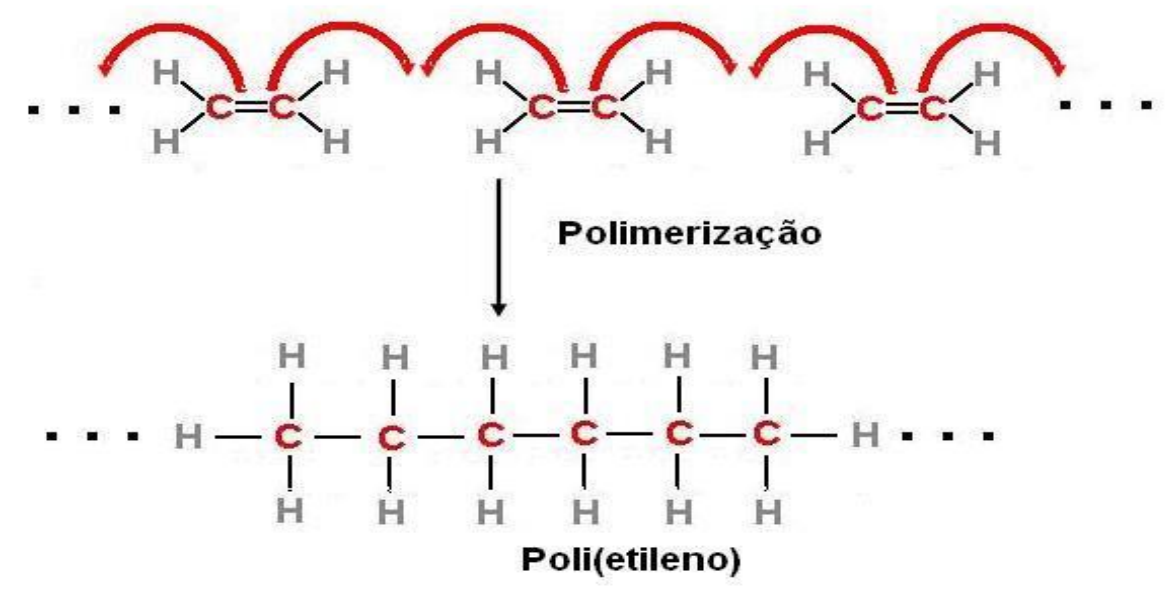

FIGURA 3 - Representação esquemática da polimerização por adição do polietileno ${ }^{17}$ 
Existem cinco tipos básicos de polietileno que podem ser produzidos ${ }^{18}$.

Polietileno de alta densidade (PEAD ou HDPE)

Polietileno de ultra alto peso molecular (PEUAPM ou UHMWPE)

Polietileno de baixa densidade (PEBD ou LDPE)

Polietileno linear de baixa densidade (PELBD ou LLDPE)

Polietileno de ultra baixa densidade (PEUBD ou ULDPE)

No entanto, nessa dissertação as considerações estarão concentradas no primeiro tipo.

\subsubsection{Polietileno de alta densidade}

Este tipo de PE é utilizado nos mais diferentes segmentos da indústria de transformação de plásticos, abrangendo os processamentos de moldagem por sopro, por extrusão e por injeção ${ }^{18}$.

Quando usado no processo de injeção, o PEAD pode servir para a confecção de baldes e bacias, banheiras infantis, conta-gotas para remédios, bandejas para pintura, potes para alimentos, assentos sanitários, tampas para garrafas, caixas d'água, produtos atóxicos como brinquedos entre outros ${ }^{18}$.

Por extrusão, é aplicado em isolamento de fios telefônicos, dutos para mineração e dragagem, revestimento de tubulações metálicas, sacos para congelados, polidutos, tubos para redes de saneamento e de distribuição de gás, redes para embalagem de frutas, fitas decorativas, sacos para lixo e sacolas de supermercados ${ }^{18}$.

O PEAD tem maior cristalinidade devido as suas cadeias não ramificadas poderem se sobrepor formando um agregado molecular compacto, sem vazios como mostra a FIG. 4. Com essa morfologia de cadeia, o material apresenta maior massa molar e densidade, o que confere, em termos macroscópicos, maior rigidez em relação aos outros polietilenos uma vez que as propriedades mecânicas do PEAD sofrem uma forte influência da massa molar, do teor de ramificações, da estrutura morfológica e da orientação ${ }^{19}$. 
(a)



(b)

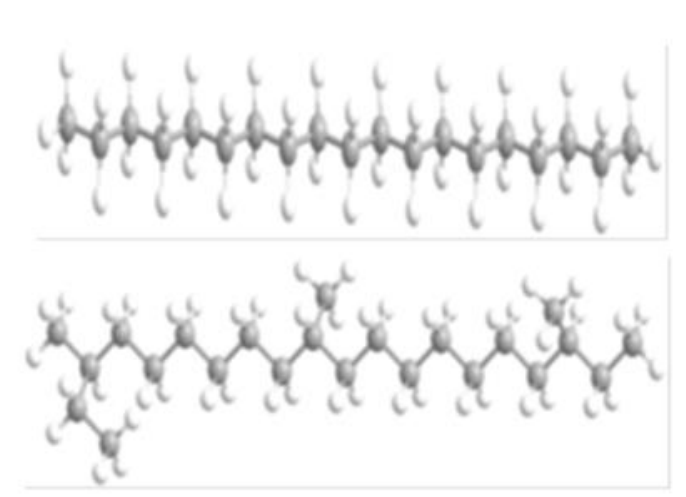

FIGURA 4 - Estrutura molecular: a) diferenças entre o polietileno de alta densidade (PEAD) e o polietileno de baixa densidade (PEBD) e b) disposição das cadeias no PEAD e PEBD ${ }^{20}$

\subsection{Borracha etileno- propileno- dieno (EPDM)}

O copolímero do monômero Etileno-Propileno-Dieno (EPDM), é utilizado em diferentes aplicações industriais, entre elas a aeroespacial, construção civil e automotiva. Os principais itens fabricados com EPDM no setor automotivo são perfis, mangueiras e vedações (41\% do consumo global); construção civil como perfis, vedações e mantas para telhado ( $21 \%$ do consumo); cabos isolantes e revestimentos ( $6 \%$ do consumo $)^{21}$.

Apresenta excelentes propriedades de resistência ao calor, envelhecimento, resistência mecânica, resistência ao ozônio e à oxidação ${ }^{22}$, permite uma ótima incorporação de cargas e plastificantes, possuindo eficácia em seu processamento.

O EPDM é constituído de três monômeros em sua estrutura polimérica (FIG. 5): o etileno (E), o propileno (P) e um dieno, como o 5-etilideno 2norboneno (ENB), que é o mais usual. Outros dienos como o dicloropentadieno (DCPD) e o 2-vinil norboneno (VNB) são também utilizados ${ }^{23}$.

Quando o EPDM contém grande quantidade de etileno a formulação aceita um maior teor de cargas de reforço ou enchimento, além de misturar com facilidade. Isso é necessário para aplicações que exigem altas propriedades físicas e resistência a intempéries ${ }^{23}$. 
O propileno altera as propriedades plásticas do polímero e a quantidade do terceiro monômero é escolhida de acordo com o grau de vulcanização desejado no produto final ${ }^{23}$. O monômero de dieno promove maior eficiência no processo de reticulação devido às insaturações, possibilitando melhores resultados no processamento ${ }^{24}$.

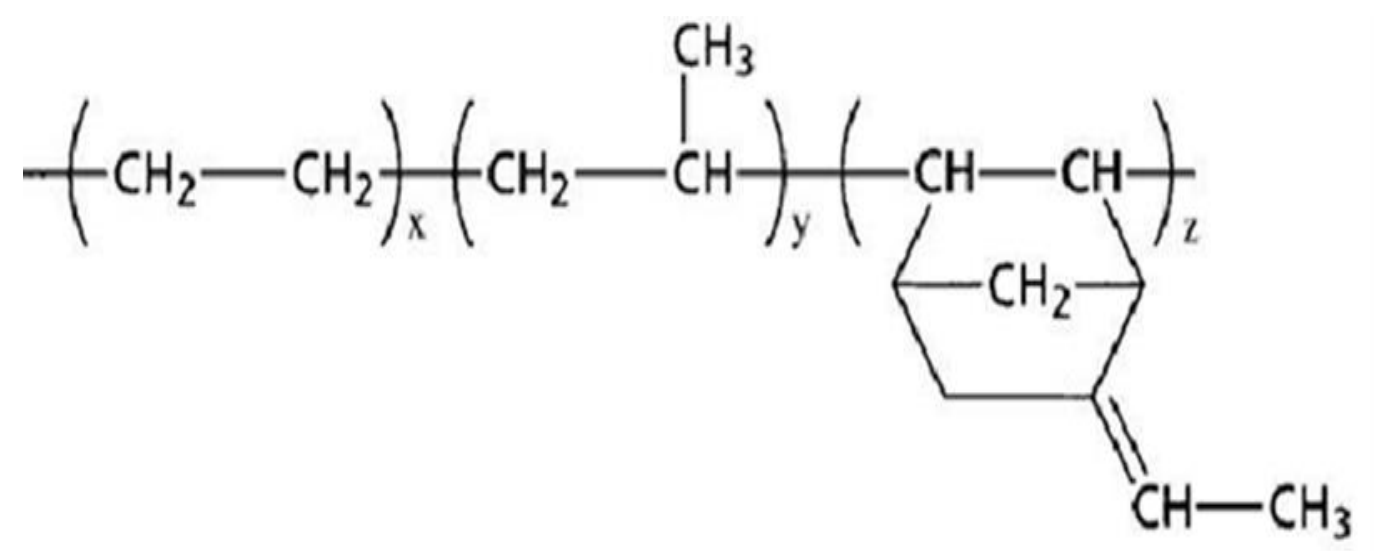

FIGURA 5 - Estrutura química do terpolímero etileno-propileno-dieno (EPDM) ${ }^{25}$

\subsection{Reciclagem}

A reciclagem é um processo que minimiza os resíduos resultantes das diversas atividades que geram insumos. O reaproveitamento de produtos descartados após o seu uso (resíduos pós-consumo) aumentou durante os últimos anos devido a fatores ambientais, econômicos e sociais.

De acordo com uma pesquisa realizada pela ABIPLAST, estima-se que no Brasil são retirados do meio ambiente aproximadamente 805 mil toneladas de resíduos pós-consumo por ano, que dão origem a mais de 725 mil toneladas de materiais plásticos reciclados ${ }^{14}$.

A maior parte das empresas brasileiras utiliza em seu processo a reciclagem mecânica, devido a fatores que podem ser descritos como: custo de mão-de-obra, baixo investimento para instalação da planta de reciclagem, disponibilidade de matéria prima, mercado crescente para a venda de polímeros reciclados ${ }^{26}$. 
Atualmente no Brasil, a reciclagem mecânica vem crescendo em volume e aumentando a diversidade dos produtos. A reciclagem de polímeros, bem como o método de reciclagem a ser empregado, depende de vários fatores como a quantidade e a qualidade do material, o custo do material e do processamento, além do mercado para o produto final ${ }^{26}$.

A coleta seletiva dos resíduos sólidos facilita a separação prévia dos polímeros, minimizando o custo e aumentando a eficiência da reciclagem. Além disso, o investimento em pesquisas na área de reciclagem de polímeros, bem como o desenvolvimento de metodologias com fins analíticos mais eficazes para os contaminantes, visa desenvolver produtos de melhor qualidade ${ }^{26}$.

\subsubsection{Tipos de Reciclagem}

Os polímeros reciclados podem ser obtidos por meio de quatro categorias de processos: primária, secundária, terciária e quaternária. As definições dessas categorias podem ser obtidas na norma ASTM D 5033-9027.

A reciclagem primária: consiste na conversão dos resíduos poliméricos industriais por métodos de processamento padrão em produtos com características equivalentes àquelas dos produtos originais produzidos com polímeros virgens. Um exemplo deste tipo são as aparas ou peças não conformes de fonte confiáveis e isentas de impurezas que são novamente introduzidas no processamento.

A reciclagem secundária: conversão dos resíduos poliméricos provenientes dos resíduos sólidos urbanos que posteriormente passará pelo processo de moagem, lavagem, secagem e reprocessamento ou uma combinação de processos em produtos que tenham menor exigência do que o produto obtido com polímero virgem (resíduos pós consumo e sobra de polímero industrial).

A reciclagem terciária: processo tecnológico de produção de insumos químicos por meio de processos termoquímicos como pirólise, hidrólise e conversões catalíticas ou combustíveis a partir de resíduos poliméricos.

A reciclagem quaternária: processo tecnológico de recuperação de energia de resíduos poliméricos por incineração controlada. 
A reciclagem primária e a secundária são conhecidas como reciclagem mecânica ou física, cuja diferença entre elas é a utilização do substrato pósprocesso industrial na primária, contra a utilização do substrato polimérico pósconsumo na reciclagem secundária. A reciclagem terciária também é chamada de reciclagem química e a quaternária de reciclagem energética ${ }^{28}$.

\subsubsection{Reciclagem mecânica}

Este tipo de reciclagem pode ser viabilizada pelo reprocessamento por extrusão, injeção, conformação ou moldagem por compressão.

Para este fim são necessárias as seguintes etapas: 1) separação do resíduo polimérico; 2) moagem; 3) lavagem; 4) secagem; 5) reprocessamento e 6) conformação do polímero em produto acabado ${ }^{28}$.

A limitação de impurezas ocorre na etapa de separação. A importância desta etapa reside no fato de que mesmo em baixa concentração, a presença de macrocontaminantes como vidro, papel, metal ou outros polímeros, pode alterar as propriedades do produto final ${ }^{29}$. A separação dos polímeros pode ser manual ou automatizada; a utilização da automatização depende da forma de coleta, das necessidades do mercado e do custo de mão-de-obra. Ainda nesta etapa procede-se à identificação dos polímeros ${ }^{27}$.

Estas etapas podem ser alteradas segundo a procedência, o tipo de polímero (FIG. 6) e as diferenças no investimento e em equipamentos utilizados no processamento ${ }^{28}$.

A reciclagem mecânica é a forma de reciclagem mais utilizada no Brasil por ser um processo simples, acessível às pequenas e médias empresas em termos de investimento para a sua instalação, apresenta custo reduzido de mãode-obra e possui incentivos de acordo com os programas de coleta seletiva do lixo urbano nas cidades, contribuindo para a diminuição ou remoção da população que trabalha informalmente nos aterros sanitários ${ }^{26}$. 


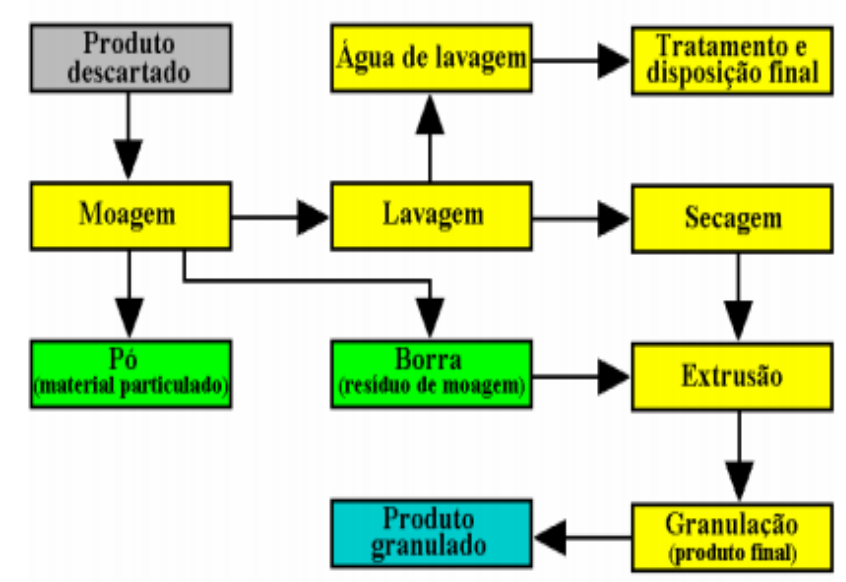

FIGURA 6 - Processos de reciclagem mecânica do PVC ${ }^{30}$

\subsection{Blendas poliméricas}

Blendas poliméricas são misturas de dois ou mais polímeros, sem que haja reação química tradicional, porém observa-se interação intermolecular entre as macromoléculas de cada componente. As blendas poliméricas apresentam-se como uma alternativa no desenvolvimento dos polímeros, podendo atuar como plástico de engenharia com importantes aplicações comerciais ${ }^{31}$.

Muitas vezes o tempo e os recursos necessários para o desenvolvimento de uma blenda são menores do que os necessários para o desenvolvimento de um novo polímero com propriedades semelhantes às da blenda. A mistura de diferentes polímeros possibilita a criação de novos materiais com propriedades muitas vezes superiores às dos componentes puros ${ }^{32}$.

A produção industrial de blendas é realizada a partir do processo de extrusão e do uso de misturadores descontínuos, este processamento consiste basicamente de duas principais fases: a de mistura ou preparação e a de moldagem $^{33}$.

A extrusão consiste na mistura dos polímeros na forma de grânulos (pellets) ou em pó em temperatura ambiente, seguido do seu aquecimento até a mudança de estado do agregado plástico. Em polímeros semicristalinos, a temperatura crítica na qual o substrato torna-se viscoso é a temperatura de fusão; em polímeros amorfos esse parâmetro é a temperatura de transição vítrea. 
Durante a fusão ou plastificação, estes polímeros sofrem uma ampla variação de temperatura, deformação e tensão ${ }^{34,35}$.

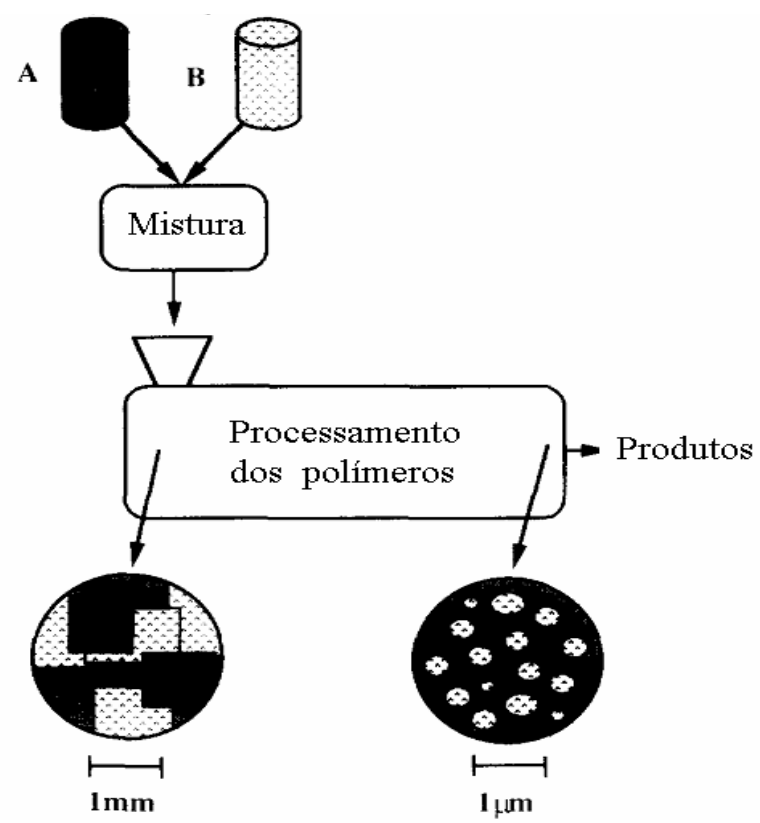

FIGURA 7 - Processo de obtenção de blendas poliméricas por extrusão ${ }^{34}$

A homogeneidade da mistura depende de alguns fatores como, aditivos, cinética no processo de mistura, temperatura de processamento e viscosidade $^{36}$. A condição para dois polímeros serem usualmente miscíveis ocorre pela natureza termodinâmica.

A energia livre $\left(\Delta G_{m}\right)$ para uma mistura é dada pela equação (1):

$$
\Delta G_{m}=\Delta H_{m}-T \Delta S_{m}
$$

em que, T é a temperatura absoluta, $\Delta H_{m}$ e $\Delta S_{m}$ são respectivamente a entalpia e a entropia de mistura ${ }^{36}$.

Uma solução polimérica é termodinamicamente estável quando a energia livre de mistura $\left(\Delta G_{m}\right)$ é negativa ${ }^{36}$. Como consequência, os polímeros serão miscíveis se a entalpia de mistura for favorável $(\Delta \mathrm{H}<0)$. 
A condição de estabilidade para existência de uma só fase na mistura exige que a derivada segunda em relação à fração volumétrica do segundo componente $\left(\Phi_{2}\right)$, com valor maior que zero, nas composições, equação (2) :

$$
\left(\frac{\partial^{2} \Delta G_{m}}{\partial \phi_{i}^{2}}\right)_{T, P}>0
$$

em que $\phi_{i}$ corresponde a fração volumétrica do polímero $i^{36}$.

De acordo com a teoria de Flory-Huggins, apud ${ }^{37}$, a entropia de mistura é dada pela equação (3):

$$
\Delta S_{m}=-k\left[\left(\frac{\phi_{1}}{r_{1}}\right) \ln \phi_{1}+\left(\frac{\phi_{2}}{r_{2}}\right) \ln \phi_{2}\right]
$$

em que $k$ é a constante de Boltzmann, $r_{1}$ e $r_{2}$ são os graus de polimerização dos polímeros 1 e 2 e $\phi_{1}$ e $\phi_{2}$ são as frações volumétricas dos polímeros 1 e 2 , respectivamente.

O aumento da massa molar do polímero, ou seja, a diminuição nos valores de $r_{1}$ e $r_{2}$ acarreta um acentuado aumento da entropia da mistura. Isto significa que os componentes tendem a interagir, comparando-se com as macromoléculas cuja entropia tende a zero à medida que diminui a massa molar.

Outro parâmetro para a avaliação da miscibilidade é a temperatura de transição vítrea $\left(T_{g}\right)$, que é uma característica fundamental dos polímeros, pois representa um limite de temperatura abaixo da qual a energia térmica não é suficiente para que as barreiras rotacionais em torno das ligações sejam superadas e assim as mudanças conformacionais do polímero são inibidas ${ }^{38}$.

Se a blenda polimérica possuir um componente cristalino, pela diminuição da temperatura de fusão $\left(T_{m}\right)$, avalia-se a miscibilidade da blenda. A partir da obtenção de $T_{m}$ por DSC, pode-se determinar o coeficiente de interação adimensional $(\eta)$ e a temperatura de fusão no equilíbrio $\left(\mathrm{T}_{\mathrm{m}}^{\circ}\right)$ entre os polímeros 1 e 2 a partir dos coeficientes angular e linear do gráfico da equação (4) de Hoffman-Weeks : 


$$
T_{m}=\left(\frac{1}{\eta}\right) T_{C}+\mathrm{T}_{m}^{o}\left(1-\frac{1}{\eta}\right)
$$

que mostra uma dependência da $T_{m}$ em função da temperatura de cristalização $\left(T_{c}\right)$, uma vez que a mobilidade das cadeias poliméricas depende da temperatura ${ }^{39}$. A partir do coeficiente angular do gráfico, pode-se avaliar a cristalização do material.

A cristalização de um polímero semicristalino ocorre em temperaturas intermediárias às $T_{g}$ e $T_{m}$, uma vez que a probabilidade de ocorrer à cristalização em valores abaixo de $T_{g}$ e em valores acima de $T_{m}$ é quase nula devido ao efeito de mobilidade das cadeias poliméricas que é muito baixo em temperaturas próximas à $T_{g}$ e muito alto em temperaturas próximas à $T_{m}{ }^{39}$.

A velocidade de cristalização pode ser alterada quando o outro componente da mistura é amorfo: havendo miscibilidade entre os componentes, com a adição de um polímero amorfo a outro semicristalino ocorre a diminuição da velocidade de cristalização; quando não há miscibilidade entre os componentes da mistura, a adição de um polímero amorfo aumenta a velocidade de cristalização ${ }^{40}$.

\subsubsection{Blendas miscíveis e compatíveis}

As blendas são miscíveis quando as cadeias de cada componente polimérico se misturam intimamente resultando em uma mistura homogênea em escala molecular, a miscibilidade ou grau de interação entre as fases existentes determina direta ou indiretamente o comportamento do material desenvolvido ${ }^{41}$.

Uma blenda miscível apresenta uma única fase (FIG. 8), com características dependentes da composição e fatores externos, tais como a temperatura e pressão. Nelas, as propriedades finais representam uma média das propriedades de ambos os componentes da blenda ${ }^{38}$. 


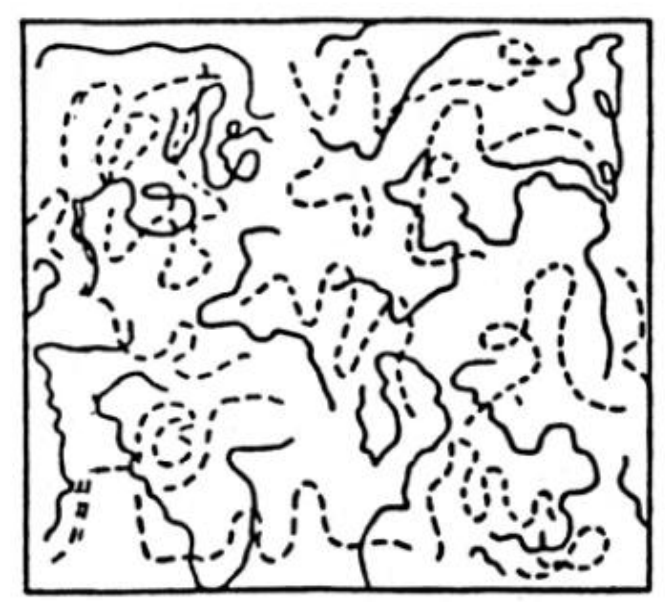

FIGURA 8 - Representação da morfologia da blenda miscível: polímero A (linha contínua) e polímero B (linha tracejada) ${ }^{42}$

O termo compatível é usado como sinônimo de miscibilidade. No entanto, na tecnologia de plásticos, a compatibilidade é frequentemente usada para descrever se um resultado ou propriedade desejada é alcançada quando os componentes são combinados, sem que para isso a mistura seja miscível ${ }^{38}$.

A compatibilização de uma determinada mistura ocorre com a diminuição da tensão interfacial estabilizando a fase dispersa, o que gera aumento da adesão entre as fases ${ }^{43}$. O efeito macroscópico é a melhoria nas propriedades ópticas e mecânicas da mistura polimérica final.

\subsubsection{Blendas poliméricas imiscíveis}

A blenda polimérica imiscível pode apresentar diferentes tipos de morfologias de fases e pode ser:

a) uma fase dispersa numa matriz contínua;

b) ambas as fases simultaneamente contínuas, conhecida como morfologia co-contínua ${ }^{41}$.

Nas blendas a imiscibilidade leva à baixa adesão interfacial, conforme mostrado na FIG. 9. Nesse caso a compatibilização é necessária, geralmente se 
faz com o uso de aditivos, modificações químicas dos polímeros ou a partir de misturas reativas ${ }^{42}$.

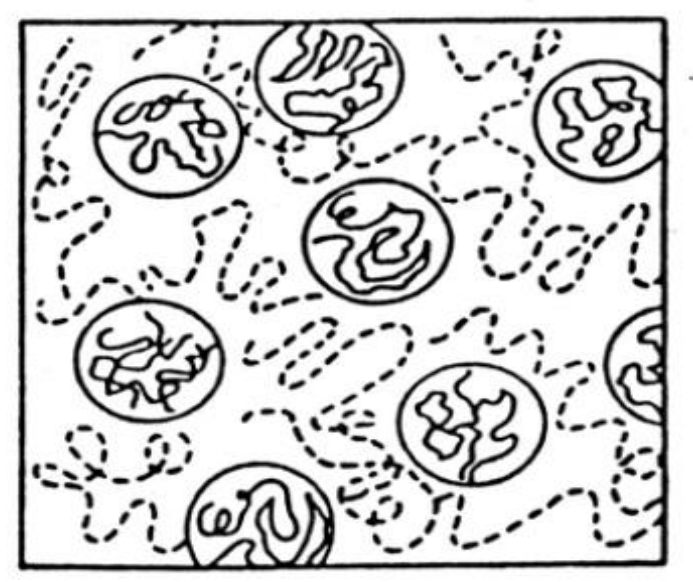

FIGURA 9 - Representação da morfologia da blenda imiscível: polímero A (linha contínua) e polímero B (linha tracejada) ${ }^{42}$

A forma, o tamanho e a distribuição espacial da fase dispersa na matriz resultam de uma complexa relação entre viscosidade e elasticidade das fases, das propriedades interfaciais, da composição da blenda e das condições de processamento $^{40}$.

Olayo e colaboradores ${ }^{44}$, estudaram o comportamento das blendas em composições de 0 à $24 \%$ de EPDM nas matrizes poliméricas de PEAD e PEBD confeccionado em extrusora mono-rosca. A adição do EPDM incrementou o processamento na extrusão, promovendo uma melhor homogeneização. A deformação na ruptura foi proporcional ao aumento do teor de EPDM; a tensão na ruptura foi proporcional ao aumento do teor de PEAD.

Stelescu e colaboradores ${ }^{45}$ pesquisaram as características estruturais de blendas de PEAD/EPDM em diferentes formulações e a utilização do anidrido maleico $1 \%$ como agente compatibilizante, o cloreto de estanho di-hidratado como agente de reticulação e o Irganox 1010 usado como estabilizante. Os resultados mostraram aumento no percentual na cristalinidade nas blendas HDPE/EPDM, o que influenciou nas propriedades mecânicas como tensão no escoamento e dureza.

Kadi e colaboradores ${ }^{46}$ estudaram o comportamento do ligante de asfalto modificado com a adição do HDPE e a blenda HDPE/EPDM 90/10 nas 
composições $1 \%$, $3 \%$ e $5 \%$. As blendas foram produzidas em uma extrusora dupla rosca e reprocessadas por 3 vezes. As amostras com 1 \% (HDPE/EPDM), apresentou melhoria nas propriedades viscoelásticas, evitando possíveis fissuras e sua propagação, melhor distribuição da fase dispersa e maior resistência no ponto de ruptura.

Vranjes e colaboradores ${ }^{47}$ pesquisaram o comportamento de adições de $5 \%$ e $7 \%$ de EPDM nas blendas de PP/HDPE em diferentes composições. A adição do EPDM aumentou a compatibilidade das blendas com matriz polimérica do HPDE 40/60. A resistência ao impacto e alongamento na ruptura foram maiores em todas as amostras. Nas amostras cuja matriz polimérica é o HDPE houve um aumento no percentual de cristalinidade e na temperatura de fusão.

Kim e colaboradores ${ }^{48}$ pesquisaram o efeito da adição do HDPE em concentrações de $20 \mathrm{phr}$ em blendas de PP/EPDM em concentrações de 100/0, 90/10, 80/20, 70/30 e 50/50. Observou-se que o aumento na concentração de EPDM promoveu a diminuição do módulo de elasticidade em todas as temperaturas investigadas ( $23{ }^{\circ} \mathrm{C},-30^{\circ} \mathrm{C}$ e $-60 \stackrel{\circ}{\circ}$ ); a adição de HDPE não alterou esses resultados na temperatura de $23^{\circ} \mathrm{C}$. $\mathrm{O}$ teste de impacto mostrou que misturas ternárias de PP/HDPE/EPDM apresentaram maior resistência. Foi observado por microscopia eletrônica de varredura (MEV) que o HDPE tende a dispersar no EPDM indicando interação entre estes componentes da blenda.

\subsection{Radiação Ionizante}

A radiação pode ser definida como energia de natureza ondulatória ou corpuscular que se propaga com alta velocidade no espaço ${ }^{49}$ A absorção da radiação nos materiais ocorre de forma distinta e provoca alterações nas propriedades físicas e químicas dos materiais ${ }^{49}$.

A interação da radiação de alta energia com a matéria pode promover os seguintes efeitos:

a) reação no núcleo atômico com a formação de novos isótopos e/ou elementos;

b) efeitos na eletrosfera, podendo haver ionização e/ou excitação eletrônica, dependendo do tipo de energia de radiação envolvida no processo ${ }^{50}$. 
Os processos de irradiação, mais disseminados industrialmente, são a irradiação gama a partir da desintegração do radionuclídeo ${ }^{60} \mathrm{Co}$ e a irradiação por aceleração de elétrons de alta energia (feixe de elétrons) gerados em aceleradores ${ }^{51}$.

Os processos de irradiação têm a vantagem de minimizar o uso de reagentes e consequentemente, de formação de rejeitos, já que torna-se muitas vezes desnecessária a presença de aditivos e outras substâncias como agentes compatibilizantes.

\subsubsection{Efeitos da radiação em polímeros}

A aplicação da radiação de alta energia em materiais poliméricos objetiva modificar ou melhorar suas propriedades para fins industriais.

O conceito dos efeitos básicos produzidos nas modificações das cadeias poliméricas pela irradiação são reticulação (geração de ligações cruzadas) e cisão, como comentados no capítulo $1^{52}$.

O predomínio da reticulação é indicado a partir do aumento de valores nas propriedades mecânicas, na viscosidade, na estabilidade térmica e também pela diminuição do índice de fluidez devido a formação de uma rede tridimensional $^{53}$. A cisão de cadeia promove a degradação, evento caracterizado pela quebra das cadeias (FIG.10), cuja alteração das propriedades mecânicas é indicada pela diminuição da resistência térmica e pelo aumento do índice de fluidez. 


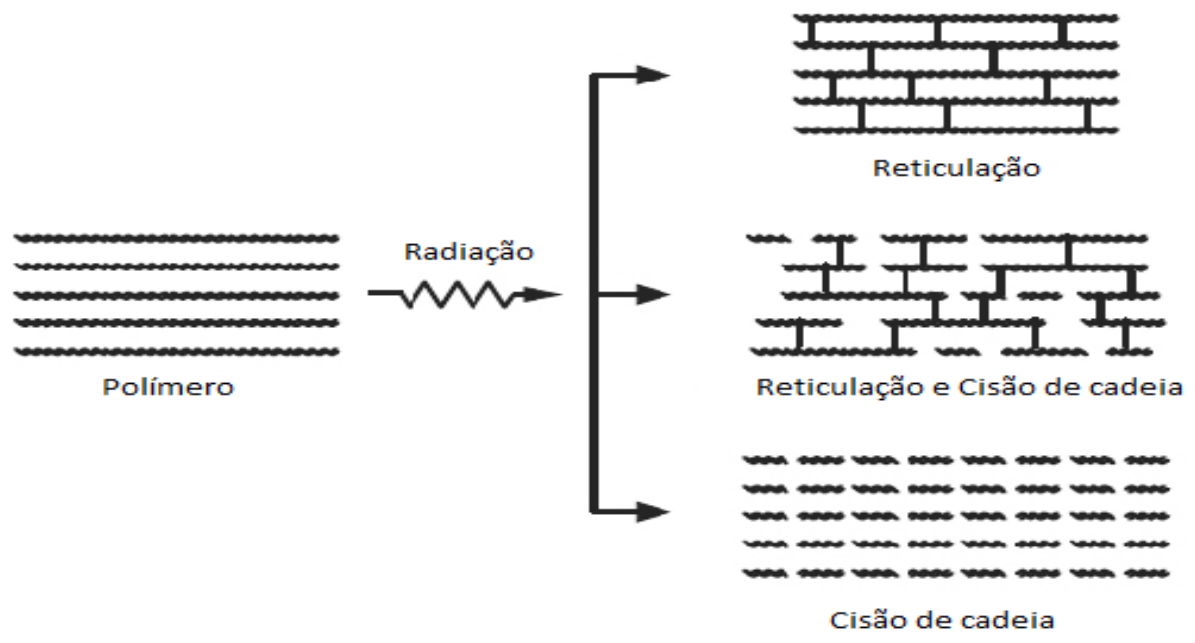

FIGURA 10 - Efeito da radiação em polímeros ${ }^{54}$

\subsubsection{Efeitos da radiação no PEAD}

O aumento da dose absorvida no processo de irradiação no PEAD promove quase sempre a formação de ligações cruzadas e consequentemente, a reticulação do material; essa tendência é o que explica na maioria das vezes o comportamento dos parâmetros mecânicos e físico-químicos avaliados na literatura como será descrito a seguir. No entanto, deve-se estar atento aos efeitos de degradação que são concorrentes e podem ser intensificados de acordo com a dose absorvida e a taxa de dose do processo, o que vai alterar o comportamento físico, químico, mecânico e térmico, entre outros, do material e isso na maioria das vezes é evidenciado pela avaliação empírica.

Adem e colaboradores ${ }^{55}$ estudaram a reticulação de PEBD virgem e reciclado, comparando o processamento por radiação gama e por feixe de elétrons em doses de até 350 kGy. Observou-se que a reticulação de ambos materiais ocorre em doses mais baixas quando o processo é realizado por feixe de elétrons, mas que a dose incipiente para a formação de gel é maior nos reciclados e isso deve estar relacionado a sua baixa massa molar. Os valores máximos de tensão na ruptura nas amostras virgens e recicladas são observados sob irradiação por feixe de elétrons até a dose de 25 kGy e a partir dessa dose os valores são decrescentes, mas sob irradiação gama os valores desse parâmetro nos dois tipos de amostra é sempre decrescente; semelhantemente, o módulo de 
elasticidade das amostras virgens e recicladas apresentou valores máximos em 25 kGy sob irradiação por feixe de elétrons, mas quando as amostras passam pelo processo de irradiação gama, esse parâmetro é máximo em 100 kGy. Os autores observaram ainda a diminuição na temperatura de fusão com o aumento da dose em ambos tipos de amostra.

Suarez e colaboradores ${ }^{56}$ pesquisaram o comportamento térmico de blendas de PEBD/PEAD reciclados na composição de 75/25 de sacos e outras embalagens pós consumo submetidas a radiação gama com doses de 100 kGy a $2.000 \mathrm{kGy}$ (taxa de dose de 2,5 kGy/h) na presença de ar atmosférico. Os autores observaram que as temperaturas de fusão e cristalização do PEBD diminuiram em função do aumento da dose absorvida (a partir de 100 kGy), que é consequência da progressiva quebra de cadeias e diminuição da massa molar.

Em outro estudo de Suarez e colaboradores $^{57}$ foi observada a degradação superficial e sua influência no comportamento da fratura e consequentes alterações das propriedades mecânicas na blenda PEBD/PEAD com composição de 75/25, ambos reciclados de embalagens plásticas pós consumo, quando submetidas a radiação gama em doses de 100 kGy a 2.000 kGy (taxa de dose de 2,5 kGy/h) em ar atmosférico.

\subsubsection{Efeitos da Radiação no EPDM}

Özdemir ${ }^{58}$, analisou o efeito da radiação gama em doses de até 184 kGy e distintas taxas de dose (1280 Gy/h e 64 Gy/h), em dois tipos de borracha EPDM com diferentes percentuais de dieno: $5 \%$, e 5,6 \% e de etileno: 50,8 \% e $51,6 \%$, utilizando dois tipos de peróxidos em diferentes concentrações entre 3-5 \% e 5-7 \%: o 2,5-di-(t-butilperoxi)-2,5-dimetil-hexano (DMBPHa) e o di-(tercbutylperoxyisopropyl)-benzeno (BBPIB) muito utilizados na vulcanização de borrachas. Observaram degradação da borracha de EPDM na taxa de dose mais alta comparada a mais baixa e no mesmo valor de dose. Além disso, a cisão de cadeia foi o mecanismo dominante da degradação em baixas doses (cerca de 31 kGy), no entanto, a reticulação foi dominante na borracha exposta à alta taxa de dose. O alto teor de etileno na borracha de EPDM mostrou tendência à reticulação. 
Davenas e colaboradores ${ }^{59}$, pesquisaram a estabilidade dos polímeros borracha etileno-propileno (EPR) e EPDM sob a radiação ionizante do feixe de elétrons com energia de $2 \mathrm{MeV}$, com doses de 0 à $800 \mathrm{kGy}$ e taxa de dose de 500 kGy/h em atmosfera inerte (argônio), e por radiação gama em atmosfera de oxigênio com doses de 0 à $500 \mathrm{kGy}$ e taxa de dose de $1 \mathrm{kGy} / \mathrm{h}$. $\mathrm{O}$ estudo mostra que em até 100 kGy há um aumento na velocidade de reticulação no início do processo devido à recombinação de radicais peroxil provenientes do oxigênio.

Zaharescu e colaboradores ${ }^{60}$ destacaram a competição dos radicais livres, gerados pela exposição à radiação gama na borracha EPDM, em diferentes reações de reticulação e de degradação oxidativa. Esta competição foi estudada na faixa de temperaturas de $130^{\circ} \mathrm{C}$ a $150^{\circ} \mathrm{C}$ em água destilada, na dose total de $150 \mathrm{kGy}$ a uma taxa de dose de 0,54 kGy/h. Durante a irradiação foram gerados os radicais livres que reticularam a borracha antes de ocorrer a oxidação térmica. Isto ocorre quando a radiação é feita em água, a penetração de oxigênio no polímero é muito lenta, dificultando assim a degradação oxidativa e favorecendo a recombinação dos radicais livres que induzem à reticulação.

Hacioglu e colaboradores ${ }^{61}$ realizaram um estudo semelhante, porém em meio aquoso e ar atmosférico. Observaram que as condições do ambiente, o tipo de peróxido e a taxa de dose de irradiação apresentaram alterações nas propriedades da borracha EPDM. A irradiação no meio aquoso resultou em menor degradação em comparação com as amostras em ar atmosférico. A perda das propriedades mecânicas foi menor em alta taxa de dose, provavelmente devido à rápida recombinação dos radicais gerados. Muitas das diferenças observadas entre a alta e baixa taxa de dose de irradiação são relacionadas à difusão do oxigênio que foi limitada pela alta taxa de dose.

\subsubsection{Efeitos da radiação na blenda PEAD/EPDM}

Zeid e colaboradores ${ }^{62}$ pesquisaram a mistura de compósitos de borracha de etileno-propileno-dieno (EPDM), polietileno de alta densidade (PEAD) e de pó de borracha de pneus (GTR) em diferentes proporções e submetidos à radiação gama em doses de até 250 kGy. A radiação gama promoveu melhoria nas propriedades de todas as composições de mistura, na condição de baixa 
proporção de GTR onde há ocorrência de adesão interfacial entre este componente e os demais na mistura.

Shin e colaboradores $^{63}$ pesquisaram as propriedades térmicas e mecânicas na blenda PEAD/EPDM e cianurato de trialilo como agente de reticulação submetendo a radiação por feixe de elétrons em doses de 50 à 300 kGy. Os resultados mostraram que em doses de $150 \mathrm{kGy}$ os valores tiveram aumento nos parâmetros estabilidade térmica, propriedades de tração e resistência ao impacto. Em doses mais elevadas, os valores desses parâmetros diminuíram. A adição do agente de reticulação para misturas de PEAD/EPDM apresentou elevado efeito de reticulação durante a irradiação.

Jya e colaboradores ${ }^{64}$ pesquisaram as propriedades térmicas e mecânicas em amostras de PEAD e da Blenda PEAD/EPDM com o retardator de chama óxido de antimônio $\left(\mathrm{Sb}_{2} \mathrm{O}_{3}\right)$; as amostras foram expostas à radiação gama em atmosfera de nitrogênio em doses de 100 kGy a 200 kGy. Os resultados mostraram aumento no percentual de alongamento na quebra das amostras que formam a blenda na dose de 100 kGy. A adição de EPDM ao PEAD e a exposição à radiação incrementam a propriedade fogo-retardante e outras propriedades físicas do termoplástico devido a reticulação da borracha que atua na redução da taxa de liberação de calor e flexibilidade do PEAD.

Mohamed e colaboradores ${ }^{65}$, estudaram o comportamento da Blenda PEAD/EPDM em concentrações de 50/50 e blendas PEAD/EPDM com a adição de carbonato de cálcio $\left(\mathrm{CaCO}_{3}\right)$ em distintos tamanhos de partículas. As blendas foram submetidas à radiação gama em ar atmosférico em doses de até 200 kGy (taxa de dose de 5,4 kGy/h). Houve aumento no valor das propriedades de dureza, tensão em $50 \%$ de alongamento, grau de reticulação e temperatura de decomposição em função do aumento da dose nas blendas sem o carbonato; nas blendas com o carbonato esses valores foram sempre maiores, principalmente em amostras com baixa granulometria do aditivo inorgânico. Esses resultados mostram que ambos os efeitos, grau de reticulação e característica de reforço do aditivo convergem para o incremento dessas propriedades. 


\section{PARTE EXPERIMENTAL}

\subsection{Materiais}

\subsubsection{Polietileno de alta densidade (PEAD)}

Foi utilizado o PEAD virgem (JV060U - Braskem), em grânulos extrusados (FIG.11), gentilmente cedido pela Empresa PPlas Indústria e Comércio LTDA. As suas propriedades estão descritas na TAB.1.

TABELA 1 - Propriedades do PEAD (JV060U-Braskem) ${ }^{66}$

\begin{tabular}{ccc}
\hline Propriedades & Valor Nominal & Unidade \\
\hline Densidade & 0,957 & $\mathrm{~g} / \mathrm{cm}^{3}$ \\
\hline Módulo flexural de elasticidade & 1.360 & $\mathrm{MPa}$ \\
\hline Tensão de escoamento & 28 & $\mathrm{MPa}$ \\
\hline Resistência ao Impacto Izod & 36 & $\mathrm{~J} / \mathrm{m}$ \\
\hline Índice de Fluidez (190/2.16) & 7.0 & $\mathrm{~g} / 10 \mathrm{~min}$ \\
\hline
\end{tabular}

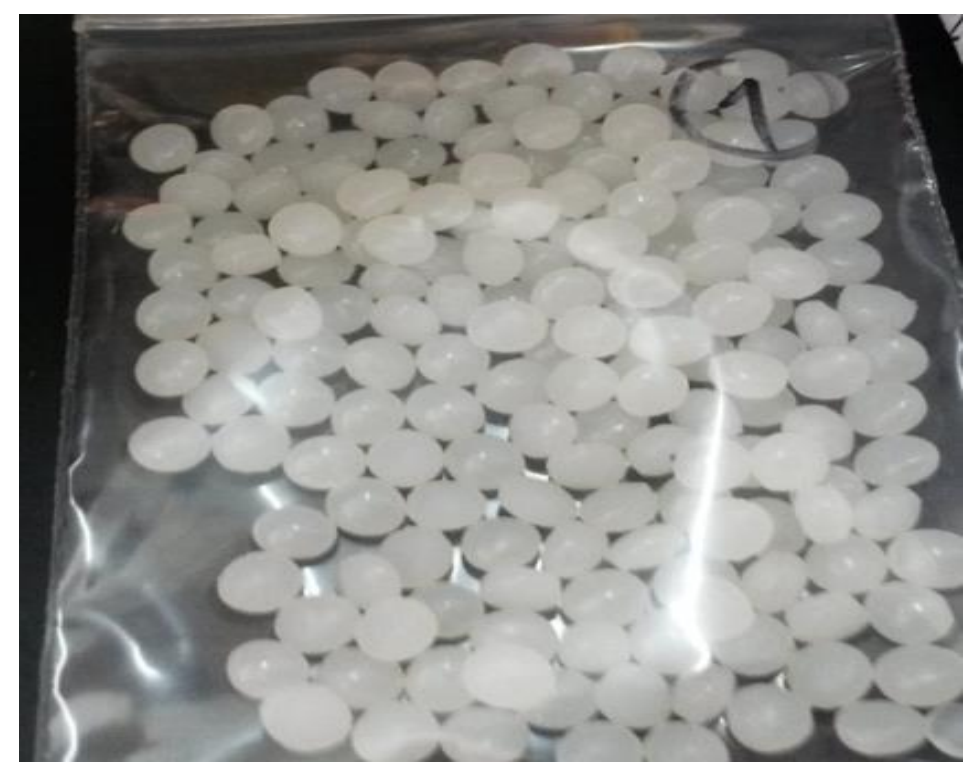

FIGURA 11 - Polietileno de alta densidade (PEAD) JV060U 


\subsubsection{Borracha de etileno- propileno- dieno (EPDM)}

O elastômero utilizado foi o EDPM (KELTAN 5470) em forma de fardo (FIG. 12), gentilmente cedido pela empresa LANXESS Indústria de Produtos Químicos e Plásticos LTDA, cujas propriedades estão na TAB. 2.

TABELA 2 - Propriedades do EPDM puro (KELTAN 5470 - LANXESS) ${ }^{67}$.

\begin{tabular}{lcc}
\hline Proporção & Valor Nominal & Unidade \\
\hline Etileno & 70 & $\%$ \\
\hline Etilideno norboneno & 4,6 & $\%$ \\
\hline Densidade & 0,86 & $\mathrm{~g} / \mathrm{dm}^{3}$ \\
\hline
\end{tabular}

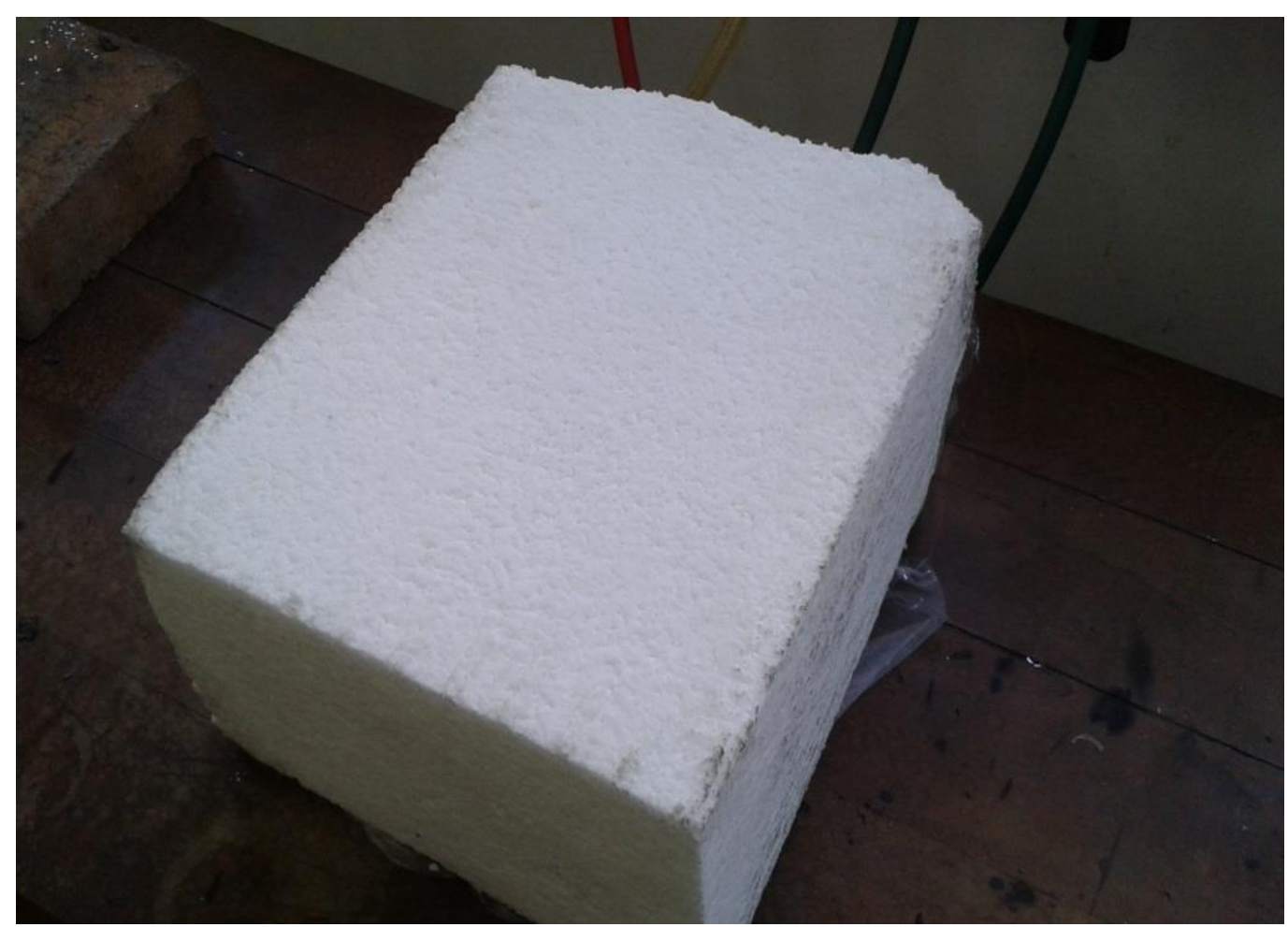

FIGURA 12 - Elastômero EPDM puro (Keltan 5470 - LANXESS) 


\subsection{Métodos}

\subsubsection{Processamento e reprocessamento do PEAD e de blendas de PEAD recilcado-EPDM}

O processamento do PEAD e de blendas de PEAD reciclado/EPDM puro foram realizados pela injeção dos grânulos, para a obtenção dos corpos de prova a serem utilizados nos ensaios mecânicos.

O reprocessamento consistiu na moagem destes corpos de prova e posterior injeção, esse procedimento foi realizado 4 vezes na ausência de qualquer tipo de aditivo. O material obtido foi chamado de $4^{\underline{a}}$ reciclagem ou $4^{\circ}$ reprocessamento. Segundo Alcântara ${ }^{68}$ á partir do $3^{0}$ reprocessamento ou $3^{\text {a }}$ extrusão do material reciclado composto por poliolefinas, se inicia o processo de degradação.

A injetora utilizada foi de marca HAITIAN, Série Saturno modelo AS 9000/6800 cedida pela Empresa PPlas Indústria e Comércio LTDA (FIG. 13), onde foi realizado os reprocessamentos e os corpos-de-prova de tração tipo I, conforme a norma D $638^{69}$, flexão (D 256) ${ }^{70}$ e impacto (D 790) ${ }^{71}$, mantendo os parâmetros padronizados em todas as amostras apresentados na TAB. 3 .

O processo de moagem foi aplicado para fragmentar todos os materiais usados (PEAD e EPDM). Este processo foi realizado em um moinho de facas de marca Primotécnica, modelo P1002, cedido pela Empresa PPlas Indústria e Comércio LTDA, com 3 facas rotativas e 2 fixas com rotação de 1600 rpm (FIG. 14). 


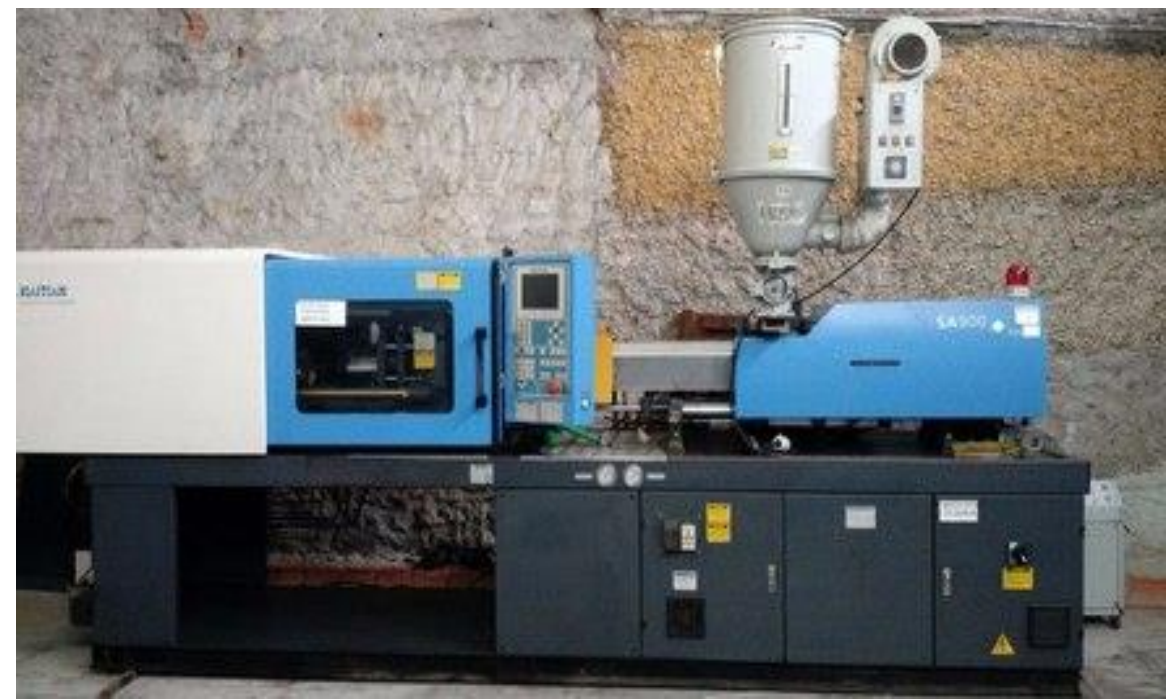

FIGURA 13 - Injetora HAITIAN Série Saturno modelo AS 9000/6800

TABELA 3 - Condições do processo de injeção

\begin{tabular}{l|l|c|c|c}
\hline Zonas de Aquecimento & 1 & 2 & 3 & Bico \\
\hline Temperatura $(\stackrel{\circ}{ } \mathrm{C})$ & 70 & 80 & 90 & 90 \\
\hline
\end{tabular}

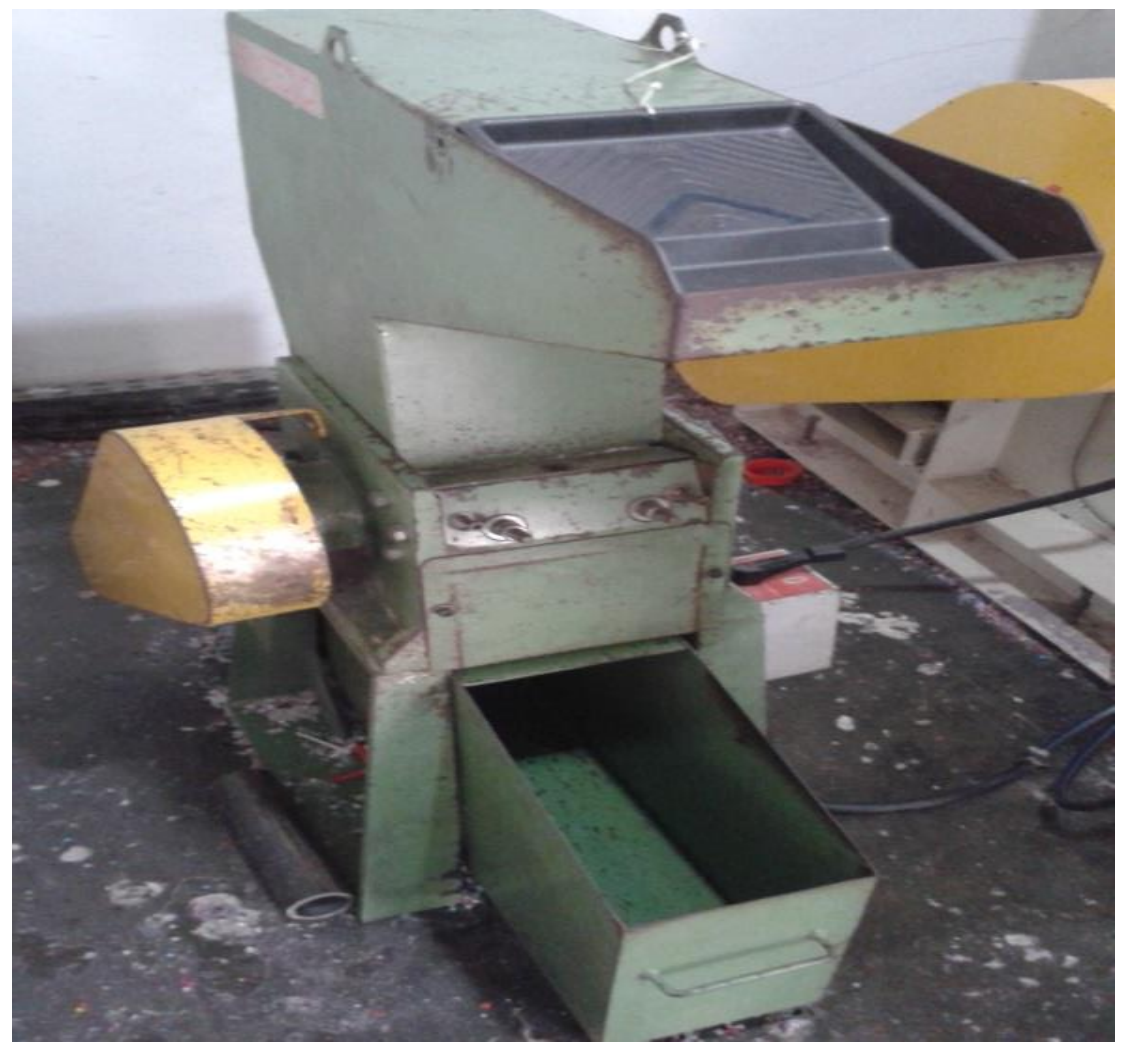

FIGURA 14 - Moinho de facas rotativas 


\subsubsection{Formação das blendas de PEAD reciclado/EPDM puro}

Os materiais PEAD reciclado e EPDM puro foram previamente pesados (balança para cargas Filizola - limite de $20 \mathrm{~kg}$ e balança analítica Shimadzu limite $200 \mathrm{~g}$ respectivamente), trabalhando-se com alíquotas de $2 \mathrm{~kg}$.

A composição da mistura de EPDM puro nas blendas foi de $1 \%, 5 \%$ e $10 \%$, foi realizada em extrusora dupla rosca cedida pela empresa NZ Cooperpolymer. O uso de extrusoras com dupla rosca é importante devido à operação ser contínua e a versatilidade em projetar o barril com posições de alimentação variada e a rosca com diferentes elementos com uma configuração específica para cada aplicação. Efeitos de mistura, cisalhamento e transporte são vinculados à sequência de elementos da rosca e, portanto devem estar harmonicamente posicionados ao longo de todo o comprimento da rosca ${ }^{72}$.

Para este processo, foi utilizada uma extrusora dupla rosca co-rotante para Produção - EB-DRC 40, L/D 47 e motor com 1550 CV e 600 rpm (FIG. 16), cujos parâmetros estão apresentados na TAB. 4.

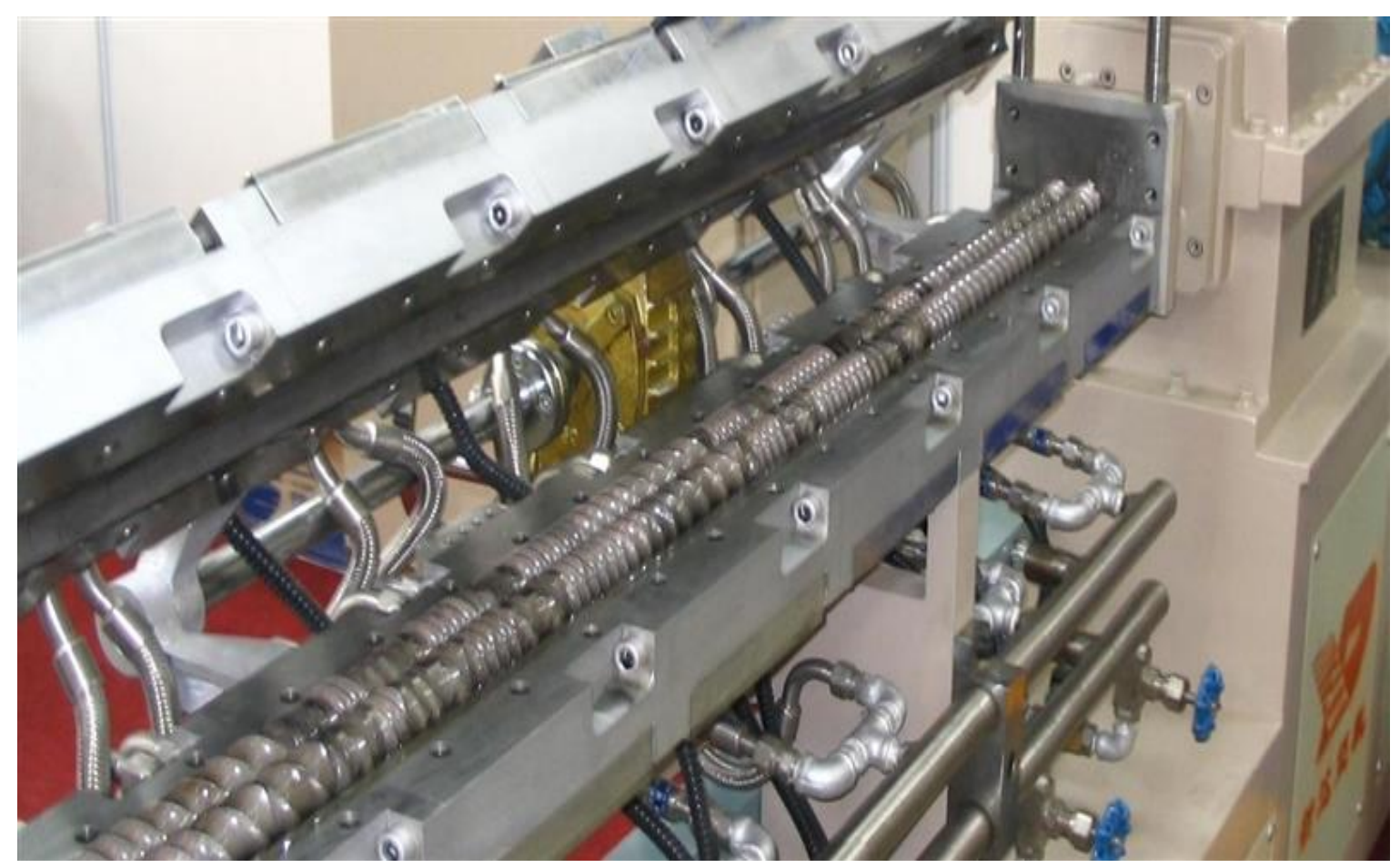

FIGURA 15 - Extrusora Dupla Rosca ${ }^{73}$ 
TABELA 4 - Condições do processo de extrusão

\begin{tabular}{l|c|c|c|c|c|c|c|c}
\hline Rotação da Rosca & \multicolumn{7}{|c}{300 rpm } \\
\hline Rotação do Alimentador & \multicolumn{10}{|c}{13 rpm } \\
\hline Zonas de Aquecimento & 1 & 2 & 3 & 4 & 5 & 6 & 7 & Cabeçote \\
\hline Temperatura $\left({ }^{\circ} \mathrm{C}\right)$ & 160 & 165 & 170 & 170 & 170 & 170 & 170 & 170 \\
\hline
\end{tabular}

\subsubsection{Processo de Irradiação gama dos corpos-de-prova}

Todos os corpos-de-prova foram irradiados no irradiador multipropósito (CTR-IPEN-CNEN/SP), cuja radiação gama provém de uma fonte de $\mathrm{Co}^{60}$. As condições desse processo foi na temperatura ambiente, na presença de ar atmosférico, nas doses de 50 kGy e 100 kGy e taxa de dose aproximadamente de 7,2 kGy.h. ${ }^{-1}$.

\subsection{Caracterização das amostras}

Os ensaios mecânicos são analises que caracterizam o comportamento dos materiais às solicitações dos esforços que the são aplicados indicando os valores de resistência mecânica podendo ser por tensões ou deformações ${ }^{74}$.

\subsubsection{Ensaios de tração}

Os ensaios de tração foram realizados conforme a norma ASTM D $638^{69}$, na máquina universal de ensaios mecânicos marca Instron modelo 5567 (Laboratório de ensaios mecânicos do CTR-IPEN-CNEN/SP), com taxa de deslocamento igual a $100 \mathrm{~mm} / \mathrm{min}$ e célula de carga de $10 \mathrm{KN}$ em temperatura ambiente. Por meio deste ensaio obtiveram-se valores do limite de escoamento e tensão no escoamento com $100 \%$ de deformação e módulo de elasticidade. Este ensaio foi realizado a partir de 5 replicatas para cada tipo de amostra. 


\subsubsection{Ensaio de flexão}

Foi utilizado o método de carga em três pontos e taxa de deflexão de $5 \%$ com célula de carga de $10 \mathrm{KN}$ em temperatura ambiente segundo a norma ASTM D $790^{70}$. O ensaio foi realizado em uma máquina universal de ensaios mecânicos marca Instron modelo 5567 (Laboratório de ensaios mecânicos do CTR-IPEN-CNEN/SP). Os valores de módulo de flexão e resistência à flexão foram provenientes da média de 5 replicatas para cada tipo de amostra.

\subsubsection{Ensaio de resistência ao impacto}

Os ensaios de resistência ao impacto tipo Izod, com martelo de (pêndulo) à temperatura ambiente, foi realizado no equipamento de ensaio de impacto marca Tinius Olsen, modelo 892 (FIG. 16a) e entalhadora (FIG. 16b), seguindo a norma ASTM D-256 ${ }^{71}$. Os parâmetros de maquina para efetuar os ensaios foram:

- Energia potencial do pêndulo 7,5454 J;

- Peso do pêndulo 1,264 Kg;

- Altura do pêndulo 608,717 mm;

- Raio do pêndulo $334,925 \mathrm{~mm}$.

Os resultados obtidos foram a média de 5 replicatas para cada tipo de amostra.

(a)

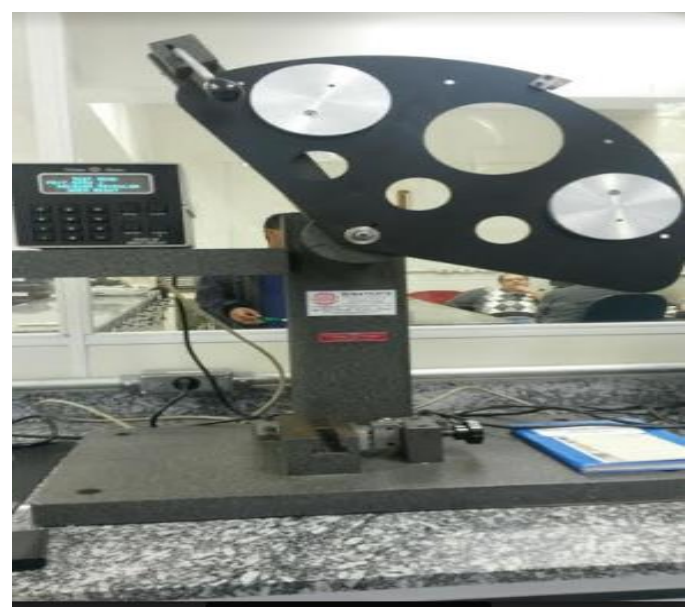

(b)

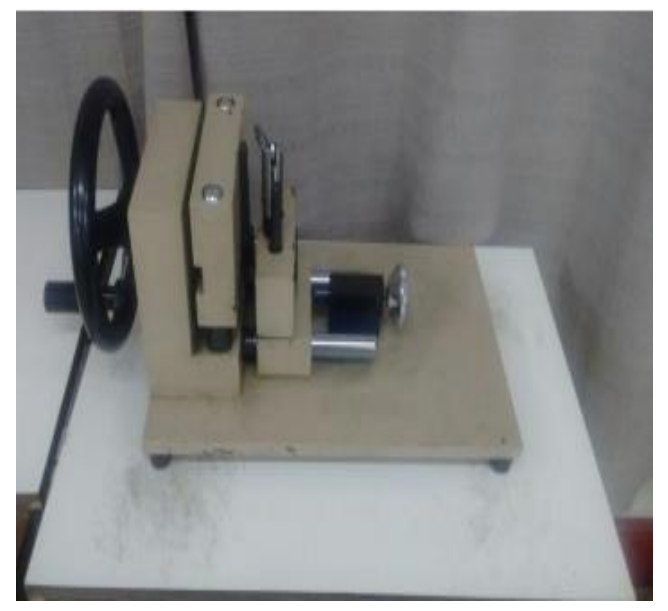

FIGURA 16 - Equipamento de Impacto (a) e Entalhadora (b) 


\subsubsection{Termogravimetria (TG)}

Segundo Mothé ${ }^{75}$, a termogravimetria baseia-se no estudo da variação da massa de uma amostra, resultante de uma transformação física ou química em função do tempo ou temperatura, é um processo contínuo que mede a variação de massa (perda ou ganho) de uma substância ou material em função da temperatura e/ou tempo.

O perfil do comportamento de degradação térmica das amostras poliméricas foi obtido em um analisador termogravimétrico marca TA Instruments, modelo SQT-600 (Laboratório de Análises Térmicas - CTR-IPEN-CNEN/SP). Utilizou-se amostras de massa entre 8 e $10 \mathrm{mg}$, que foram degradadas na faixa de temperatura de $25{ }^{\circ} \mathrm{C}$ a $800{ }^{\circ} \mathrm{C}$ e razão de aquecimento de $20{ }^{\circ} \mathrm{C} / \mathrm{min}$ em cadinho de alumina sob ar comprimido no fluxo de $100 \mathrm{~mL}$. $\mathrm{min}^{-1}$. Esse ensaio foi desenvolvido conforme a norma ASTM D6370-99 ${ }^{76}$.

\subsubsection{Difração de raios $X$}

A difração de raios $X$ é uma técnica para o estudo de materiais que obtem informações sobre a distância interatômica , ângulos de ligação e aspectos estruturais dos materiais ${ }^{77}$. Esta técnica identifica as posições atômicas e a composição química das amostras investigadas, além das tensões na sua rede cristalina, e também identificar as fases cristalinas nela presentes.

As fases das amostras foram avaliadas pela análise por difração de raios-X utilizando-se um difratômetro Rigaku Multiflex (CCTM-IPEN-CNEN/SP), cuja raia de radiação foi o do $\mathrm{Cu} K \alpha(\lambda=1,54056 \AA)$, tensão de operação de $40 \mathrm{kV}$ e corrente de $20 \mathrm{~mA}$; a varredura do ângulo $(2 \theta)$ teve valor de $1 \% \mathrm{~min}$. na faixa de $5^{\circ}$ a $80^{\circ}$.

\subsubsection{Calorimetria exploratória diferencial (DSC)}

Mothé $^{75}$ define a DSC como uma técnica que mede as temperaturas e o fluxo de calor associado com as transições dos materiais em função da 
temperatura e do tempo. Tais medidas fornecem informações qualitativas e quantitativas sobre mudanças físicas e químicas que envolvem processos endotérmicos e exotérmicos. A técnica fornece informações sobre caracterização e medidas especificas como: transição vítrea, temperatura e tempo de cristalização, ponto de fusão, cinética de reação entre outros.

As distintas transições térmicas das amostras foram obtidas em um calorímetro exploratório diferencial Perkin Elmer modelo DSC 6000 (Laboratório de Análises Térmicas do CTR-IPEN-CNEN/SP). As Amostras com massa entre 8 e $10 \mathrm{mg}$, foram colocadas em cápsula fechada de alumínio e submetidas ao seguinte ciclo térmico:
a) resfriamento de $30{ }^{\circ} \mathrm{C}$ à $-70^{\circ} \mathrm{C}$;
b) aquecimento de $-70^{\circ} \mathrm{C}$ à $160^{\circ} \mathrm{C}$ e
c) resfriamento de $160^{\circ} \mathrm{C}$ à $30^{\circ} \mathrm{C}$.

A razão de aquecimento foi de $10^{\circ} \mathrm{C} / \mathrm{min}$. teve o mesmo valor em todo ciclo de temperaturas estudadas e o processo foi realizado na presença de $\mathrm{N}_{2}$ ultra puro, sob fluxo de $100 \mathrm{~mL}$. $\mathrm{min}^{-1}$. Este procedimento foi desenvolvido conforme a norma ASTM D3418-15 ${ }^{78}$.

Essa técnica permitiu verificar as transições de fase (fusão e cristalização) das amostras e determinar a temperatura de fusão e de cristalização, bem como o grau de cristalinidade de acordo com a equação (5),

$$
X_{c}=\frac{\Delta H_{f}}{\Delta H_{o}} \cdot 100
$$

em que $\Delta \mathrm{H}_{f}$ é a variação de entalpia da amostra e $\Delta \mathrm{H}_{0}$ é a variação de entalpia de fusão do polietileno $100 \%$ cristalino assumido como $290 \mathrm{~J} / \mathrm{g}^{79}$.

\subsubsection{Espectrometria no infravermelho por transformada de Fourier (FTIR)}

As vibrações moleculares envolvem energias que correspondem a energias de fótons infravermelhos ${ }^{80}$, baseia-se na análise da absorção da radiação de diferentes frequências. Sua principal função é identificar grupos 
funcionais em amostras orgânicas ou inorgânicas, por meio dos valores peculiares de absorção de cada elemento.

Os ensaios de espectrometria de absorção no infravermelho por transformada de Fourier (FTIR) foram realizados no espectrômetro FTIR marca Thermo Nicolet, modelo Nexus 670 (CCTM-IPEN-CNEN/SP). As amostras na forma placas de aproximadamente $300 \mu \mathrm{m}$ foram analisadas no modo transmissão, na faixa da radiação infravermelho média, intervalo de frequência de $400 \mathrm{~cm}^{-1}$ a $4.000 \mathrm{~cm}^{-1}$, com resolução de $2 \mathrm{~cm}^{-1}$, e o espectro obtido foi 0 resultado da média de 16 amostragens.

\subsubsection{Determinação do grau de reticulação}

A determinação do grau de reticulação é uma técnica utilizada para avaliar o percentual de reticulação da rede tridimensional por conta da perda de massa da amostra. Esta técnica permite observar as mudanças estruturais dos materiais.

Neste ensaio, as amostras de massa de cerca de $0,3 \mathrm{~g}$ foram envoltas em uma tela de aço inox (FIG. 17b), de abertura de malha igual a 500 mesh, colocadas em um balão de fundo redondo contendo xileno (FIG. 17a) e deixadas sob refluxo durante 24 horas. Esse ensaio foi realizado segundo os procedimentos da norma ASTM D $2765^{81}$. Durante a extração, a fração reticulada (fração gel) fica retida na tela de aço, enquanto que a fração não reticulada é dissolvida.

(a)

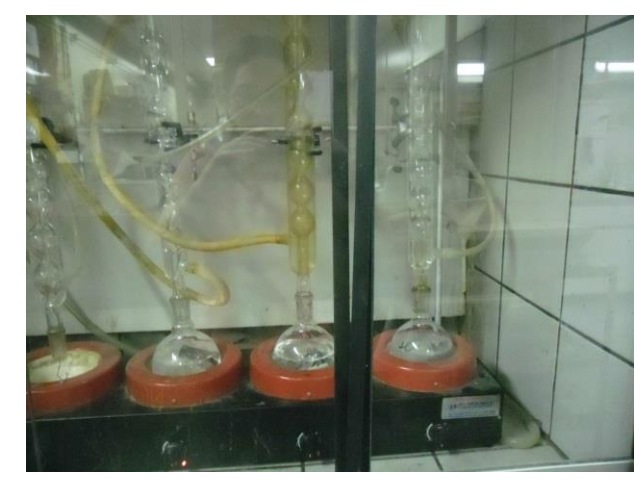

(b)

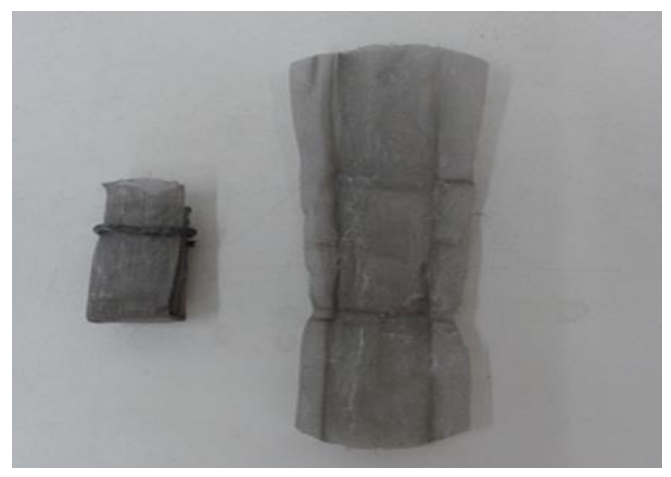

FIGURA 17- Determinação de fração gel. Sistema em refluxo (a); tipo de tela e amostra embalada para a extração (b). 
Este ensaio foi realizado em triplicata. As amostras foram secas por aproximadamente 4 horas em estufa à $150^{\circ} \mathrm{C}$. Após esse processo as amostras foram pesadas e a fração gel foi calculada segundo a equação (6).

$$
F G=\frac{M_{f}}{M_{i}} \cdot 100
$$

em que $M_{f}$ é massa final e $M_{i}$ é massa inicial de cada amostra.

\subsubsection{Microscopia eletrônica de varredura (MEV)}

A análise de interação e miscibilidade em blendas poliméricas depende de técnicas analíticas que possibilitem a determinação da composição química da amostra. A microscopia eletrônica de varredura (MEV) é uma técnica que permite o estudo da interação dos materiais por alta resolução, profundidade de foco e utilização de recursos analíticos, que possibilitam a realização in-situ de microanálise da superfície da amostra ${ }^{82}$.

A morfologia das amostras foi verificada em microscópio eletrônico de varredura (MEV), da marca HITACHI, modelo TM 3000 (CCTM-IPEN-CNEN/SP). As amostras dos corpos de prova poliméricos foram recobertas com ouro por sputtering, onde foi verificada não só a morfologia superficial das amostras como a da superfície transversal após fratura por criogenia. Para a verificação da labilidade do EPDM nas heterogeneidades, as amostras foram imersas em tolueno por cerca de 7 dias, secas em estufa à vácuo sob temperatura de $60{ }^{\circ} \mathrm{C} \mathrm{e}$ em seguida, submetidas à observação após metalização com ouro. 


\section{RESULTADOS E DISCUSSÃO}

\subsection{Espectrometria no infravermelho por transformada de Fourier (FTIR)}

A espectrometria na região da radiação infravermelha tem uso difundido na caracterização de materiais por ser um tipo de análise rápida e simples, mas que fornece informações valiosas a cerca das moléculas que constituem o material investigado, mais especificamente de certos grupos de átomos que vibram em determinadas frequências deste tipo de radiação, independentemente da estrutura da molécula principal ${ }^{83}$.

A espectrometria no infravermelho do PEAD virgem (FIG. 18) mostra três bandas fortes características desse polímero de origem olefínica ${ }^{84}$ : região de $2.970 \mathrm{~cm}^{-1}$ a $2.850 \mathrm{~cm}^{-1}$ devido à vibração das deformações axial assimétrica $\mathrm{e}$ simétrica do grupo metileno $\left(-\mathrm{CH}_{2}^{-}\right)$, região $1.477 \mathrm{~cm}^{-1}$ a $1.430 \mathrm{~cm}^{-1}$ devido à deformação angular simétrica no plano do $\left(-\mathrm{CH}_{2}-\right)$ e na região de 730 $\mathrm{cm}^{-1}$ a $710 \mathrm{~cm}^{-1}$ devido à vibração de deformação angular assimétrica no plano do $\left(-\mathrm{CH}_{2}{ }^{-}\right)$.

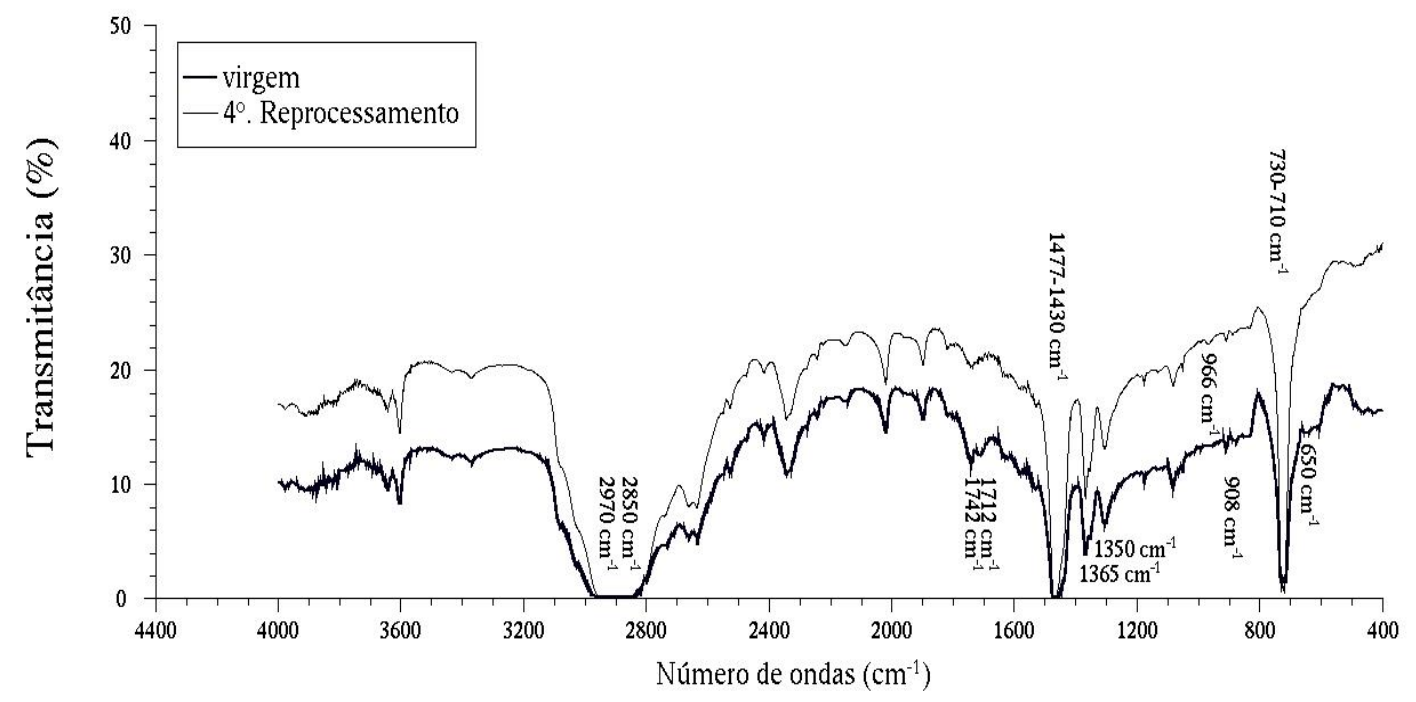

FIGURA 18 - Espectros de FTIR do PEAD virgem e 4º reprocessamento 
Vibrações fracas são observadas em $650 \mathrm{~cm}^{-1}$ devido à vibração angular fora do plano da ligação $\mathrm{C}$-H olefínico, em $908 \mathrm{~cm}^{-1}$ devido à vibração do grupo vinila $\left(-\mathrm{H}_{2} \mathrm{C}=\mathrm{CH}_{2}-\right)$, vibrações médias são observadas na região de 1.350 $\mathrm{cm}^{-1}$ a $1.150 \mathrm{~cm}^{-1}$ devido à deformação angular assimétrica em fase no plano do grupo $\left(-\mathrm{CH}_{2}-\right)$, mais especificamente um dublete em $1.366 \mathrm{~cm}^{-1}$ e em $1.351 \mathrm{~cm}^{-1}$ devido à vibração de deformação em movimento de leque desse grupo e finalmente em $1.742 \mathrm{~cm}^{-1}$ observa-se uma vibração de deformação axial da ligação dupla $-\mathrm{C}=\mathrm{C}^{-}{ }^{84}$.

A banda em $1.712 \mathrm{~cm}^{-1}$ é característica do grupo carbonila $(>C=O)$, que é indicativo de oxidação do material, mas neste caso pode estar relacionada à presença de aditivos antioxidante e estabilizante UV presente no polímero virgem como descrito no certificado de composição do material ${ }^{66}$, na classe de antioxidantes geralmente os fenóis (monofenóis e os tetrafenóis) e as aminas são utilizados $^{85}$. Em geral, os antioxidantes podem atuar no mecanismo de iniciação ou de propagação das reações de oxidação no polímero dependendo da classe e composição molecular ${ }^{85}$. Neste aspecto pode-se também não descartar a presença de algum contaminante durante a obtenção do corpo de prova.

O PEAD reciclado mostrou além das bandas fortes características dos polímeros parafínicos, o desaparecimento da banda na região de $650 \mathrm{~cm}^{-1}$, o que sugere a formação de ligações cruzadas nas condições do reprocessamento e também o surgimento de uma banda fraca na região de $966 \mathrm{~cm}^{-1}$, que é atribuída às vibrações do grupo transvinilideno ou éter vinílico ${ }^{86}$; sua formação é atribuída às reações de grupos alquila provenientes de processo de degradação. Desde que os aditivos antioxidantes têm por função reagir com radicais livres específicos (R·) e radicais peróxido e hidroperóxido (ROO·), introduzindo novas reações de terminação ou até mesmo destruindo essas espécies instáveis, pode-se prever o surgimento de espécies oxidadas no termoplástico sujeito a esse processo de reciclagem termomecânica ${ }^{85}$; o aditivo contido no material original pode ter atuado e formado como produto principal, cadeias cindidas terminadas com dupla ligação, como mostra o esquema da FIG. 19. Esse comportamento é factível e pode explicar o desaparecimento da banda em $1.712 \mathrm{~cm}^{-1}$ e o surgimento da banda em $1.742 \mathrm{~cm}^{-1}$ assim como a banda em $966 \mathrm{~cm}^{-1}$. 


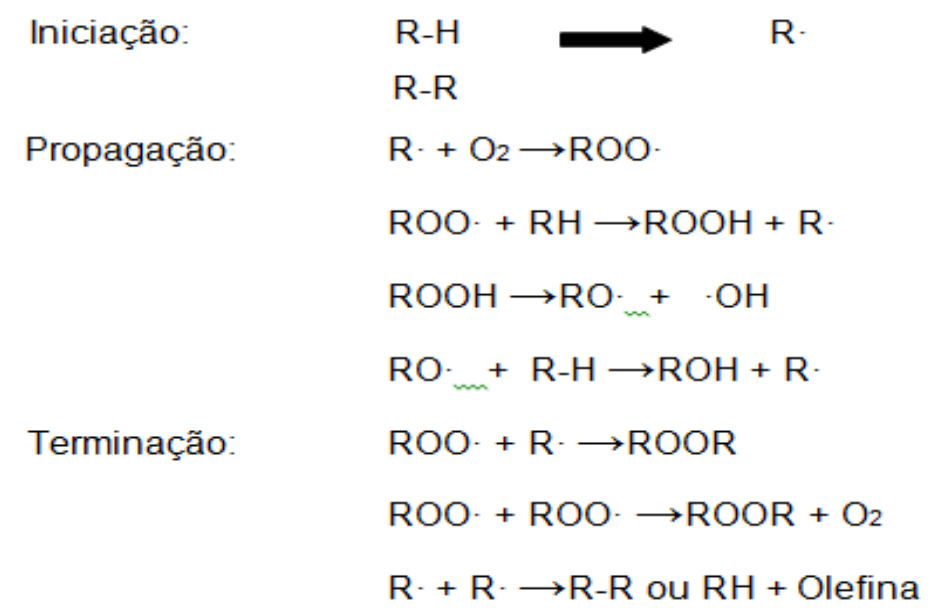

FIGURA 19 - Mecanismo da oxidação termomecânica em polímeros ${ }^{87}$

Na FiG. 20 é mostrado o espectro ATR-FT-IR do EPDM puro. Por constituir-se de moléculas com cadeias hidrocarbonadas de origem olefínica, as três bandas mais intensas vistas no espectro do HDPE virgem estão também presentes neste espectro: região de $2.970 \mathrm{~cm}^{-1}$ a $2.850 \mathrm{~cm}^{-1}$, região $1.477 \mathrm{~cm}^{-1} \mathrm{a}$ $1.430 \mathrm{~cm}^{-1}$ e na região de $730 \mathrm{~cm}^{-1}$ a $710 \mathrm{~cm}^{-1}$. Observa-se também uma banda em $1375 \mathrm{~cm}^{-1}$ devido à deformação simétrica do grupo $\mathrm{CH}_{3}$, sendo esta banda utilizada também em análise qualitativa da verificação de propileno no EPDM ${ }^{88}$.

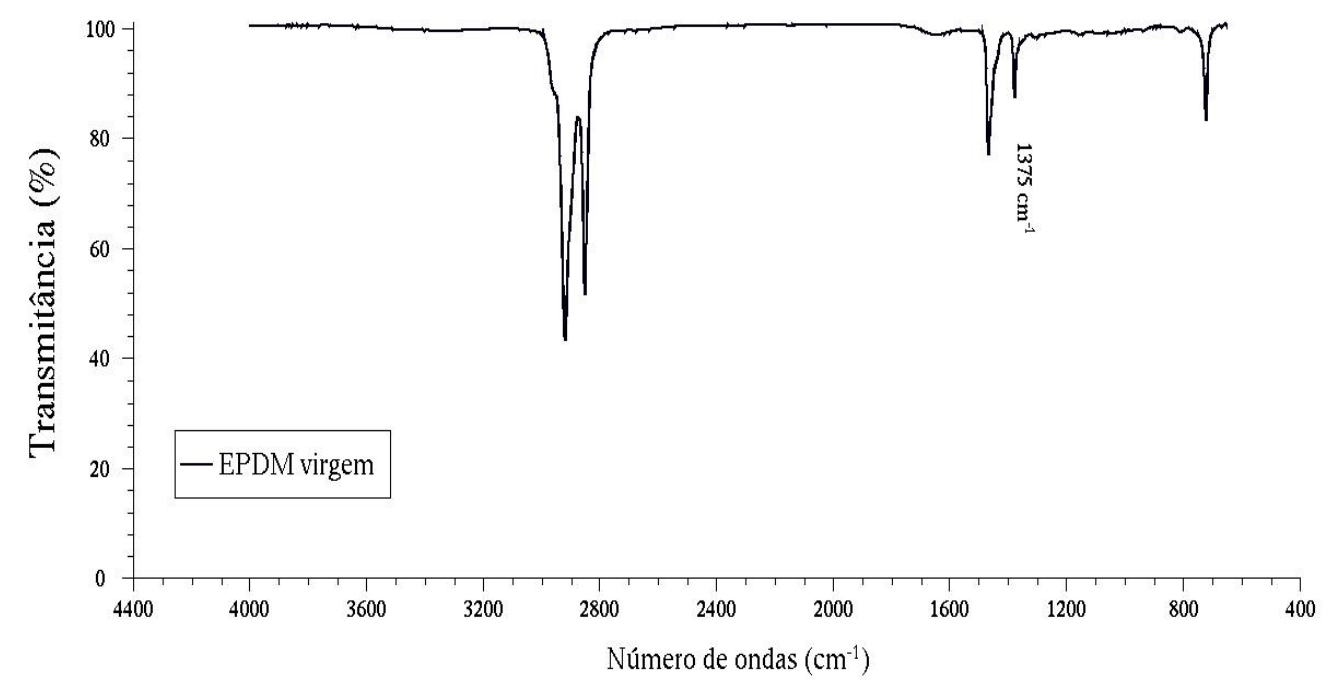

FIGURA 20- Espectro ATR-FTIR do EPDM puro 
Os espectros das blendas não irradiadas são mostradas na FIG. 21. Observa-se que as bandas relativas à presença de duplas ligações nas regiões de $650 \mathrm{~cm}^{-1}, 966 \mathrm{~cm}^{-1}$ e $1.742 \mathrm{~cm}^{-1}$ ficam mais evidentes (mais profundas e/ou mais largas) com o aumento da concentração do elastômero na blenda, mostrando a influência da concentração do EPDM. Com o aumento da concentração da borracha, a banda em $1.375 \mathrm{~cm}^{-1}$, relativa à vibração de deformação simétrica do grupo metila $\left(-\mathrm{CH}_{3}\right)$ em uma ramificação' região essa característica do EPDM (FIG. 20), torna-se mais larga à medida que a concentração deste componente aumenta na blenda. A banda em $1.712 \mathrm{~cm}^{-1}$ não é evidente nesses resultados, sugerindo a ausência de material oxidado durante as condições de formação da blenda.

Esses resultados evidenciam a presença do elastômero não só em termos qualitativos como também na condição semi -quantitativos.



FIGURA 21 - Espectros FTIR das blendas de PEAD 4ํrep./EPDM não irradiados

Quando estas blendas são irradiadas (FIG. 22 e 23), observa-se 0 desaparecimento da banda em $650 \mathrm{~cm}^{-1}$ (na dose mais baixa é observado na menor e maior concentração; na dose mais alta, nas concentrações mais altas), sugerindo a ocorrência de ligações cruzadas necessária à reticulação do material e que esse processo ocorre evidentemente na parte elastomérica do material. 
A banda em $966 \mathrm{~cm}^{-1}$ torna-se mais profunda com o aumento da dose, sugerindo o aumento da concentração da espécie transvinilideno, evidenciando a degradação do material quando exposto à essas doses de radiação.

A banda em $1.742 \mathrm{~cm}^{-1}$ não se apresenta mais larga, ao contrário, apresenta estreitamento em função do aumento de dose, esse processo é mais evidenciado quando se observa a banda em $1.712 \mathrm{~cm}^{-1}$ que mostra aumento de profundidade em função do aumento de dose, sugerindo a ocorrência de degradação. A banda em $1.375 \mathrm{~cm}^{-1}$ apresentou-se inalterada nessas condições, sugerindo que apesar de sofrer degradação, a parte elastomérica continua presente.

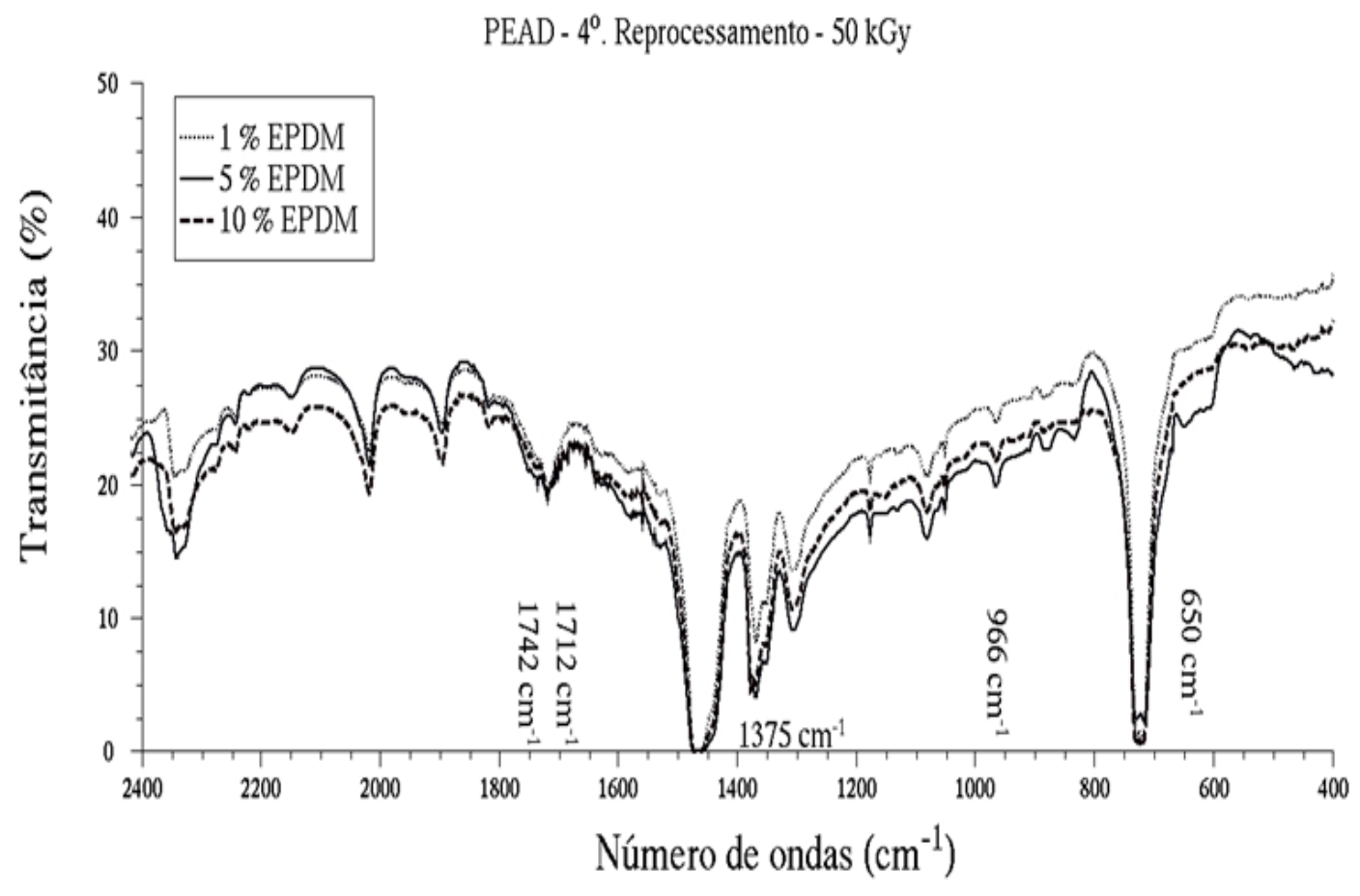

FIGURA 22 - Espectros FTIR das blendas de PEAD 4ํㅏㅁ./EPDM irradiados sob radiação gama na dose de 50 kGy 
PEAD - $4^{0}$. Reprocessamento - $100 \mathrm{kGy}$

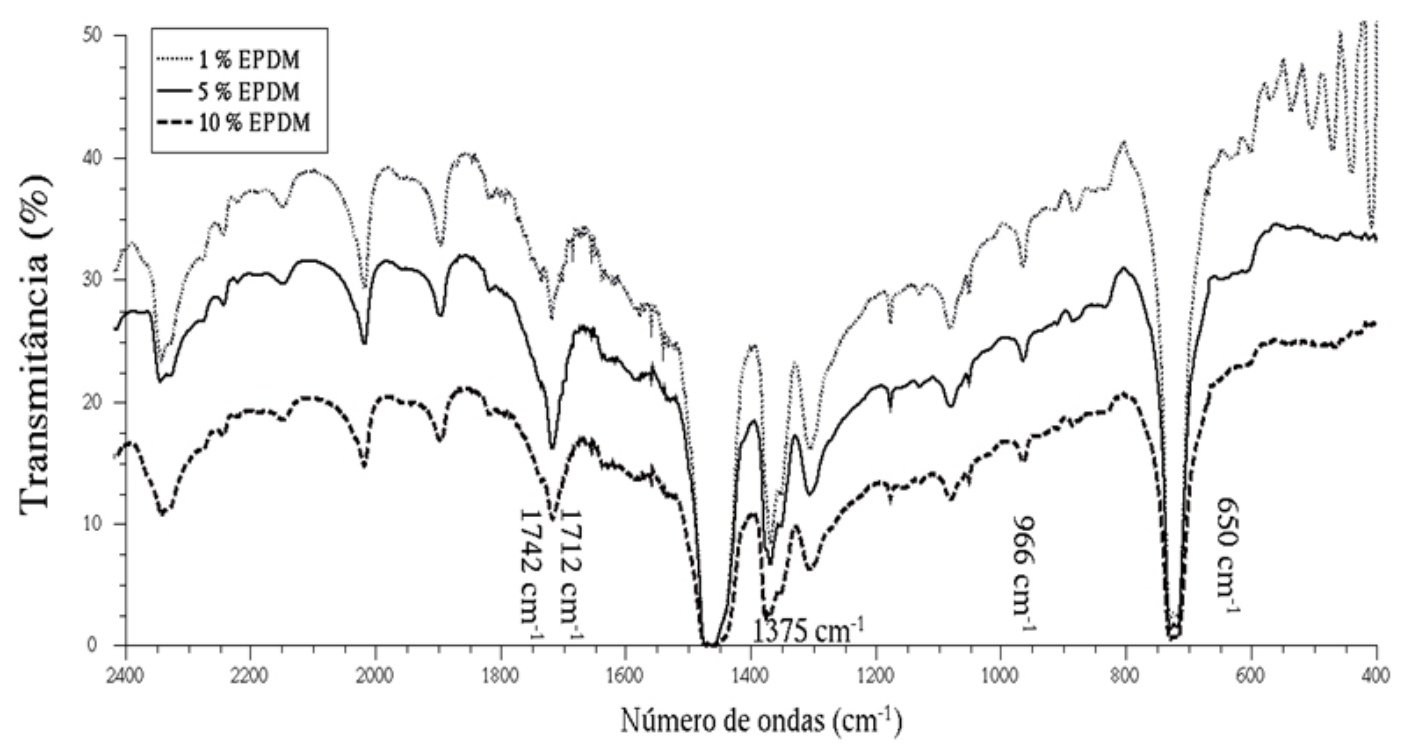

FIGURA 23 - Espectros de FTIR das blendas de PEAD 4ํrep./EPDM irradiados sob radiação gama na dose de $100 \mathrm{kGy}$

\subsection{Determinação do grau de reticulação}

A determinação do grau de reticulação é um ensaio macroscópico e serviu para evidenciar as observações obtidas por FTIR. A FIG. 24 mostra que todas as blendas irradiadas sofreram reticulação, como evidenciado nos espectros mostrados no item 5.1, e esses resultados foram comparados com o do termoplástico virgem, que evidentemente não formou fração gelificada após o ensaio, evidenciando que o material de partida obviamente não tinha sido reticulado.

Na menor dose absorvida (50 kGy), observou que o grau de reticulação tem tendência a aumentar com o aumento da concentração do elastômero: de 32 $\%$ (1 \% e 5\% de EPDM) a $50 \%$ (10\% de EPDM), evidenciando que esse componente é mais suscetível à reticulação.

Com o aumento da dose, todas as composições das blendas testadas obtiveram resultados médios próximos a $70 \%$, sendo evidenciado o aumento no grau de reticulação das blendas. As blendas não irradiadas não foram submetidas 
ao ensaio por não apresentarem evidência de processo de reticulação na análise sob a radiação infravermelho (FTIR).

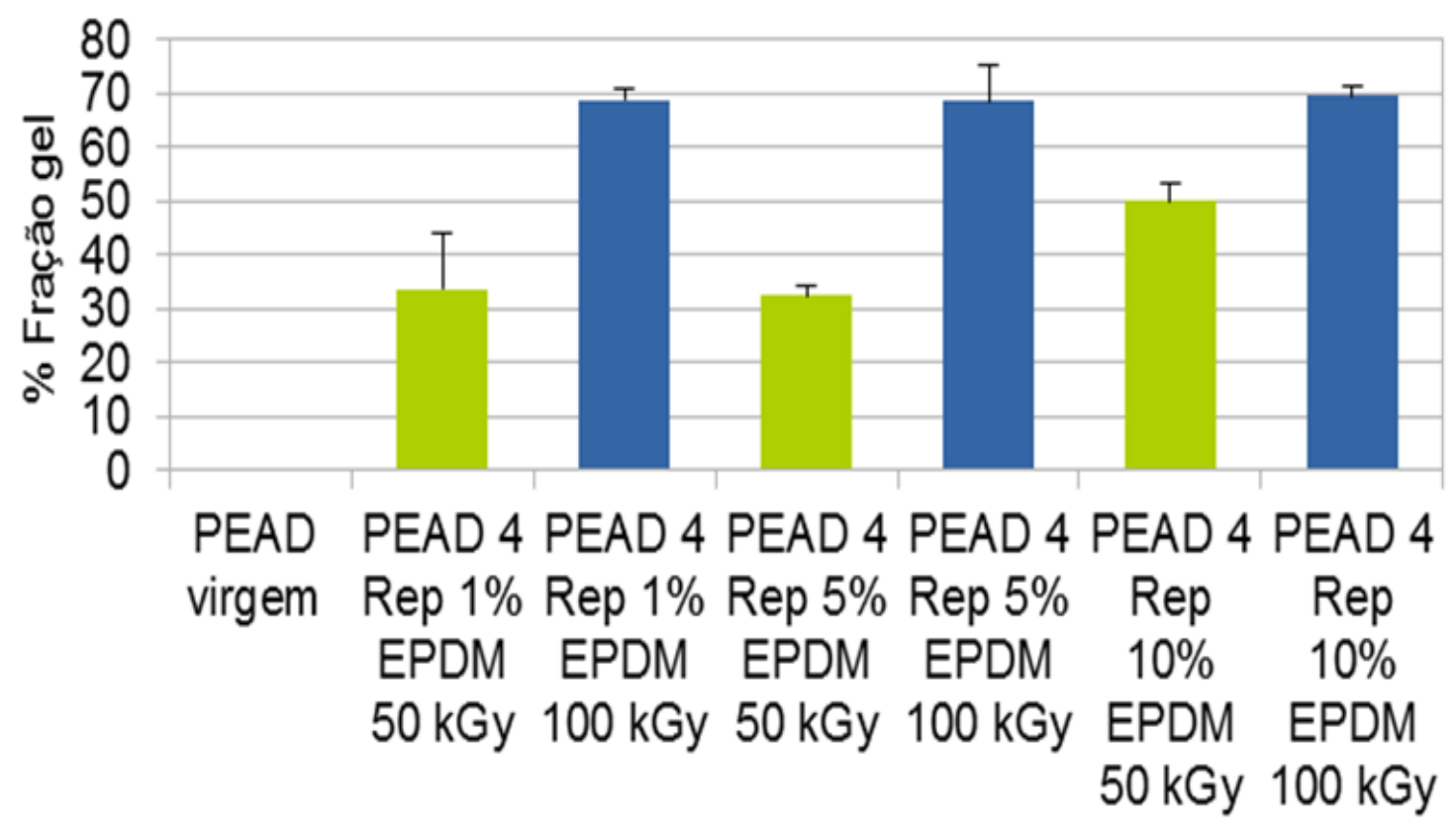

FIGURA 24 - Grau de reticulação das blendas irradiadas

\subsection{Termogravimetria (TG)}

A degradação térmica da amostra injetada de PEAD virgem é mostrada na FIG. 25a. Observa-se um evento secundário na temperatura média de $143{ }^{\circ} \mathrm{C}$ (TAB. 5) com perda de massa de $3 \%$ (TAB. 5), devido à presença de material volátil; em seguida, o evento principal ocorre na faixa de temperatura de $260 \stackrel{\circ}{\mathrm{C}}$ a $422{ }^{\circ} \mathrm{C}$ com perda de massa média de $84 \%$ (TAB. 5), devido à termodegradação da matriz polimérica formada pelo esqueleto hidrocarbonado ${ }^{89}$.

Ainda observa-se mais dois eventos: um na faixa de $445{ }^{\circ} \mathrm{C}$ a $480{ }^{\circ} \mathrm{C}$ cuja perda média de massa é de $8 \%$ (tabela 5 ) e outro na faixa de temperatura média de $480{ }^{\circ} \mathrm{C}$ a $560{ }^{\circ} \mathrm{C}$ relativos aos últimos $5 \%$ restantes do material (TAB.5), além da degradação dos produtos provenientes da oxidação do material durante o ensaio, que foi realizado sob fluxo de $\mathrm{ar}^{90}$.

O evento na faixa de $445{ }^{\circ} \mathrm{C}$ a $480{ }^{\circ} \mathrm{C}$ pode estar relacionado a uma possível contaminação dos corpos-de-prova por material poliolefínico, já que 
foram obtidos por injeção em um equipamento utilizado em rotina industrial de processamento de polipropileno (PP); a faixa de degradação observada ocorre justamente na mesma faixa da degradação do $P P^{91,92}$.

O PEAD após a $4^{\text {a }}$ reciclagem (FIG. 25b) apresenta os mesmos eventos do PEAD virgem, porém o evento principal apresenta alteração na degradação e que é apresentada pela curva da calorimetria diferencial, que mostra que o pico principal está alargado com tendência à ocorrência de outro evento menor, mas que está integrado ao evento principal. Além disso, o evento principal nesta amostra já ocorre em mais de $90 \%$ da amostra.

Segundo a literatura consultada $^{93}$, esse comportamento de degradabilidade térmica é apresentada pelo polietileno de alta densidade após reprocessamento, indicando a possível quebra de ligações cruzadas, de uma possível reticulação fomentada pelo reprocessamento e/ou a efeitos de degradação da matriz polimérica do material nessas condições. Nesta amostra ainda, há a presença da provável contaminação por PP ou poliolefina, porém aqui já se mostra menor (cerca de $2 \%$, ver TAB. 5), sugerindo que o reprocessamento pode ter degradado o contaminante.

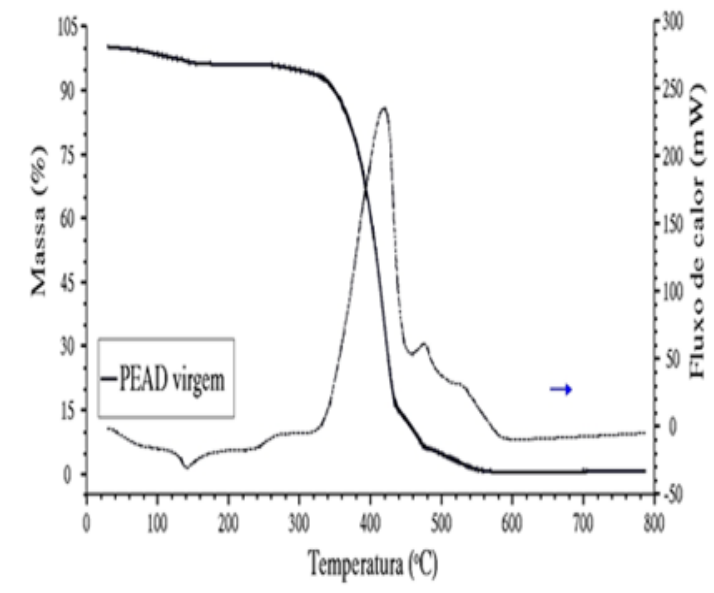

(a)

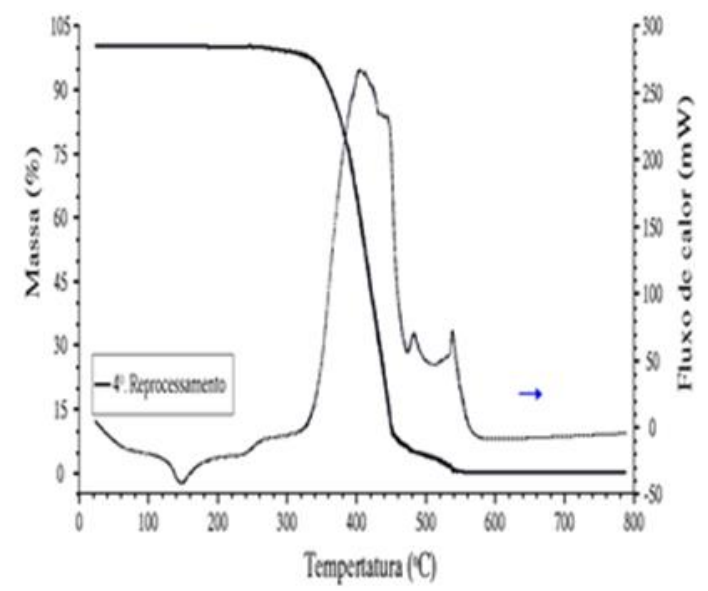

(b)

FIGURA 25 - Curva termogravimétrica das amostras (a) PEAD puro e (b) PEAD $4^{\circ}$ reprocessamento

O EPDM puro (FIG. 26a) mostra um comportamento característico de degradabilidade térmica: um único evento que ocorre na faixa de temperatura de $422{ }^{\circ} \mathrm{C}$ a $500 \stackrel{\circ}{\circ}$, cuja temperatura média do pico é de $479{ }^{\circ} \mathrm{C}$. 
Esse comportamento está de acordo com a literatura consultada, porém segundo os resultados de Özdemir ${ }^{58}$, a temperatura do pico da degradação está em $459 \stackrel{\circ}{\circ} \mathrm{C}$; no trabalho do autor o ensaio foi realizado sob fluxo de nitrogênio e nada foi mencionado sobre o pré-tratamento da amostra previamente à análise.

Neste trabalho a amostra foi previamente tratatada para a remoção de contaminantes e a análise foi realizada sob fluxo de ar comprimido. A termooxidação sofrida nestas condições pode ter sido a causa do aumento do valor da temperatura do pico de termodegradação deste elastômero. Apesar desta discrepância quantitativa, considerou-se que o produto utilizado tem a qualidade esperada.

O comportamento da termodegradação e o perfil do termograma do PEAD $4^{\circ}$ reciclagem $/ 1 \%$ EPDM puro (FIG. 26b) apresentou semelhanças ao da amostra PEAD virgem. Esse resultado mostra que a presença do EPDM promoveu alteração na composição do PEAD 4ํㅜ reciclagem, sugerindo integração entre as cadeias do elastômero à matriz polimérica, além de sobrepujar o efeito de cadeias cindidas do termoplástico reprocessado.

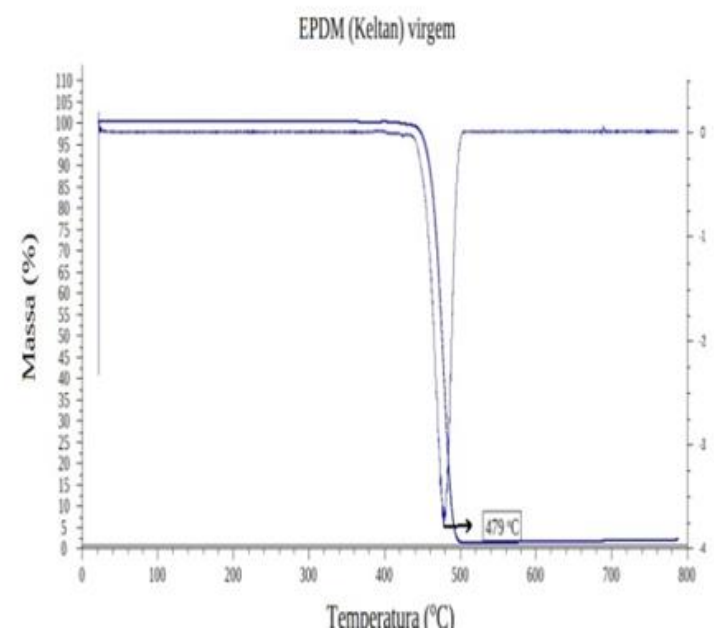

(a)



(b)

FIGURA 26 - Curva termogravimétrica da amostra EPDM puro (a) e PEAD $4^{\circ}$ rep./ $1 \%$ EPDM puro (b). 
TABELA 5 - Parâmetros obtidos das curvas termogravimétricas das amostras de PEAD e suas blendas com a borracha EPDM puro

\begin{tabular}{|c|c|c|c|c|c|c|c|c|}
\hline \multirow{4}{*}{$\begin{array}{l}\text { Amostra } \\
\text { PEAD virgem }\end{array}$} & \multicolumn{5}{|c|}{$\begin{array}{l}\text { Temperatura do pico }\left({ }^{\circ} \mathrm{C}\right) \\
\text { Calorimetria diferencial }\end{array}$} & \multicolumn{3}{|c|}{$\begin{array}{l}\text { Percentagem de } \\
\text { degradação (\%) }\end{array}$} \\
\hline & \multirow{3}{*}{\begin{tabular}{|c|} 
Endotérmico \\
$143(5,0)$
\end{tabular}} & \multicolumn{4}{|c|}{ Exotérmico } & \multirow{3}{*}{\begin{tabular}{|c|}
$\begin{array}{c}\text { Evento } \\
\text { Principal }\end{array}$ \\
\\
$84(13)$
\end{tabular}} & \multicolumn{2}{|c|}{$\begin{array}{c}\text { Eventos } \\
\text { secundários }\end{array}$} \\
\hline & & \multirow{2}{*}{$\begin{array}{c}E P^{\dagger} \\
422 \\
(4,5)^{\ddagger}\end{array}$} & \multicolumn{3}{|c|}{ Eventos secundários } & & & \\
\hline & & & - & $\begin{array}{c}471 \\
(13,0)\end{array}$ & $\begin{array}{l}531 \\
(5,1)\end{array}$ & & $\begin{array}{c}8,2 \\
(1,2)\end{array}$ & $\begin{array}{c}5,0 \\
(1,3)\end{array}$ \\
\hline PEAD $4^{\circ} . R$ & $146(2,0)$ & $\begin{array}{c}420 \\
(14,2)\end{array}$ & - & $\begin{array}{l}449 \\
(7,8)\end{array}$ & $\begin{array}{l}537 \\
(3,1)\end{array}$ & $93(3,0)$ & $\begin{array}{l}1,3 \\
(1,5)\end{array}$ & $\begin{array}{c}5,7 \\
(2,9)\end{array}$ \\
\hline $\begin{array}{l}\text { PEAD } 4^{\circ} . R \\
/ 1 \% \text { EPDM }\end{array}$ & $141(1,8)$ & $\begin{array}{l}430 \\
(7,0)\end{array}$ & - & $\begin{array}{c}475 \\
(6,5)\end{array}$ & $\begin{array}{l}538 \\
(3,4)\end{array}$ & $90(2,2)$ & $\begin{array}{c}4,9 \\
(2,1)\end{array}$ & $\begin{array}{c}4,8 \\
(0,2) \\
\end{array}$ \\
\hline $\begin{array}{l}\text { PEAD 4\%.R } \\
15 \% \text { EPDM }\end{array}$ & $143(2,0)$ & $\begin{array}{l}421 \\
(5,6)\end{array}$ & - & $\begin{array}{c}476 \\
(22,0)\end{array}$ & $\begin{array}{l}539 \\
(8,5)\end{array}$ & $94(1,2)$ & $\begin{array}{l}2,6 \\
(0,5)\end{array}$ & $\begin{array}{c}4,5 \\
(0,8)\end{array}$ \\
\hline $\begin{array}{l}\text { PEAD 4‥R } \\
/ 10 \% \text { EPDM }\end{array}$ & $144(2,6)$ & $\begin{array}{c}428 \\
(3,1)\end{array}$ & - & - & $\begin{array}{l}542 \\
(2,9)\end{array}$ & $94(1,1)$ & - & $\begin{array}{c}6,2 \\
(1,1)\end{array}$ \\
\hline $\begin{array}{l}\text { PEAD 4 }{ }^{\circ} . \mathrm{R} \\
/ 1 \% \text { EPDM - } \\
50 \mathrm{kGy}\end{array}$ & $143(1,3)$ & $\begin{array}{l}441 \\
(3,5)\end{array}$ & $\begin{array}{l}397 \\
(7)\end{array}$ & - & $\begin{array}{l}546 \\
(2,0)\end{array}$ & $95(1,2)$ & - & $\begin{array}{c}4,8 \\
(1,5)\end{array}$ \\
\hline $\begin{array}{l}\text { PEAD 4. } . R \\
15 \% \text { EPDM - } \\
50 \mathrm{kGy}\end{array}$ & $141(0,6)$ & $\begin{array}{c}434 \\
(1,7)\end{array}$ & $\begin{array}{l}384 \\
(6,4)\end{array}$ & - & $\begin{array}{l}547 \\
(1,0)\end{array}$ & $96(0,8)$ & - & $\begin{array}{c}4,1 \\
(0,8)\end{array}$ \\
\hline $\begin{array}{l}\text { PEAD 4. } . R \\
/ 10 \% \text { EPDM } \\
-50 \mathrm{kGy}\end{array}$ & $143(1,0)$ & $\begin{array}{c}437 \\
(1,5)\end{array}$ & $\begin{array}{l}384 \\
(0,7)\end{array}$ & - & $\begin{array}{l}550 \\
(2,9)\end{array}$ & $97(0,7)$ & - & $\begin{array}{c}2,6 \\
(0,7)\end{array}$ \\
\hline $\begin{array}{l}\text { PEAD 4 }{ }^{\circ} . \mathrm{R} \\
/ 1 \% \text { EPDM - } \\
100 \mathrm{kGy}\end{array}$ & $141(1,0)$ & $\begin{array}{l}451 \\
(3,1)\end{array}$ & $\begin{array}{l}389 \\
(9,9)\end{array}$ & - & $\begin{array}{l}547 \\
(8,5)\end{array}$ & $87(11)$ & - & $\begin{array}{c}5,7 \\
(1,3)\end{array}$ \\
\hline $\begin{array}{l}\text { PEAD } 4{ }^{\circ} . \mathrm{R} \\
/ 5 \% \text { EPDM - } \\
100 \mathrm{kGy}\end{array}$ & $139(2,3)$ & $\begin{array}{l}454 \\
(3,8)\end{array}$ & $\begin{array}{c}414 \\
(10,5)\end{array}$ & - & $\begin{array}{l}537 \\
(6,0)\end{array}$ & $93(0,7)$ & - & $\begin{array}{c}6 \\
(1,4)\end{array}$ \\
\hline $\begin{array}{l}\text { PEAD 4. } . R \\
/ 10 \% \text { EPDM } \\
-100 \mathrm{kGy} \\
\end{array}$ & $142(2,1)$ & $\begin{array}{l}451 \\
(6,1)\end{array}$ & $\begin{array}{l}391 \\
(7,8)\end{array}$ & - & $\begin{array}{l}542 \\
(4,5)\end{array}$ & $94(2,0)$ & - & $\begin{array}{c}5,1 \\
(1,3)\end{array}$ \\
\hline
\end{tabular}


A TAB. 5 apresenta os parâmetros provenientes das curvas de degradação térmica e calorimetria diferencial das amostras estudadas. A temperatura do primeiro evento (endotérmico) ocorreu entre os valores médios de $139{ }^{\circ} \mathrm{C}$ a $146{ }^{\circ} \mathrm{C}$ em todas as amostras e é aquele que aconteceu com até $3-5 \%$ de perda de massa, esse evento correspondeu à degradação de substâncias mais leves (voláteis).

Ainda na TAB. 5 e FIG. 27, a temperatura do evento principal nas amostras em que foram adicionados $5 \%$ e $10 \%$ do elastômero está dentro da faixa de erro da temperatura desse parâmetro para o termoplástico reciclado, sugerindo que a adição do elastômero não alterou 0 produto, indicando compatibilidade entre os mesmos. Como no PEAD 4 vezes reciclado, o evento principal nas amostras contendo EPDM ocorreu em mais de $90 \%$ da amostra. Além disso, nesse tipo de amostra a possível contaminação com PP foi ainda verificada, porém a adição do elastômero à matriz do termoplástico tem sua contribuição, visto pelo pico na temperatura média de $475 \stackrel{\circ}{\mathrm{C}}$ nas amostras contendo EPDM e também pelo correspondente teor de degradação nesta fase na amostra (2-7 \%).

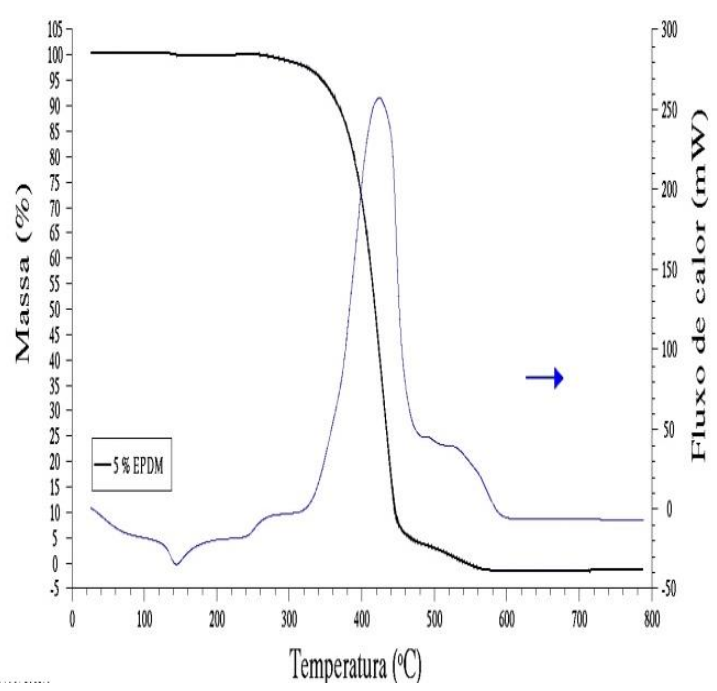

(a)

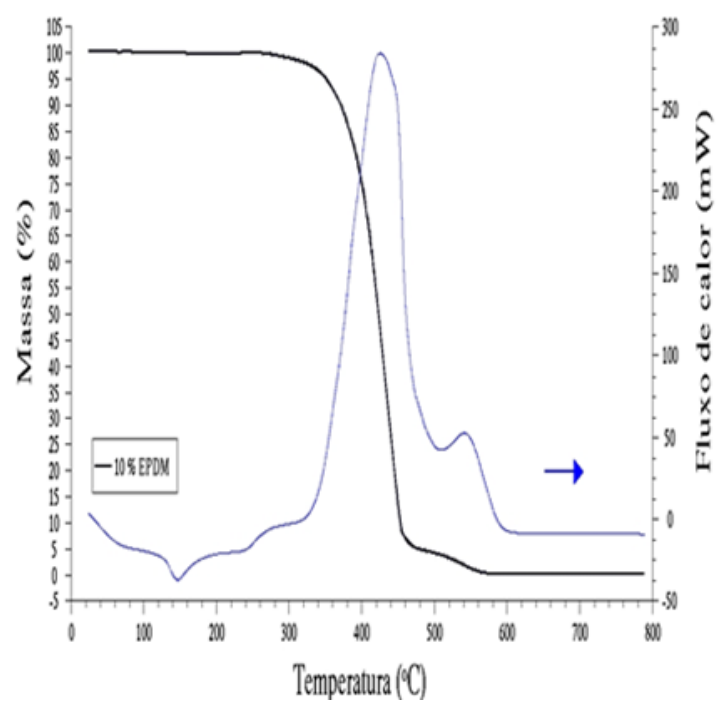

(b)

FIGURA 27 - Curvas termogravimétricas das amostras PEAD $4^{\circ}$ Rep./ $5 \%$ de EPDM puro (a) e (b) com $10 \%$ de EPDM puro 
Segundo a TAB. 5 e as curvas termogravimétricas da FIG. 28, as amostras de PEAD $4^{\circ}$ reciclagem com EPDM e irradiadas em 50 kGy apresentaram tendência na elevação do valor da temperatura do pico do evento principal, além de um ombro em temperatura menor (média de $384^{\circ} \mathrm{C}$ ) no perfil da calorimetria diferencial. Segundo a literatura ${ }^{94}$, o aumento do valor da temperatura na etapa principal de degradação indica uma possível reticulação do material. É possível que a quebra de ligações cruzadas ocorra em temperatura mais baixa, o que pode justificar o ombro nitidamente observado na calorimetria diferencial, mas nenhum indicativo desse evento foi encontrado na literatura. A temperatura mais alta no evento principal em relação às amostras não irradiadas, eleva também a temperatura do último evento secundário relacionado à degradação do material oxidado durante a degradação térmica sob fluxo de ar.

Em termos quantitativos, o evento principal apresentou tendência ao aumento do valor de temperatura e o último evento apresentou tendência à sua diminuição em relação às mesmas amostras não irradiadas, estes resultados podem estar relacionados ao aumento da reticulação das amostras.

O aumento da dose de radiação para 100 kGy também mostrou tendência no aumento da temperatura média do evento principal, porém a temperatura do último evento secundário e a avaliação quantitativa deles a partir do termograma mostram tendência a ter valores semelhantes às mesmas amostras não irradiadas. Com esses resultados, pode-se inferir que apesar do aumento da dose de radiação promover maior reticulação das amostras, como observado quantitativamente pelos resultados de fração gel (item 5.2), o efeito de degradação não pode ser negligenciado, principalmente no sentido de aumentar a quantidade de material degradado no último evento secundário. 
(a)
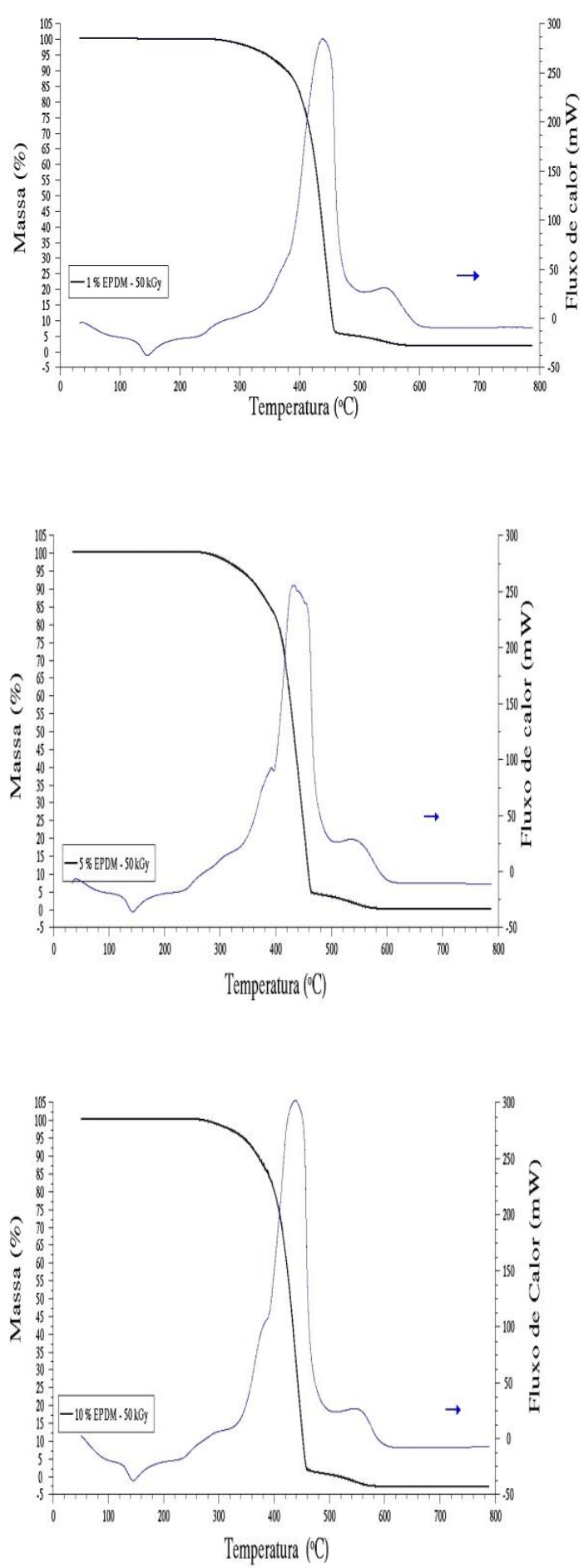

(b)
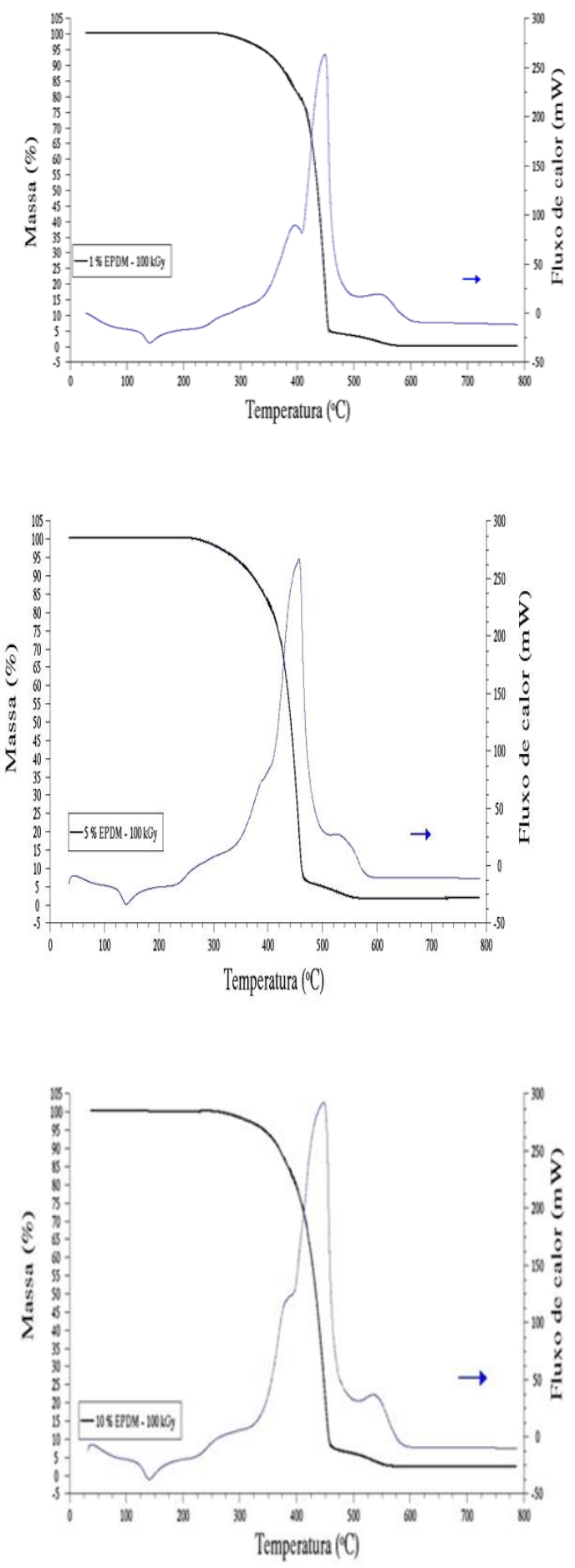

FIGURA 28 - Curvas termogravimétricas das amostras de PEAD $4^{\circ} \mathrm{rep} . / 1 \% 5 \% \mathrm{e}$ $10 \%$ de EPDM puro irradiados com 50kGy coluna (a) e 100 kGy coluna( b) 


\subsection{Calorimetria exploratória diferencial (DSC)}

O comportamento térmico do PEAD virgem e após a $4^{a}$ Reciclagem quanto à calorimetria exploratória diferencial está mostrado na FiG. 29 e os valores dos parâmetros extraídos destas curvas estão apresentadas na TAB. 6 .

O PEAD virgem mostrou um único pico em evento endotérmico, em cujo máximo foi extraída a temperatura de fusão $\left(131,7^{\circ} \mathrm{C}\right)$ e também um único pico em evento exotérmico, onde foi extraída a temperatura de cristalização $\left(115,1^{\circ} \mathrm{C}\right)$. O reprocessamento não conduziu a alterações significativas nesses resultados. O pequeno aumento do valor médio do grau de cristalinidade da amostra reciclada comparada à amostra virgem está dentro da faixa de erro da medida, sugerindo que nesse nível de reprocessamento não houve alteração na região cristalina de ambos tipos de materiais, embora segundo Strömberg; Karlsoon ${ }^{79}$, o rearranjo de cadeias durante o reprocessamento permite um aumento gradual na cristalinidade. Observou também que o pico relativo ao evento de fusão do PEAD reprocessado apresenta-se com tendência a formar dublete no evento endotérmico; esse comportamento bimodal também foi verificado por Camacho; Karlsoon ${ }^{93}$, os quais sugerem ser indicativo de degradabilidade das cadeias, o que conduziu à diminuição da massa molar do material reprocessado.

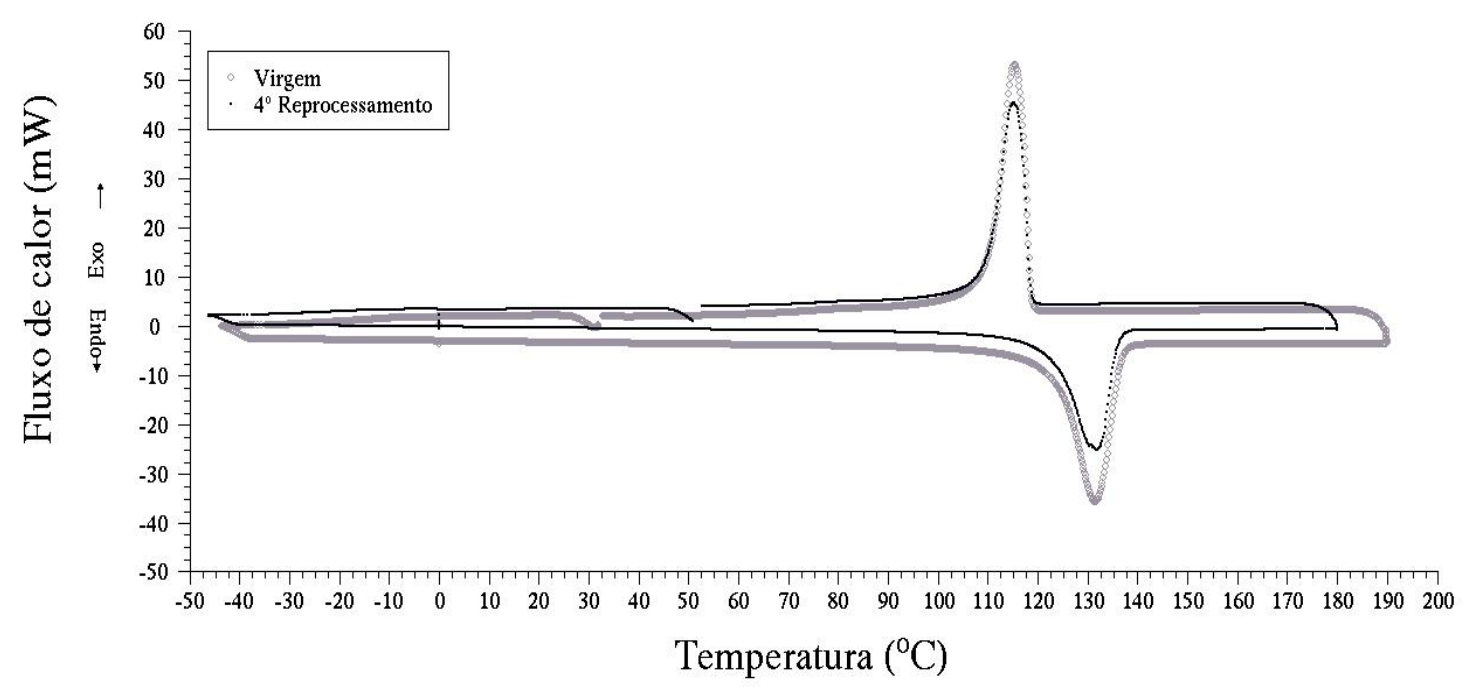

FIGURA 29 - Curvas de DSC do PEAD virgem e $4^{\circ}$ reprocessamento 
Na curva de DSC do EPDM puro (FIG. 30), a temperatura de transição vítrea foi verificada em cerca de $-46 \stackrel{\circ}{\circ} \mathrm{C}$, não havendo outro evento a ser reportado dentro da faixa de temperatura analisada ( $-55{ }^{\circ} \mathrm{C}$ a $160 \stackrel{\circ}{\circ}$ ), indicando que o elastômero é amorfo. Esses resultados concordam com a literatura consultada $^{95,96}$. Além disso, há uma alteração no comportamento endotérmico em $45{ }^{\circ} \mathrm{C}$ e no exotérmico (presença de um máximo) em $20{ }^{\circ} \mathrm{C}$. Segundo a literatura ${ }^{97}$, esses dois pequenos eventos estão relacionados com a presença do etileno em concentração acima de $60 \%$. No entanto, não há outras evidências sobre esse assunto na literatura, devendo-se fazer um exame mais detalhado. A hipótese da presença de contaminantes também não pode ser descartada, já que as amostras submetidas a esse tipo de caracterização térmica não passaram por pré-tratamento como aquelas submetidas à termogravimetria (item 5.3).

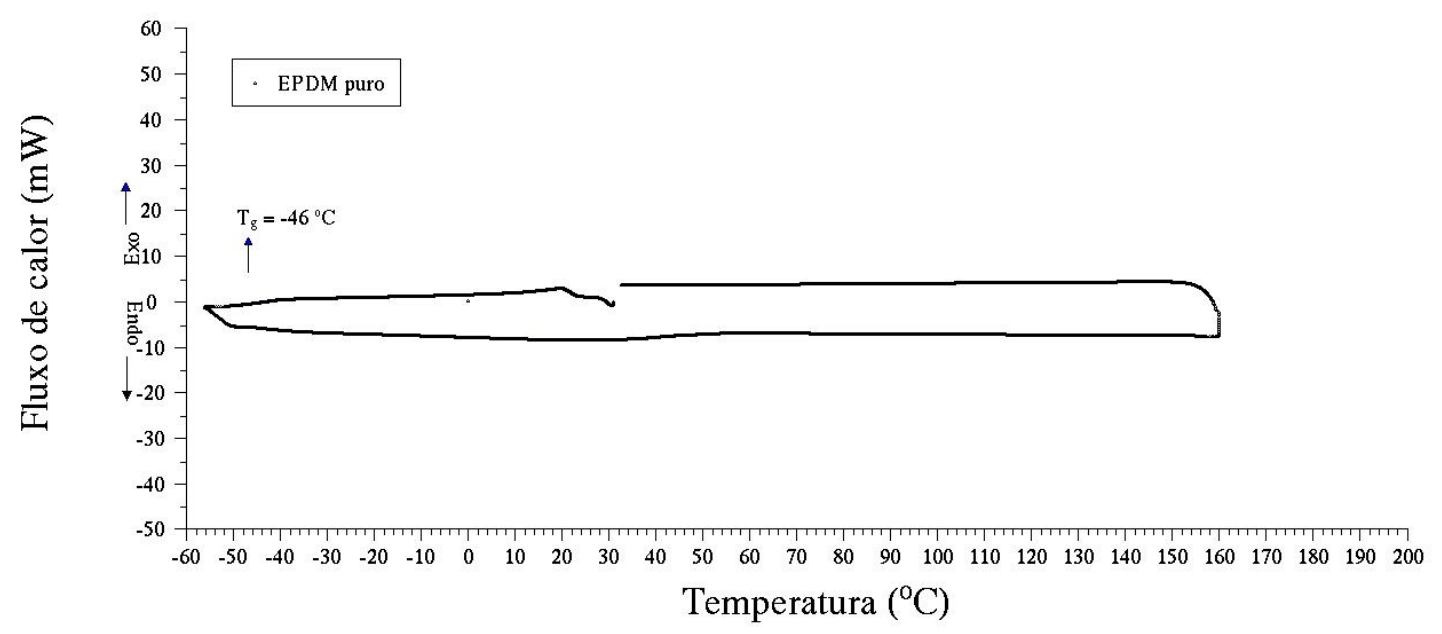

FIGURA 30 - Curva de DSC do EPDM puro

Analisando os termogramas das blendas formadas entre 0 termoplástico reciclado e o elastômero (FIG 31), observou semelhança qualitativa em relação ao termograma do PEAD reciclado, apresentando somente um evento de cristalização e um evento de fusão; as temperaturas do pico de fusão foram semelhantes ao do PEAD reciclado e as temperaturas de cristalização acompanharam essa tendência (TAB. 6), indicando miscibilidade e compatibilidade entre os dois componentes em cada tipo de blenda. Quanto ao grau de cristalinidade, as blendas mostraram tendência de diminuição do grau de 
cristalinidade em relação ao termoplástico reciclado, com exceção à blenda contendo $10 \%$ de EPDM que apresentou um valor médio não esperado e com desvio padrão muito alto, sugerindo a ocorrência de algum erro de ordem técnica. A tendência de decréscimo da cristalinidade da matriz termoplástica com o aumento da quantidade de elastômero (amorfo) também foi um comportamento esperado de acordo com a literatura consultada ${ }^{95,96}$.

Blendas PEAD/EPDM não irradiadas

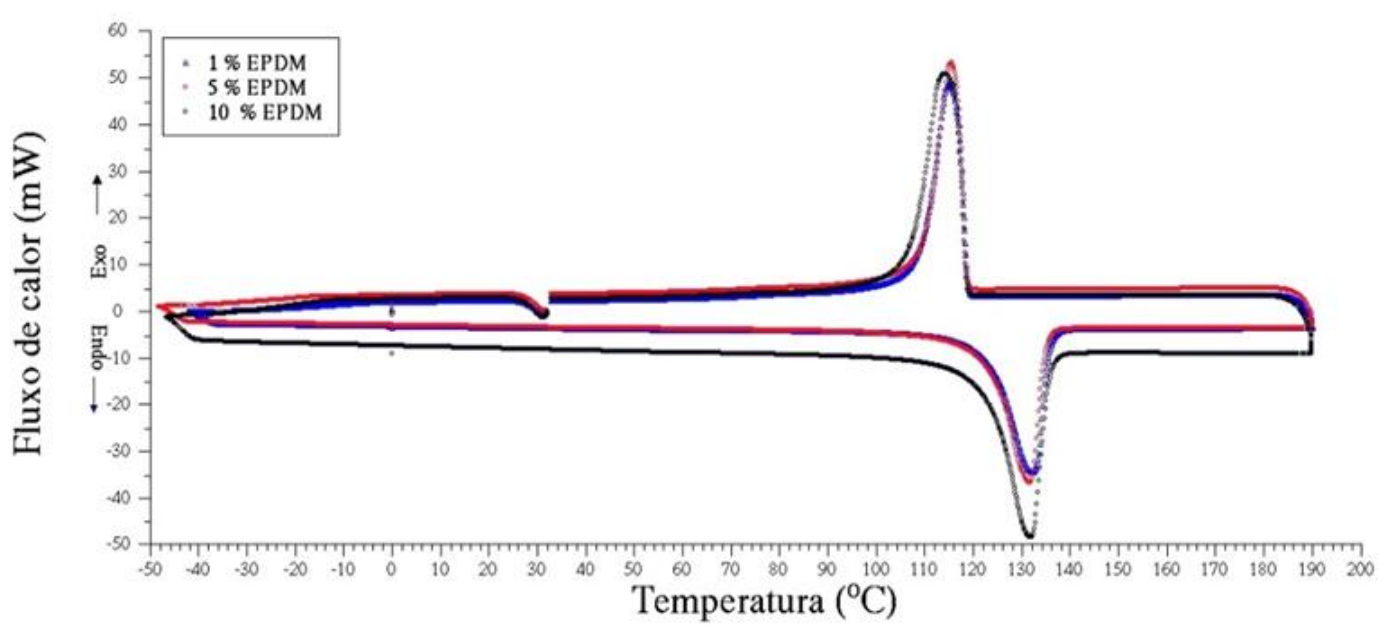

FIGURA 31 - Curvas de DSC das blendas não irradiadas de PEAD 4ํep. com EPDM nas concentrações de $1 \%, 5 \%$ e $10 \%$

As blendas irradiadas na dose de 50 kGy (FIG. 32a), apresentaram temperaturas do pico de fusão com valores médios menores que os dos seus correspondentes não irradiados, sugerindo a ocorrência de um processo de degradação; a tendência de diminuição desse parâmetro em função do aumento do elastômero esta presente. Os valores médios da temperatura do pico de cristalização acompanharam esse comportamento. Os valores médios do grau de cristalinidade são menores do que os dos seus correspondentes não irradiados e também apresentaram tendência de queda em função do aumento da concentração de EPDM indicando a tendência à degradabilidade da sua região cristalina no processo por irradiação. A diminuição do grau de cristalinidade está relacionada ao aumento do processo de reticulação na amostra ${ }^{98,99}$.

$\mathrm{O}$ aumento da dose de radiação conduz ao mesmo comportamento das amostras irradiadas na menor dose em relação às temperaturas dos picos de 
fusão e cristalização, porém os valores em módulo foram sempre menores, indicando a tendência do efeito de degradação que as amostras sofrerem após o processo de irradiação. Os valores do parâmetro grau de cristalização também acompanharam o mesmo comportamento observado nas amostras irradiadas sob a dose de 50 kGy.

Blenda PEAD/EPDM - Irradiação gama - 50 kGy

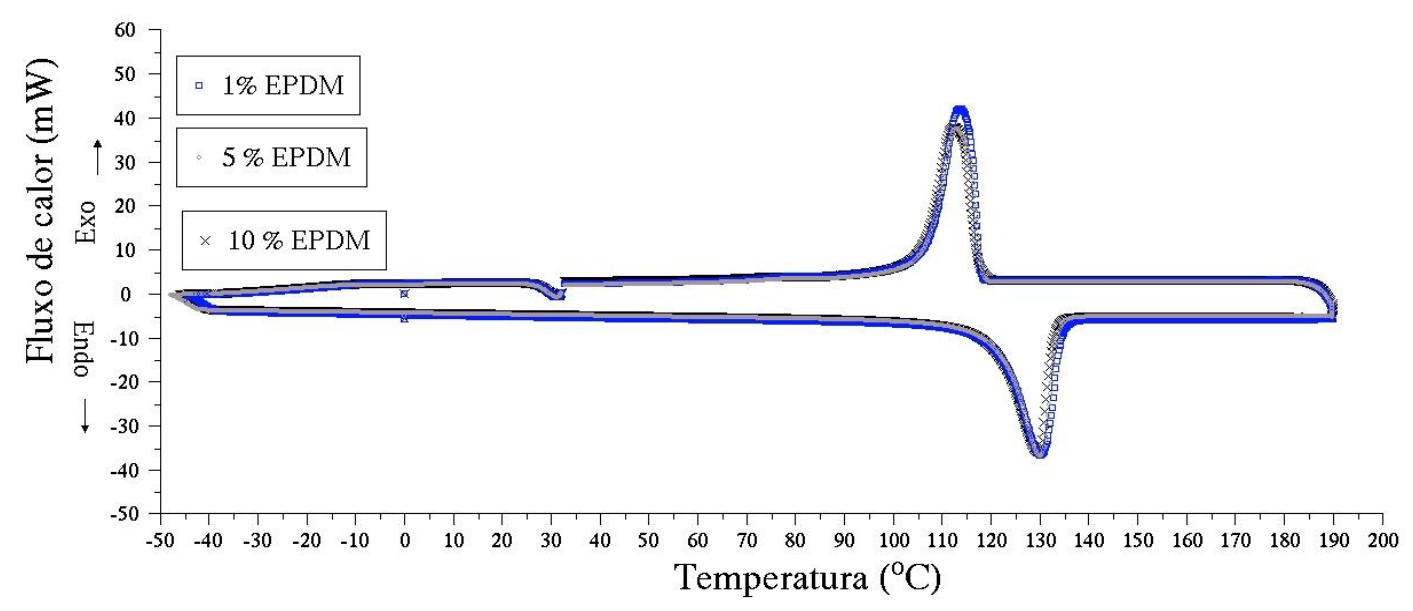

(a)

Blenda PEAD/EPDM - Irradiação gama - 100 kGy

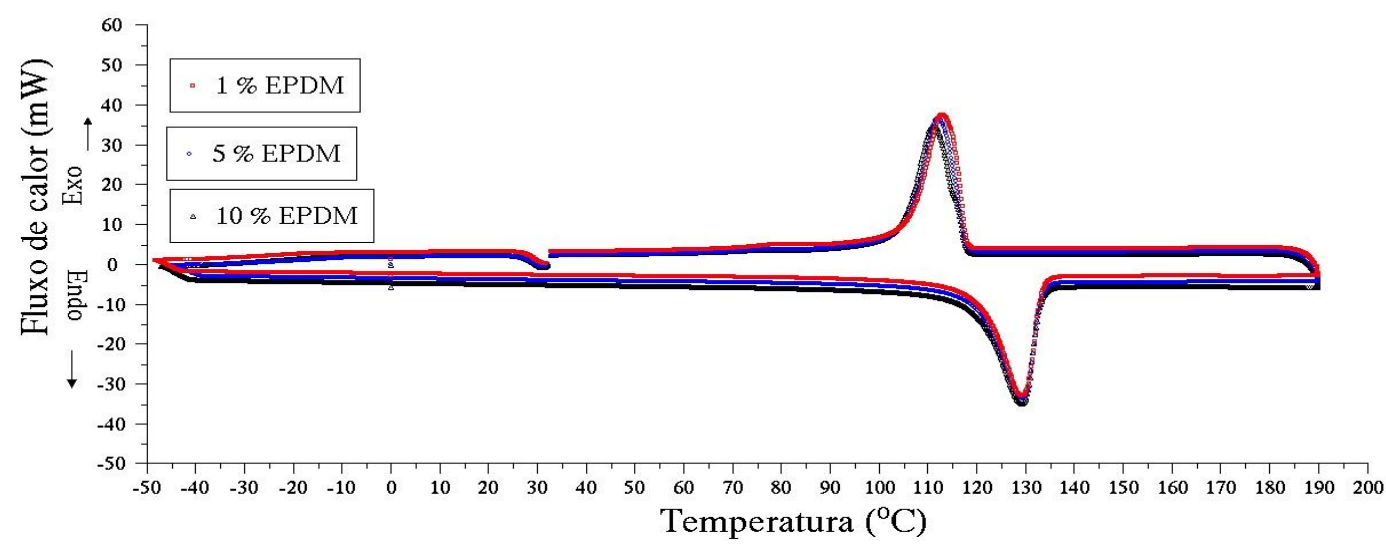

(b)

FIGURA 32 - Curvas de DSC das blendas irradiadas de PEAD 4 rep. com EPDM nas concentrações de $1 \%, 5 \%$ e $10 \%$ nas doses de: 50 kGy (a) e 100 kGy (b) 
TABELA 6 - Parâmetros de temperaturas de fusão e cristalização $\left(T_{f}\right)$ e $\left(T_{m}\right)$, entalpia de fusão $\left(\Delta H_{f}\right)$ e grau de cristalização $\left(X_{c}\right)$ obtidos pela técnica de DSC do EPDM puro, PEAD virgem e reciclado e suas blendas, irradiadas e não irradiadas

\begin{tabular}{|c|c|c|c|c|}
\hline & $T_{f}\left({ }^{\circ} \mathrm{C}\right)$ & $\Delta H_{f}(\mathrm{~J} / \mathrm{g})$ & $X_{c}(\%)$ & $T_{c}\left({ }^{\circ} \mathrm{C}\right)$ \\
\hline EPDM puro & - & - & - & - \\
\hline PEAD virgem & $131,7(0,4)^{\ddagger}$ & $168,4(9,0)$ & $58,1(3,0)$ & $115,1(0,0)$ \\
\hline PEAD 4ㄹ Reciclagem & $131,6(0,4)$ & $164,2(8,0)$ & $58,6(2,7)$ & $115,0(0,2)$ \\
\hline PEAD 4ㄹ Reciclagem/ 1\% EPDM & $132,1(0,1)$ & $165,7(5,7)$ & $57,1(1,9)$ & $114,8(0,3)$ \\
\hline PEAD 4a Reciclagem/ 5\% EPDM & $131,7(0,4)$ & $163,5(14,9)$ & $56,4(5,0)$ & $115,2(0,4)$ \\
\hline PEAD 4ª Reciclagem/ 10\% EPDM & $132,1(0,9)$ & $169,0(47,8)$ & $58,3(15,9)$ & $114,0(0,8)$ \\
\hline PEAD 4a Reciclagem/ 1\% EPDM- 50 kGy & $130,7(0,5)$ & $163,3(4,4)$ & $56,3(1,5)$ & $113,3(0,4)$ \\
\hline PEAD 4a Reciclagem/ 5\% EPDM- 50 kGy & $130,1(0,0)$ & $163,0(3,3)$ & $56,2(1,1)$ & $113,2(0,5)$ \\
\hline PEAD 4ª Reciclagem/ 10\% EPDM- 50 kGy & $129,7(0,4)$ & $153,8(10,7)$ & $53,0(3,6)$ & $112,2(0,3)$ \\
\hline PEAD 4ㄹ Reciclagem/ 1\% EPDM- 100 kGy & $130,3(0,8)$ & $171,9(8,4)$ & $59,3(2,8)$ & $113,4(0,4)$ \\
\hline PEAD 4ª Reciclagem/ 5\% EPDM- 100 kGy & $129,7(0,2)$ & $163,4(10,8)$ & $56,3(3,6)$ & $112,5(0,2)$ \\
\hline PEAD 4⿳亠丷 Reciclagem/ 10\% EPDM- 100 kGy & $129,4(0,3)$ & $159,3(3,2)$ & $54,9(1,1)$ & $111,5(0,1)$ \\
\hline
\end{tabular}

\subsection{Difração de raios $X$}

Nas FIG. (33 a-b) são mostrados os difratogramas das amostras de PEAD virgem e PEAD 4ำ reprocessamento indicando as principais reflexões das faces (110) e (200). 


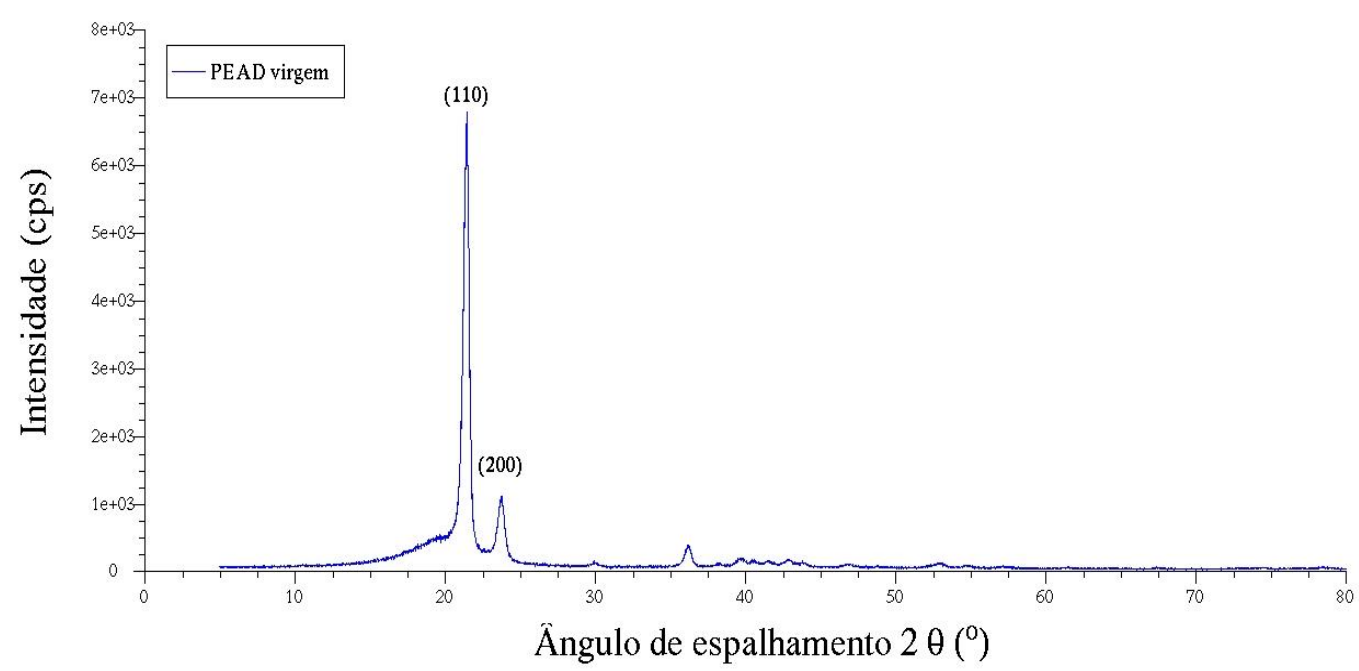

(a)

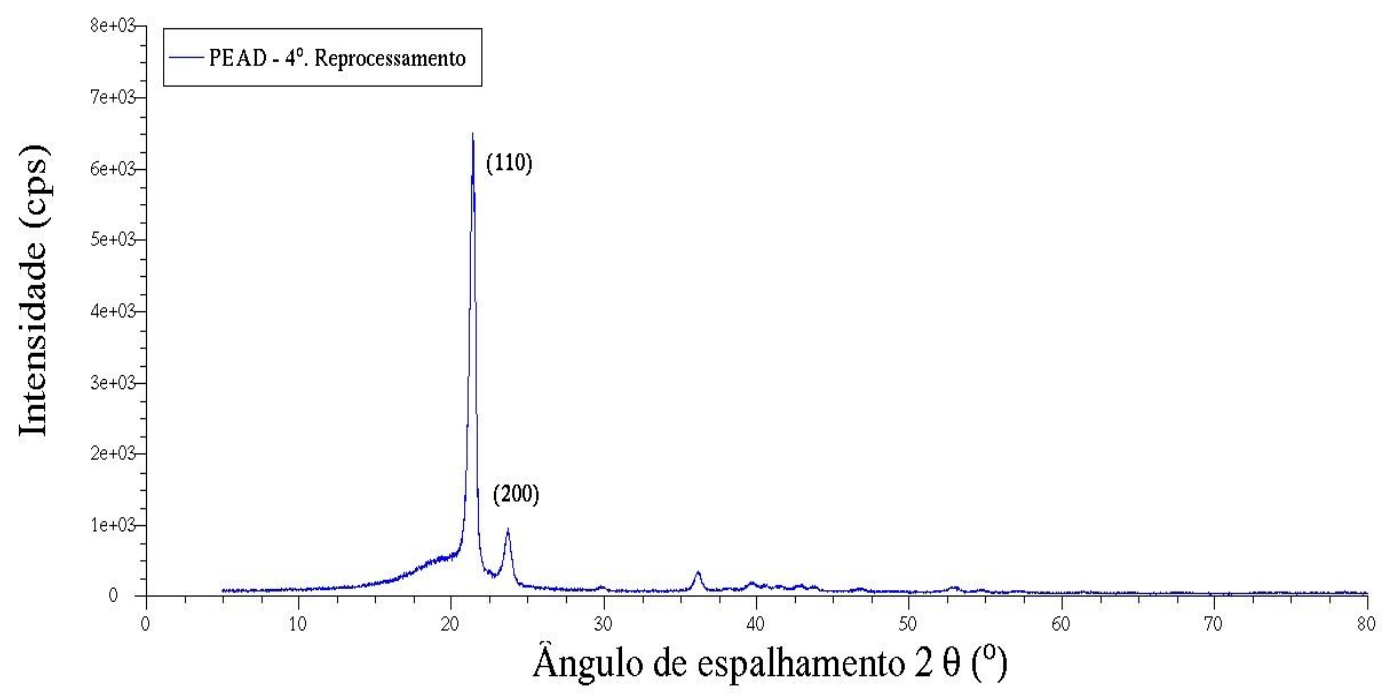

(b)

FIGURA 33- Difratogramas das amostras de PEAD virgem (a) e 4ํㅜ rep. (b)

O parâmetro grau de cristalinidade foi determinado também por difratometria de raios X (FIG. 34). Observa-se nesses resultados comportamento semelhante ao verificado por calorimetria exploratória diferencial (item 5.4). O PEAD virgem apresentou grau de cristalinidade alto $(72 \%)$ e quando esse termoplástico passa por 4 ciclos de reciclagem, esse parâmetro apresentou um valor próximo (74 \%), sugerindo que apesar do processo de reciclagem promover a degradação termomecânica, não houve mudanças relevantes na região cristalina do termoplástico. 
A formação de blendas entre o termoplástico reciclado e o EPDM puro mostrou que a inclusão do elastômero promoveu a diminuição do grau de cristalinidade na matriz polimérica, confirmando o que já foi discutido no item 5.4. Somente nesse caso a blenda com $1 \%$ de EPDM apresentou uma tendência no aumento do grau de cristalinidade, atingindo $79 \%$; como os resultados apresentados não foram realizados em triplicata, protocolo obedecido nos ensaios anteriores, não se pode afirmar que este seja um valor preciso.

O processo de irradiação promoveu o aumento do grau de cristalinidade das blendas em relação às concentrações correspondentes não irradiadas, indicando que a irradiação promoveu ordenação na região cristalina das blendas; a tendência de diminuição do grau de cristalinidade em função do aumento do teor de EPDM é um comportamento que não se alterou com o processo de irradiação. $\mathrm{O}$ aumento da dose de radiação absorvida promoveu o aumento dos valores desse parâmetro em comparação aos das amostras irradiadas na menor dose, indicando que o aumento da dose absorvida nesse limite, intensificou o processo de ordenação da região cristalina; no entanto, a blenda com o menor teor de EPDM apresentou um pequeno decréscimo no grau de cristalinidade em relação ao seu correspondente irradiado na menor dose, sugerindo que a partir de 100 kGy houve uma tendência de degradação, como visto no item 5.1 .

Embora se constatou a tendência de aumento do grau de cristalinidade nas amostras irradiadas, o desvio dos valores é de cerca de $13 \%$; um estudo estatístico deverá ser realizado futuramente para avaliar a significância desse desvio.

Apesar do grau de cristalinidade dos termoplásticos e de suas blendas com EPDM determinado por difratometria de raios $X$ apresentarem comportamento semelhante ao do determinado por calorimetria exploratória diferencial, os seus valores diferem. Isso pode estar relacionado ao fato de que por DSC a cristalização ocorreu em taxa constante e por difração de raios $\mathrm{X}$ o comportamento foi verificado sem que haja eventos induzidos por ciclos de resfriamento/aquecimento. 


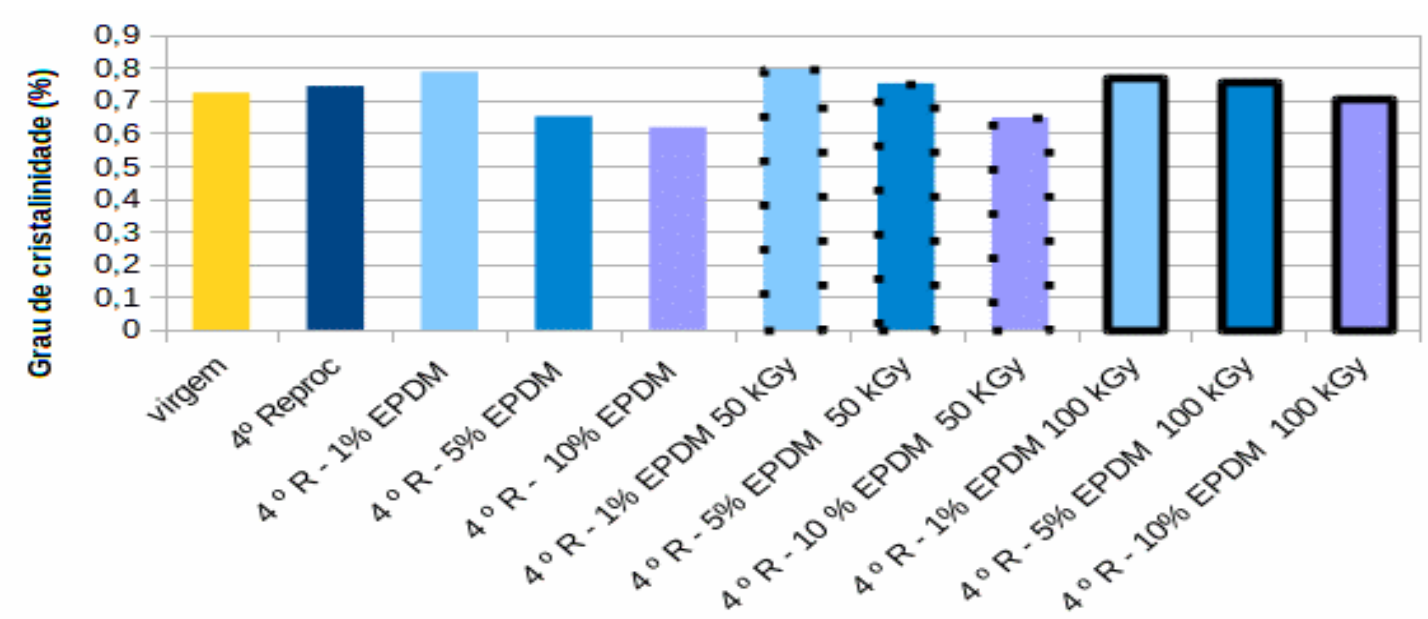

FIGURA 34 - Grau de cristalinidade por difração de raios X do PEAD virgem, $4^{\circ}$ rep. e suas blendas PEAD 4ำrep./EPDM puro, não irradiadas e irradiadas

Em relação ao tamanho do grão do cristalito (FIG. 35), o parâmetro medido para o PEAD virgem foi de $16,53 \mathrm{~nm}$; ao passar por quatro processos de reciclagem este termoplástico apresentou tamanho de cristalito menor $(14,08 \mathrm{~nm})$. Este foi um resultado esperado após o processo termomecânico nos distintos reprocessamentos (cisalhamento sob temperatura), que permitiu a desagregação e degradação dos grãos.

A adição de EPDM à matriz do termoplástico promoveu um aumento do tamanho do cristalito relativamente aos valores desse parâmetro no PEAD reciclado: $16,09 \mathrm{~nm}$ na blenda com $1 \%$ de EPDM, 18,76 nm na blenda contendo $5 \%$ de EPDM e 16,09 nm na blenda com $10 \%$ de EPDM. Esses resultados sugeriram que a mistura do elastômero à matriz do termoplástico teve sucesso e que a compatibilização foi alta, devido a uma possível co-cristalização entre as cadeias dos componentes em efeito crescente até $5 \%$ de elastômero. Segundo Stelescu e colaboradores ${ }^{45}$, o tamanho do cristalito tende a ser menor em blendas de PEAD com altas concentrações de EPDM.

A co-cristalização é um processo onde ambos componentes da mistura polimérica se cristalizam na mesma lamela cristalina e acontecem em polímeros que apresentam miscibilidade na massa fundida, repetição nas unidades químicas e semelhantes parâmetros de retículo de células unitárias cristalinas; apesar de 
ser um fenômeno raro, ocorre em situações em que o polímero apresenta semelhanças químicas ${ }^{100}$.

Segundo Gupta e colaboradores, o aumento do espaço interplanar conjugado com o aumento do tamanho do cristalito pode ser um indicativo do fenômeno de co-cristalização, já que os segmentos de cadeia molecular de um componente são diferentes do outro componente em termos de mobilidade, o que gera forças distintas na região do limite dos cristalitos e provoca o aumento do espaço interplanar ${ }^{101}$. O aumento do tamanho do cristalito conjugado ao aumento do espaço interplanar ocorreu nas blendas deste trabalho (FIG. 35 e 36). No entanto, um estudo mais específico deve ser realizado para verificar a existência desse fenômeno de co-cristalização.

O processo de irradiação, no entanto, induziu a desagregação dos cristalitos nas blendas: na dose menor esse efeito está presente na blenda com maior teor de elastômero, sugerindo que nas blendas com $1 \%$ e 5 \% de EPDM o tamanho dos cristalitos não foram afetados por essa magnitude de dose absorvida; na dose maior, a diminuição do tamanho do cristalito ocorreu na blenda com até $5 \%$ de EPDM, mas o processo parece não afetar esse parâmetro quando a blenda tem 10 \% de EPDM. Um resultado não esperado ocorre quando a blenda com 1 \% de EPDM com dose de $100 \mathrm{kGy}$ : o tamanho do cristalito aumenta em 14,4 \% em relação a blenda de mesma composição não irradiada.

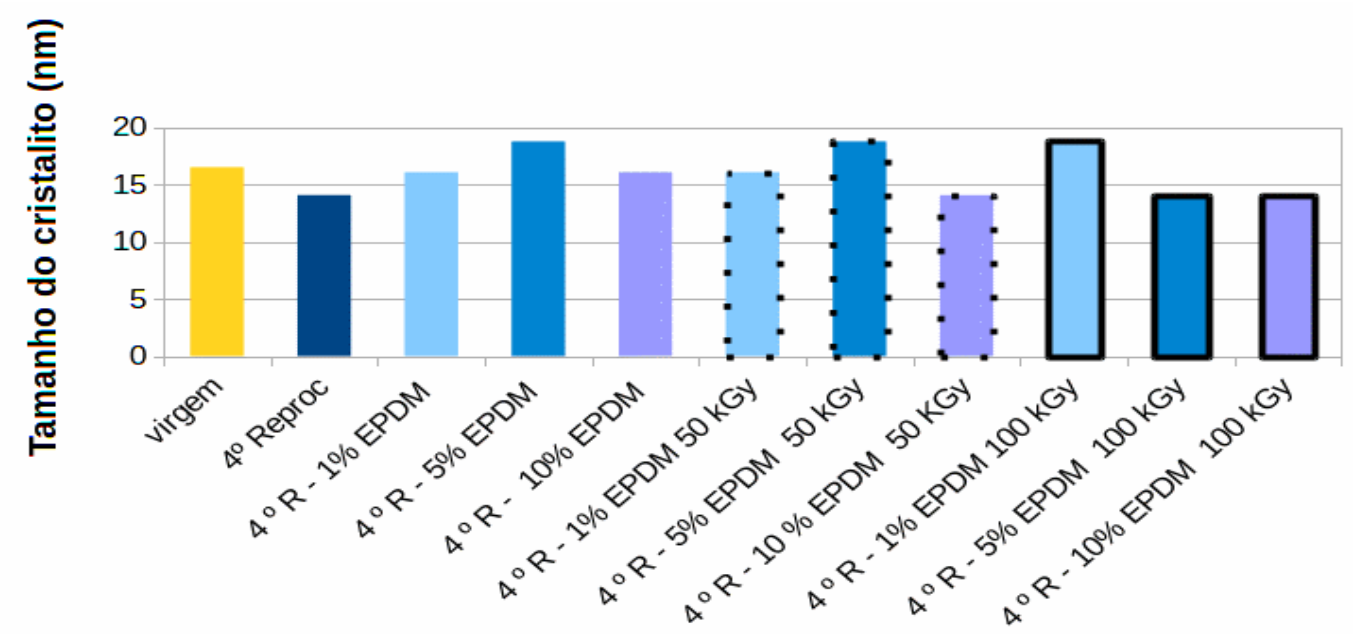

FIGURA 35 - Tamanho do cristalito no PEAD virgem, 4ํㅜ rep. e suas blendas PEAD 4ํㅏ. 
Na FIG. 36 a-b é mostrada o comportamento quanto à distância interplanar na geometria ortorrômbica dos cristalitos presentes nas amostras. O valor calculado para a distância interplanar na reflexão 110 (FIG. 36 a), no PEAD virgem foi de $0,4136 \mathrm{~nm}$, mas que ao ser submetido ao reprocessamento, esse valor tem tendência a aumentar $(0,4147 \mathrm{~nm})$; este é um comportamento esperado, já que com os sucessivos ciclos de termo-oxidação e cisalhamento, os cristalitos do material original sofrerem degradação e/ou desorganização, aumentando a área amorfa.

A mistura entre o termoplástico reciclado com o EPDM puro apresentou tendência de aumento no espaço interplanar dos cristalitos na face 110, principalmente quando o elastômero estava nas concentrações de 5 \% e 10 \%; a blenda com composição $1 \%$ teve um resultado diferente; nesse caso, houve a necessidade de replicata do ensaio como já foi mencionado anteriormente.

Com o processo de irradiação verificou-se a tendência à diminuição da distância interplanar (face 110), este resultado sugere que a irradiação promove o processo de reticulação na região cristalina. $O$ aumento do valor da dose absorvida não altera esse comportamento, com exceção à blenda com $1 \%$ de EPDM puro que tem um comportamento diferente: verifica-se aumento da distância interplanar sob a dose de 50 kGy em relação ao correspondente não irradiado e diminuição desse parâmetro quando a dose aumenta para 100 kGy.

A distância interplanar no plano de reflexão da face 200 (FIG. 36b) não tem valores alterados entre o PEAD virgem e o PEAD 4으 reprocessamento, valores semelhantes foram encontrados nas blendas com $1 \%$ e $10 \%$ de EPDM puro. Segundo Stelescu e colaboradores ${ }^{45}$, a mistura de PEAD com o elastômero pouco alterou a distância interplanar nos cristalitos. No entanto, na blenda com 5 \% do elastômero verificou a diminuição do valor desse parâmetro. O processo de irradiação pouco alterou esses resultados nas distintas doses aplicadas, sugerindo que esse processo não desagrega o arranjo cristalino original nesse plano de reflexão. 


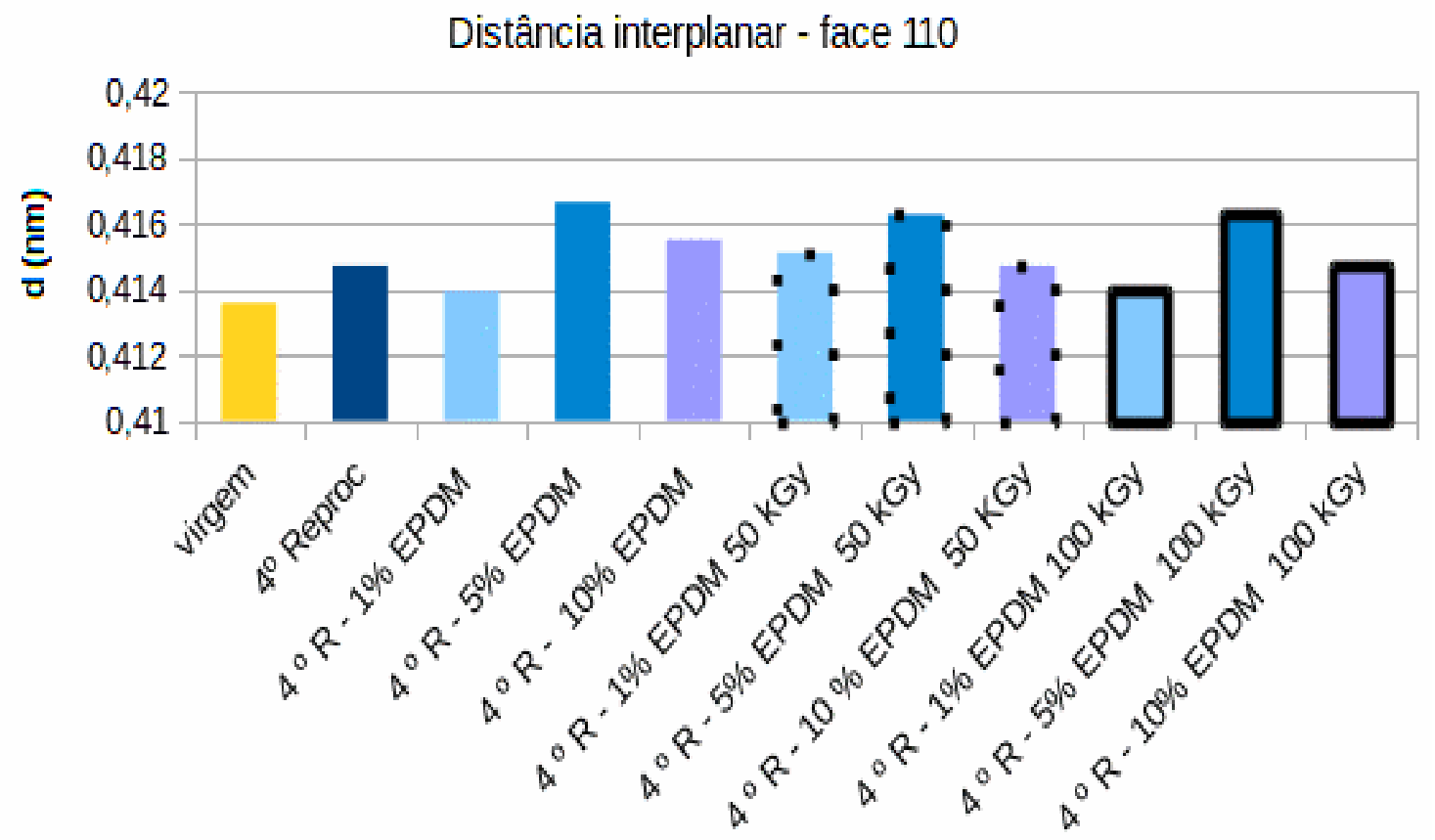

(a)

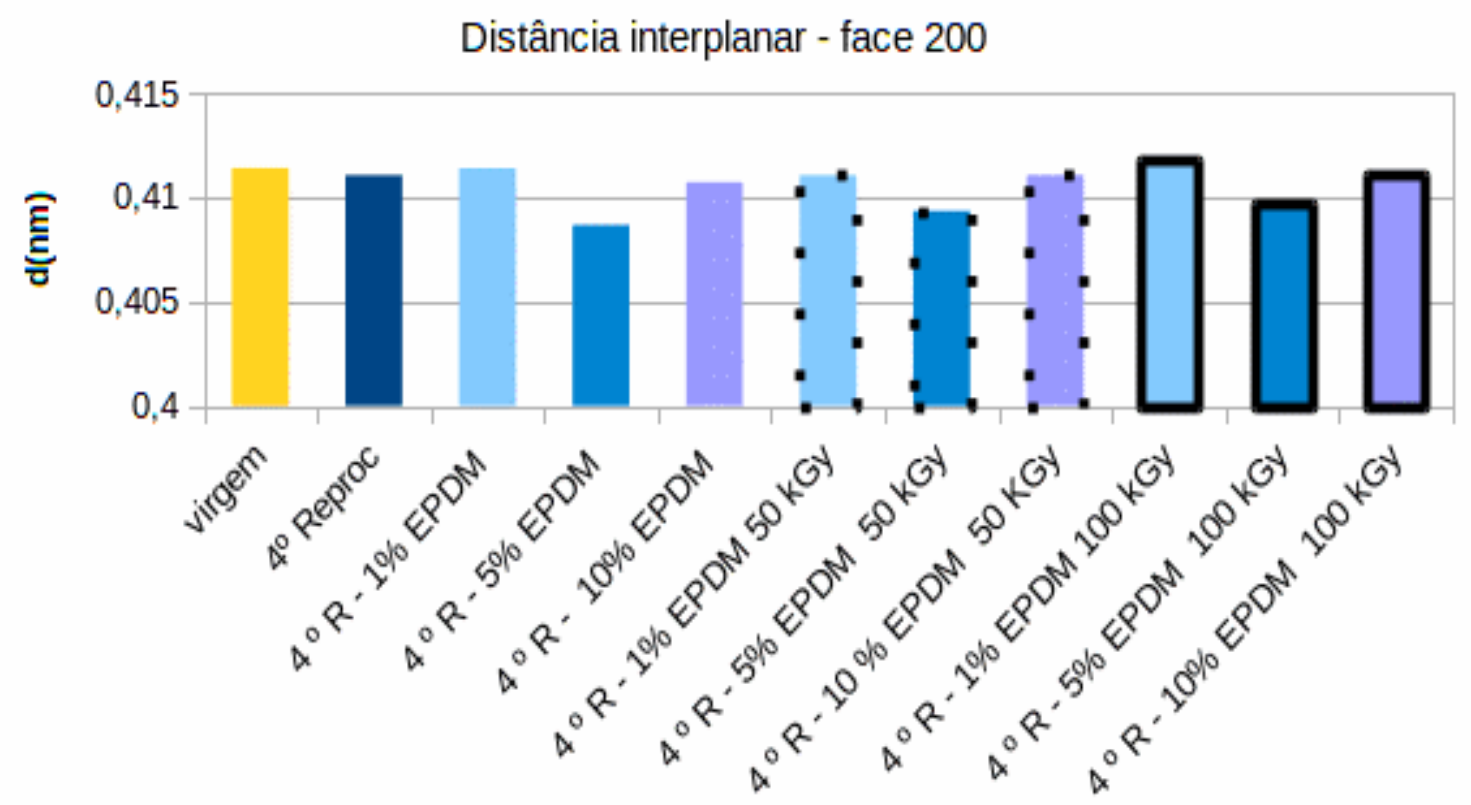

(b)

FIGURA 36 - Distância interplanar entre os cristalitos nas faces (a) 110 e (b) 200 no PEAD virgem, 4ํㅜ rep. e suas blendas PEAD 4ํrep./EPDM puro, não irradiadas e irradiadas. 


\subsection{Ensaios de tração}

$\mathrm{Na}$ caracterização mecânica por tração foram escolhidos três parâmetros que são importantes em blendas formadas por termoplásticos e elastômeros: a avaliação do módulo de elasticidade (módulo de Young ou módulo tênsil de elasticidade), a tensão no escoamento e a tensão em $100 \%$ de deformação.

Com esses parâmetros foi possível avaliar o comportamento do material em estudo em três fases da curva tensão em função da deformação: a deformação elástica (reversível), a deformação plástica (logo após a região elástica) e a deformação à frio (após o empescoçamento da amostra segundo a direção da tração aplicada), região onde houve desenovelamento das cadeias e o seu alinhamento com relação à aplicação da carga de tração.

O módulo de elasticidade das amostras do termoplástico virgem e reciclado e das blendas não irradiadas e irradiadas está mostrado na FIG. 37. O PEAD virgem apresentou valor médio de $1.198 \mathrm{MPa}$, que é um valor próximo ao da literatura $(1.030 \mathrm{MPa} \text { a } 1.090 \mathrm{MPa})^{102}$. No entanto, o PEAD 4ㅇ․ reprocessamento apresentou um valor superior (1.640 $\mathrm{MPa})$, indicando que o reprocessamento promoveu uma reticulção, tornando a amostra mais rígida que o termoplástico original. A mistura do termoplástico reciclado com o elastômero resultou em pequena redução do valor médio do módulo de elasticidade, embora estejam muito próximos ao valor médio do PEAD virgem, (1.060 MPa para a blenda com $1 \%$ de EPDM puro, 914 MPa para a blenda com 5 \% EPDM puro e 1.160 MPa para a blenda com 10 \% de EPDM puro). A diminuição do módulo de Young nas amostras com o elastômero é um comportamento esperado, já que a sua presença torna o material mais maleável.

O processo de irradiação nas doses de 50 kGy e 100 kGy provocou o aumento do valor médio desse parâmetro em função do aumento da concentração do EPDM na blenda. Com o aumento da dose, houve elevação no valor do módulo, sendo esse comportamento esperado, já que o processo de irradiação promove a formação de ligações cruzadas neste tipo de material, conduzindo a uma estrutura molecular tridimensional e consequentemente, aumentando a rigidez do material. No entanto, observou que a blenda com $10 \%$ de EPDM puro irradiada na maior dose apresentou um comportamento distinto, 
com os menores valores do parâmetro mecânico, sugerindo que nestas condições pode ter ocorrido a degradação desta blenda. Esse resultado deve ser detalhadamente investigado em trabalho futuro.

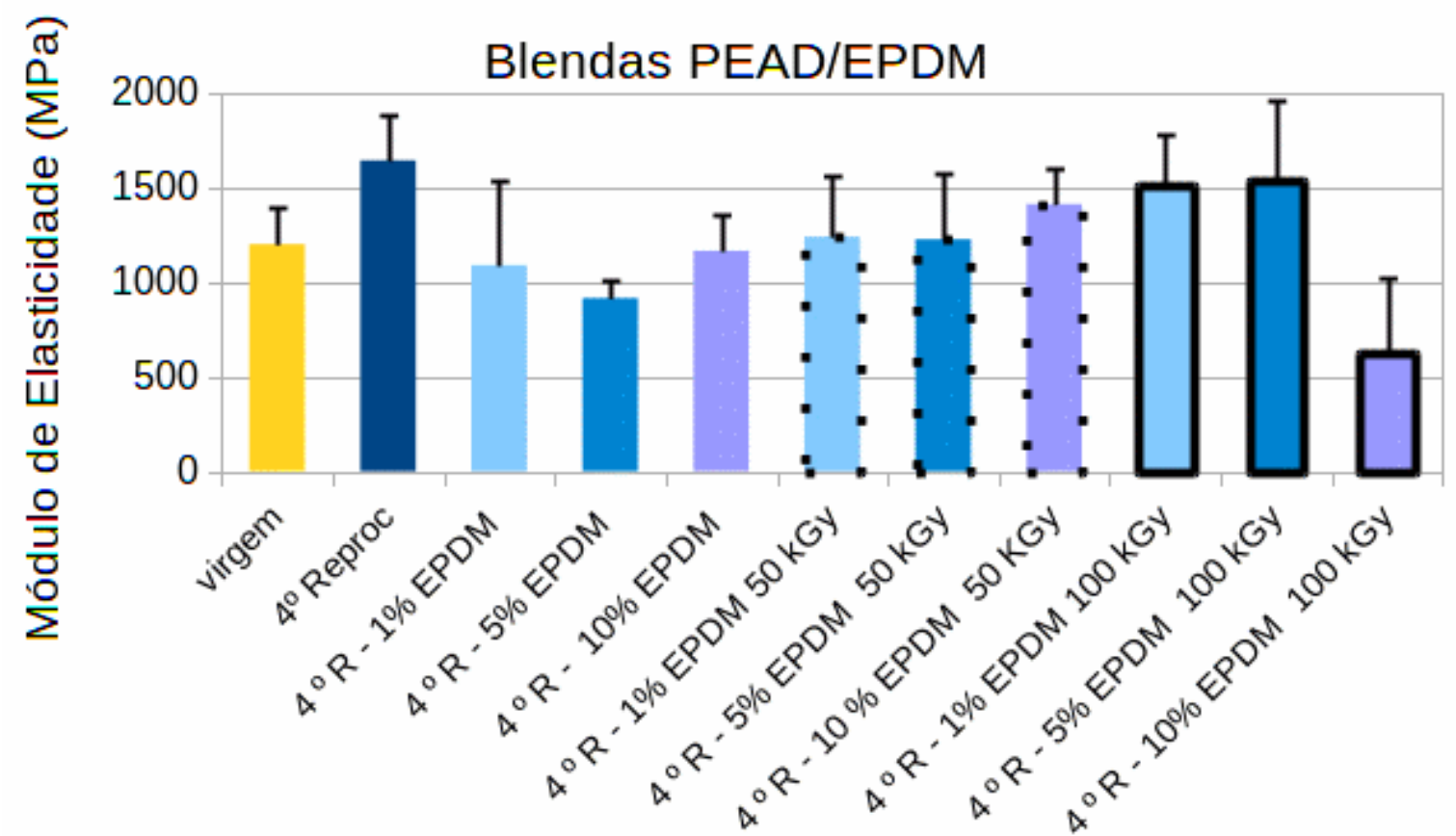

FIGURA 37 - Módulo de elasticidade do PEAD virgem, 4ำ rep. e das blendas de PEAD 4ํrep./EPDM puro, não irradiadas e irradiadas

Os resultados de tensão limite de escoamento (FIG. 38) mostraram que as amostras de PEAD virgem apresentaram valores médios de 22,8 Mpa e que é próximo ao valor de referência (TAB. 1). O PEAD após o 4ำ reprocessamento apresentou um pequeno decréscimo $(21,0 \mathrm{MPa})$, que é o comportamento esperado para um material que passou por quatro ciclos de cisalhamento e temperatura.

Nas blendas de PEAD 4ำ reprocessamento com EPDM puro não irradiadas observou-se decréscimo nos valores em função do aumento da concentração de EPDM na mistura - valores médios de 20,8 MPa (1 \% de EPDM) à 17,2 $\mathrm{MPa}$ (10\% de EPDM). Este também foi um comportamento esperado já que a presença da borracha tem a característica de influenciar na redução da tensão limite de escoamento. Segundo Silva e colaboradores ${ }^{96}$, o comportamento mecânico das blendas de PEAD com elastômero depende do grau de 
cristalinidade do material, sendo que o comportamento mecânico reproduz o grau de cristalinidade como verificado no item 5.5 (FIG. 34).

A irradiação das amostras nas doses de 50 e 100 kGy mostraram resultados interessantes descritos a seguir:

- Na dose mais baixa, as blendas com $1 \%$ de EPDM puro não alteraram o valor em relação à mesma blenda não irradiada, porém com $5 \%$ e $10 \%$ de EPDM puro os valores médios aumentaram por volta de $12 \%$ em relação às mesmas amostras não irradiadas; a blenda irradiada com $5 \%$ de EPDM puro teve o valor médio da tensão limite de escoamento próximo ao valor do PEAD virgem.

- $\mathrm{Na}$ dose mais alta, as blendas com $1 \%$ e $5 \%$ de EPDM puro apresentaram aumento dos valores médios de tensão limite de escoamento em torno de $10 \%$ em relação às mesmas blendas não irradiadas e esses valores estão próximos aos do PEAD virgem, no entanto, com $10 \%$ de EPDM puro o valor médio desse parâmetro foi maior cerca de $15 \%$ do que este mesmo tipo de amostra não irradiada.

Esses resultados mostraram que a irradiação nos níveis de dose aplicados às blendas de PEAD $4^{\circ}$ reprocessamento com EPDM puro em concentrações entre $1 \%$ e $5 \%$, favoreceu o aumento da tensão limite de escoamento sugerindo que o início da deformação em blendas com pequenas adições de EPDM pode ocorrer sob maior tração mecânica quando o processo de irradiação é aplicado ao produto final; sendo assim, é possível obter um material reciclado com qualidade mecânica comparada ao PEAD virgem quando se conjuga o processo de irradiação à pequenas quantidades desse elastômero na matriz polimérica. 


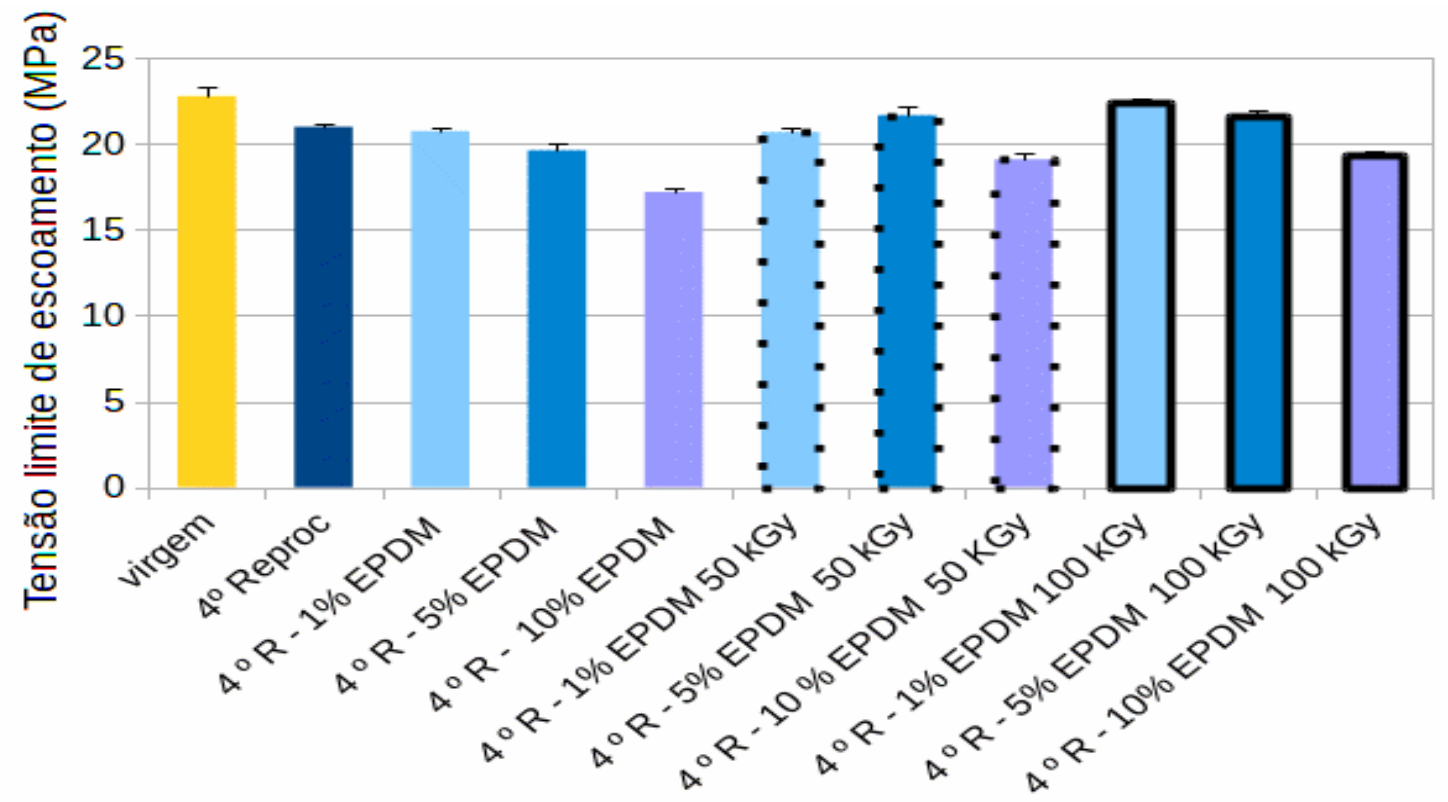

FIGURA 38 - Tensão limite de escoamento do PEAD virgem, 4ํrep. e das blendas de PEAD 4ํㅜ rep./EPDM puro, não irradiadas e irradiadas

A FIG.39 apresenta comportamento da tensão em $100 \%$ de deformação. Os resultados indicaram que o PEAD virgem apresentou valor médio de 11,8 MPa; O PEAD 4ำ reprocessamento apresentou o valor médio desse parâmetro ligeiramente menor, mas dentro do limite do desvio dos valores do termoplástico original. As blendas apresentaram tendência de redução nos valores médios desse parâmetro, sendo que a amostra com maior concentração de EPDM apresentou o menor valor (10,5 MPa). A tendência de diminuição da tensão em $100 \%$ de deformação nas blendas mostra que o elastômero, mesmo presente em pequenas quantidades na blenda, tem o efeito típico de relaxação sob a aplicação da tensão nessa região da curva tração-deformação.

Por outro lado, as amostras irradiadas apresentaram um comportamento crescente desse parâmetro em relação às blendas não irradiadas, chegando a ser em torno de $20 \%$ maior do que os valores do termoplástico virgem. Este comportamento pode estar relacionado ao processo de reticulação das blendas sob o efeito da irradiação, e que segundo a literatura ${ }^{103}$, pode levar à formação de ligações cruzadas (reticulação) nas regiões cristalina e amorfa desse tipo de material. 




FIGURA 39 - Tensão em 100 \% de deformação do PEAD virgem, 4ํㅜㄹ. ep das blendas de PEAD 4ํrep./EPDM puro, não irradiadas e irradiadas

\subsection{Ensaio de Flexão}

A FIG. 40 mostra o comportamento do módulo de flexão (módulo de elasticidade flexural) das amostras de PEAD virgem e reprocessado (4 vezes) e blendas de PEAD 4ํㅏㅁoprocessamento/EPDM puro, não irradiadas e irradiadas.

As amostras de PEAD virgem e PEAD 4ำ reprocessamento apresentaram médias semelhantes (721,2 MPa e 706,4 MPa respectivamente). As blendas não irradiadas apresentaram decréscimo dos valores médios com o aumento da composição do EPDM (658,2 MPa com 1 \% de EPDM, 609,1 MPa com $5 \%$ de EPDM e 519,1 MPa com $10 \%$ de EPDM).

As amostras irradiadas apresentaram aumento nas médias do módulo de flexão em relação às não irradiadas em cerca de $4 \%$ na menor dose e em cerca de $9 \%$ na maior dose. A amostra de PEAD reciclado/1\% EPDM irradiada sob dose de 100 kGy apresentou o valor médio desse parâmetro muito próximo à média do PEAD virgem, sugerindo que o processo de irradiação contribuiu para a reticulação deste tipo de blenda, o que possibilita a obtenção de desempenho semelhante ao termoplástico virgem.

É conhecido que o comportamento dos módulos de flexão e de elasticidade são semelhantes e diferem em termos de valores. Considerando o 
comportamento do módulo de flexão (FIG.40) em relação ao do módulo tênsil de elasticidade (FIG. 37) medidos neste trabalho, observou diferenças tanto em termos quantitativos como qualitativos. O módulo flexural de elasticidade medido para o PEAD virgem tem valores cerca de $50 \%$ abaixo dos valores típicos deste tipo de material (TAB.1), porém o comportamento qualitativo das demais amostras apresenta coerência. O módulo tênsil de elasticidade apresenta valor próximo ao da literatura para o PEAD virgem, porém o comportamento das demais amostras não é o esperado, principalmente o aumento do valor desse parâmetro com o aumento da concentração de EPDM nas amostras irradiadas. A metodologia experimental deve ser detalhadamente investigada nos próximos trabalhos; essas discrepâncias podem estar relacionadas à calibração do método e/ou ao espaço amostral insuficiente.

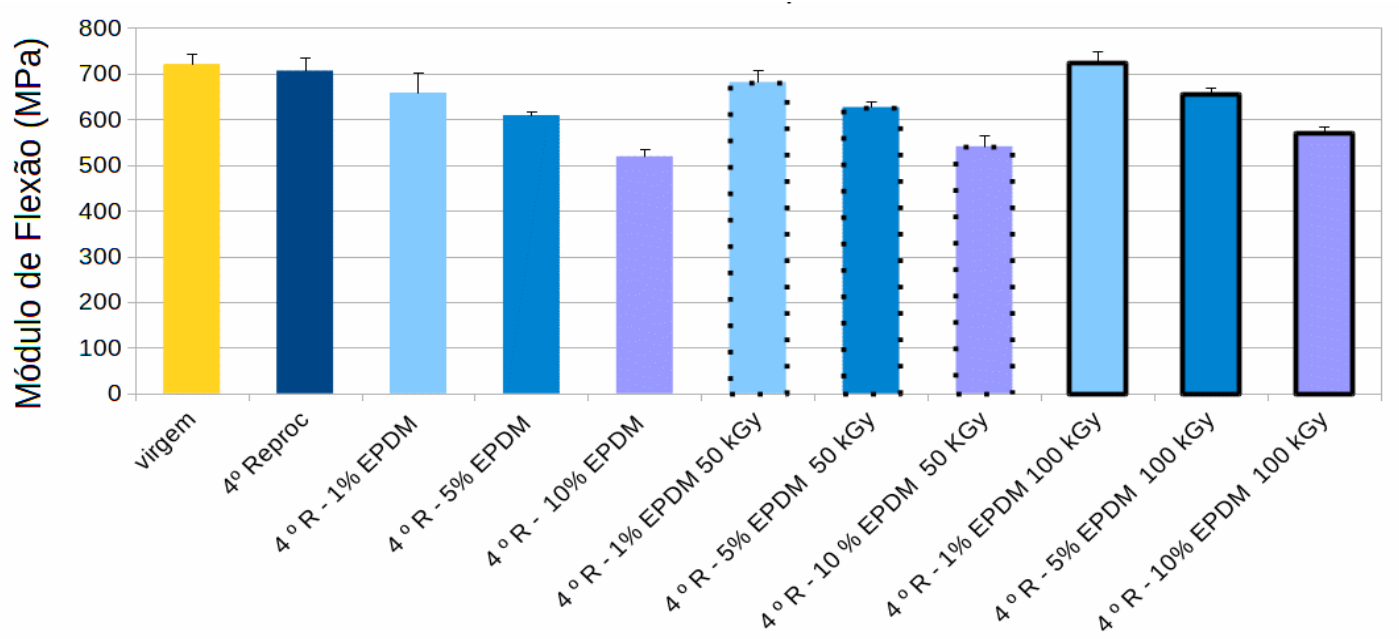

FIGURA 40 - Módulo flexural de elasticidade do PEAD virgem, e 4ํㅜ rep. e das blendas de PEAD $4^{\circ}$ rep/EPDM puro, não irradiadas e irradiadas

A tensão máxima de flexão (FIG. 41) mostrou comportamento qualitativo semelhante ao verificado no módulo flexural de elasticidade. O PEAD virgem e O PEAD reprocessado (4 vezes) apresentaram valores médios muito próximos (19, $2 \mathrm{MPa}$ e 18,8 MPa respectivamente). $\mathrm{O}$ aumento da concentração de EPDM nas blendas provoca a diminuição da tensão máxima de flexão $(17,8$ $\mathrm{MPa}, 16,3 \mathrm{MPa}$ e 14,1 MPa respectivamente para as blendas contendo $1 \%, 5 \%$ e $10 \%$ de EPDM), sendo um comportamento previsto. 
O processo de irradiação das blendas produziu como efeito o aumento do valor médio desse parâmetro em cerca de $5 \%$ nas amostras irradiadas na dose de $50 \mathrm{kGy}$ e cerca de $10 \%$ nas amostras irradiadas na dose de $100 \mathrm{kGy}$ em relação as amostras não irradiadas. A amostra de PEAD 4- reprocessamento/1\% EPDM puro irradiada sob dose de $100 \mathrm{kGy}$ apresentou o valor médio desse parâmetro acima da amostra do PEAD virgem. Esse comportamento é mais um indicativo de reticulação das blendas promovido pela irradiação.

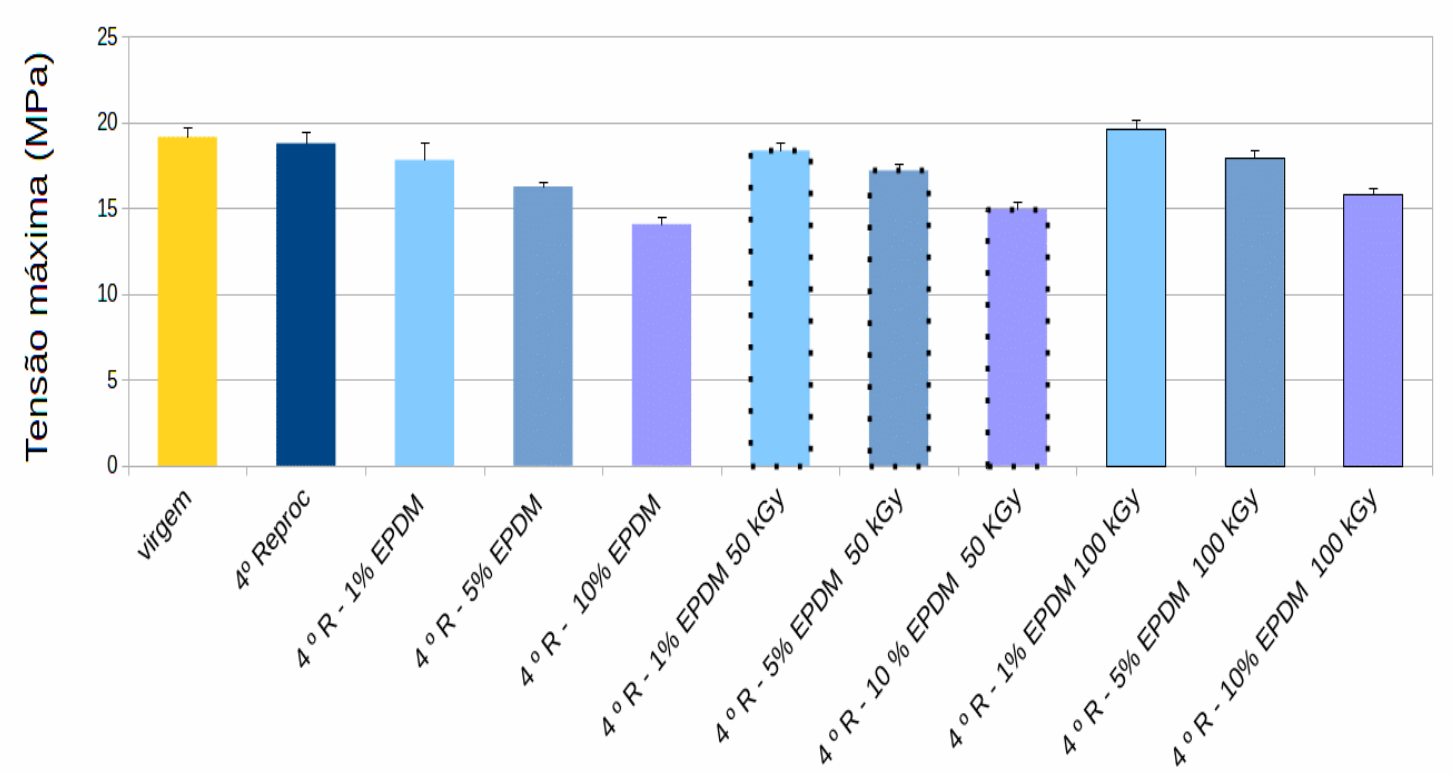

FIGURA 41 - Tensão máxima de flexão do PEAD virgem, $4^{\circ}$ rep. e das blendas de PEAD 4\%/EPDM puro, não irradiadas e irradiadas

\subsection{Ensaio de resistência ao impacto}

$\mathrm{Na}$ FIG. 42 observa-se que as amostras de PEAD virgem apresentaram um valor médio de $45,3 \mathrm{~J} / \mathrm{m}$, valor este próximo ao valor de referência $36 \mathrm{~J} / \mathrm{m}$ (TAB. 1). Este resultado foi considerado coerente, já que neste teste mecânico há muitas variáveis, desde temperatura do ensaio às condições de obtenção dos corpos-de-prova, que influenciam na reprodução de um resultado de referência com baixa margem de erro ${ }^{104}$.

$O$ valor médio desse parâmetro para o PEAD reciclado também foi próximo ao do termoplástico virgem $(47,6 \mathrm{~J} / \mathrm{m})$, sugerindo que o número de 
reciclagens não trouxe alterações significativas com relação à medida desse parâmetro.

A resistência ao impacto das blendas não irradiadas mostrou tendência de aumento do valor médio em função do aumento da concentração do elastômero (83 J/m, $89 \mathrm{~J} / \mathrm{m}$ e 189,8 $\mathrm{J} / \mathrm{m}$ respectivamente para os teores de $1 \%$, $5 \%$ e $10 \%$ de EPDM puro), o qual é um resultado esperado. Nota-se um aumento percentual por volta de $300 \%$ no valor do parâmetro na blenda com 10 \% de EPDM em relação ao PEAD reciclado, o que sugere que nesse nível de concentração do elastômero a resistência ao impacto é alta em comparação ao material reciclado. Esse comportamento de alta resistência ao impacto em blendas com baixa concentração de EPDM já foi observado por Stelescu e colaboradores $^{45}$, em cujo trabalho o EPDM está presente na concentração mínima de $20 \%$.

O processo de irradiação gera como efeito o aumento desse parâmetro nas blendas em função do aumento da concentração do EPDM e também em função do aumento de dose. Na menor dose, verifica-se que o valor médio da resistência ao impacto é idêntico à amostra não irradiada quando a blenda tem $1 \%$ de EPDM, porém ocorre um aumento percentual por volta de $146 \%$ e 217 \% respectivamente nas blendas com $5 \%$ e 10 \% do elastômero comparadas a esses mesmos teores nas blendas não irradiadas. Na maior dose, o aumento dos valores médios de resistência ao impacto das amostras irradiadas comparadas às não irradiadas é de $45 \%, 377 \%$ e $242 \%$ respectivamente quando os teores de EPDM são $1 \%, 5 \%$ e $10 \%$.

Os maiores valores médios de resistência ao impacto na maioria das amostras irradiadas sugere que nessas condições houve a geração de ligações cruzadas tornando as amostras com maior tenacidade. Consequentemente a formação de uma estrutura tridimensional dada pela reticulação nessas condições, conjugada às características do elastômero compatibilizado e misturado ao termoplástico produziram tal incremento deste parâmetro avaliado. 


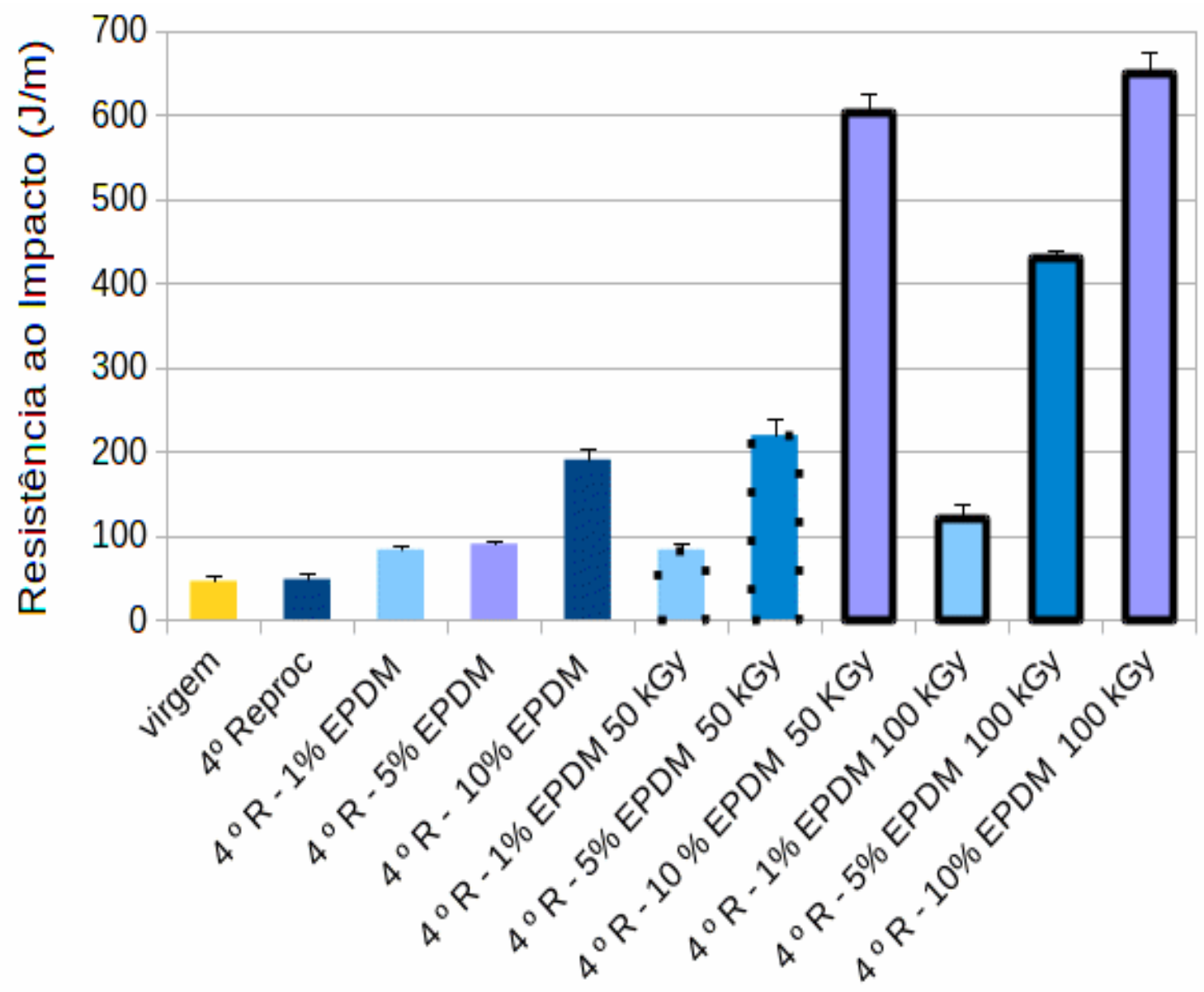

FIGURA 42 - Resistência ao Impacto do PEAD virgem, 4ํㅜㄹ. e das blendas PEAD 4ํㅏ. $\mathrm{rep}$ /EPDM puro, não irradiadas e irradiadas

\subsection{Microscopia eletrônica de varredura (MEV)}

A partir do exame das micrografias eletrônicas de varredura (MEV), 0 reprocessamento não apresentou nenhuma variação na superfície da fratura (FIG. 43), as amostras de PEAD virgem e PEAD 4ํㅜ reprocessamento não indicou nenhum evento superficial que poderia ter ocasionado uma propagação mais rápida da trinca e consequentemente uma menor resistência 
(a)

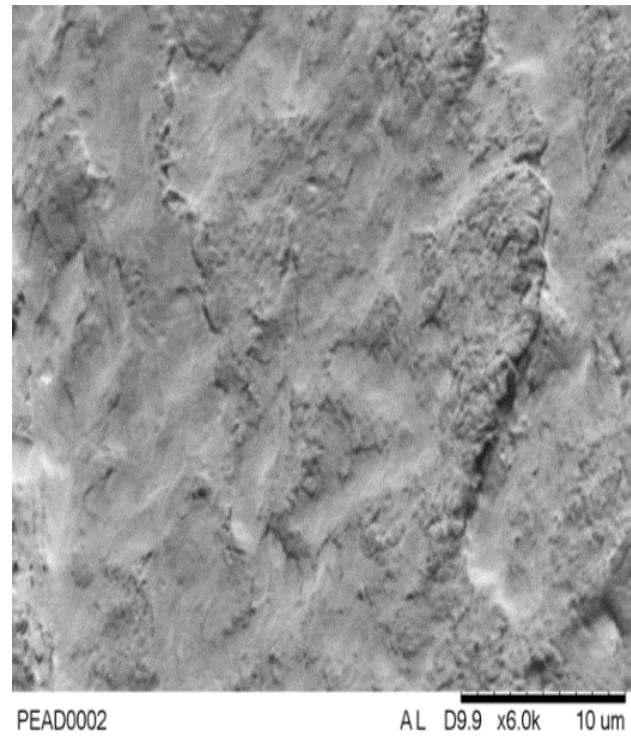

(b)

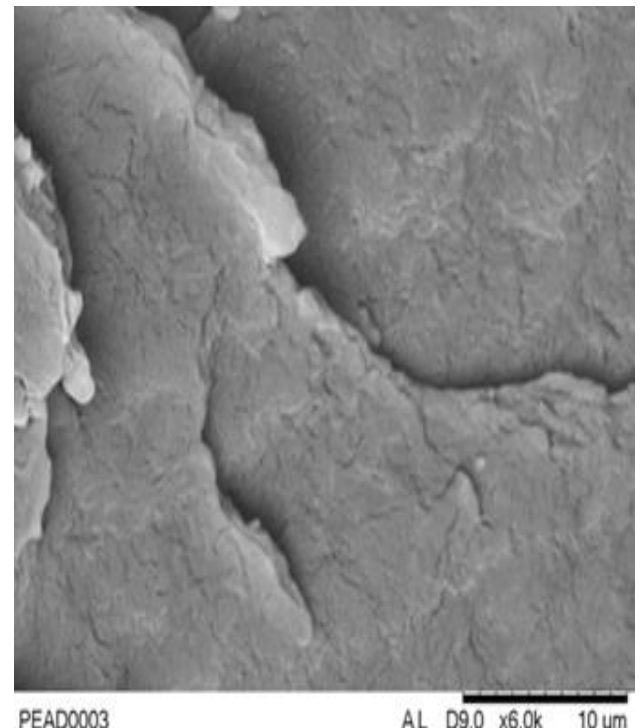

FIGURA 43 - Micrografias obtidas por microscopia eletrônica de varredura do PEAD virgem (a) e PEAD 4ํㅡㄹ Reprocessamento (b)

Nas amostras blendas de PEAD 4ํㅜ Reprocessamento/EPDM puro nas composições de $1 \%, 5 \%$ e $10 \%$ não irradiadas (FIG.44 a, b e c), não apresentaram nenhum domínio esférico que caracteriza fases dispersas sobre a matriz do PEAD. Este resultado confirma o estudo de $\mathrm{Kadi}^{46}$, que indica a interação do PEAD sobre o EPDM, promovendo uma fase continua, obtendo boa adesão interfacial e sem a visualização de fragilidade na região da fratura. As imagens indicam a miscibilidade dos materiais.

As amostras irradiadas em 50 kGy e 100 kGy (FIG. 44d-i), apresentaram o mesmo comportamento das blendas não irradiadas, indicando na superfície da fratura por criogenia uma fase contínua e boa adesão interfacial. Maiores concentrações de EPDM não alteraram a morfologia da blenda, indicando o comportamento de miscibilidade do EPDM na matriz polimérica do PEAD reciclado, o que pode concluir que nestas composições os efeitos do reprocessamento e o da radiação gama não promoveram nenhuma alteração em relação às amostras não irradiadas. 
1\% EPDM

(a)

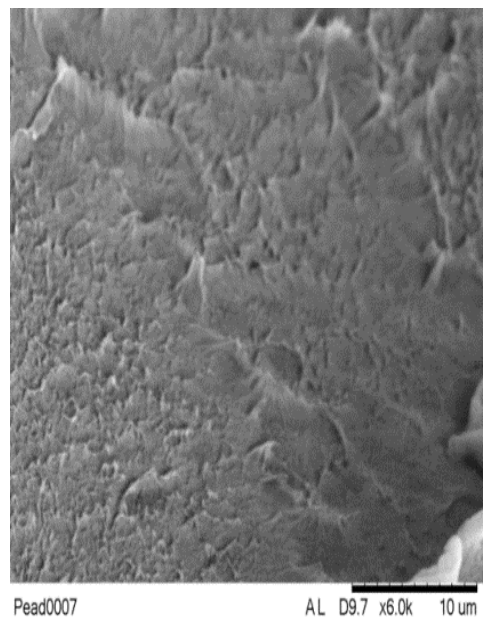

(d)

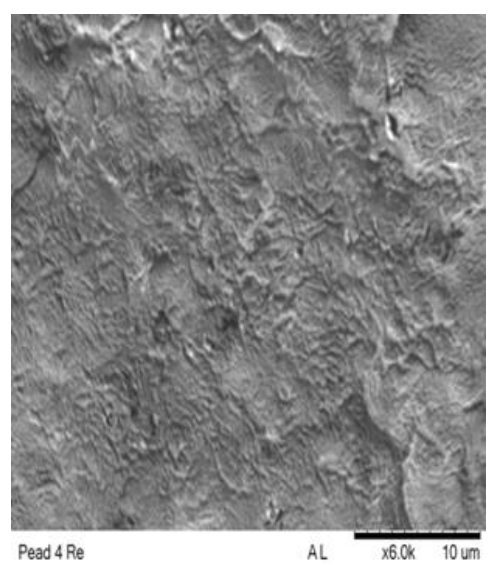

PEAD 4 ReplEpdm 1\% $50 \mathrm{kG}$

(g)

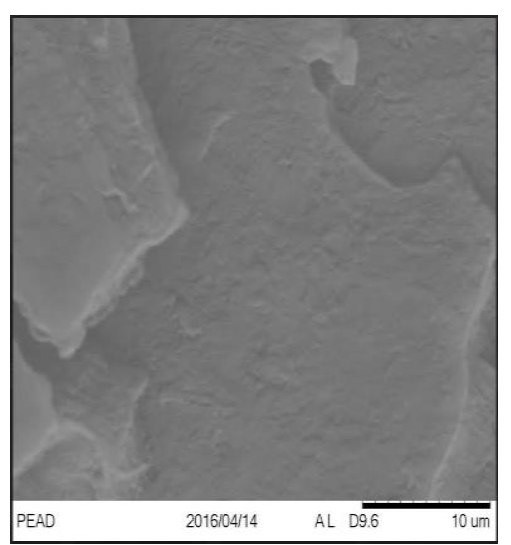

$5 \%$ EPDM

(b)

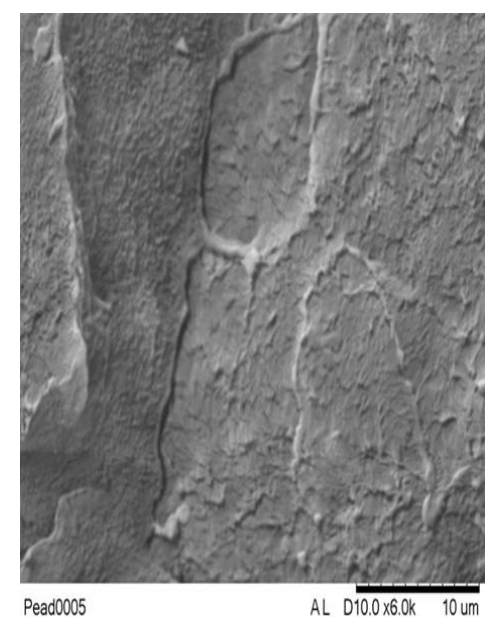

(e)

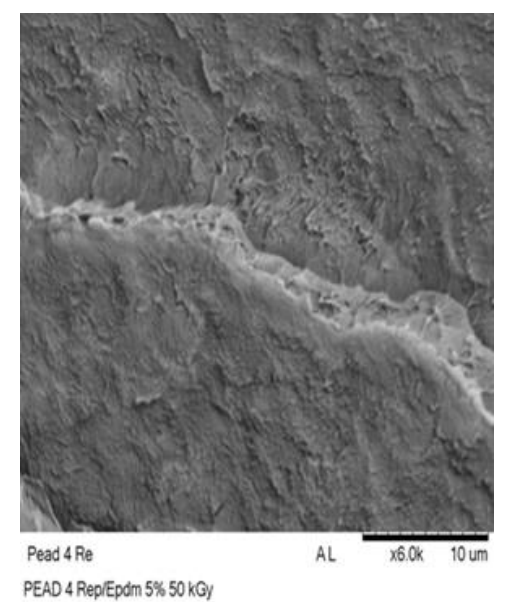

(h)

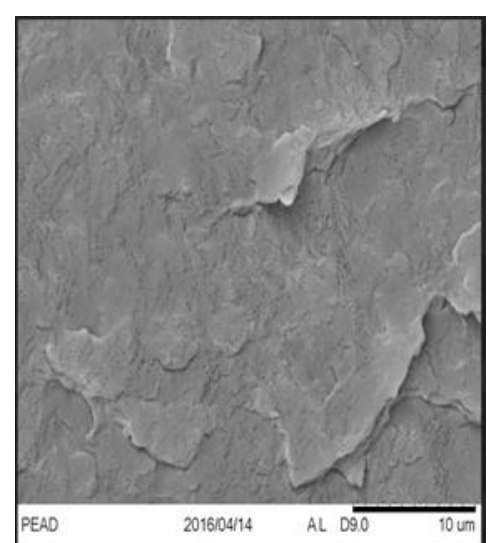

$10 \%$ EPDM

(c)

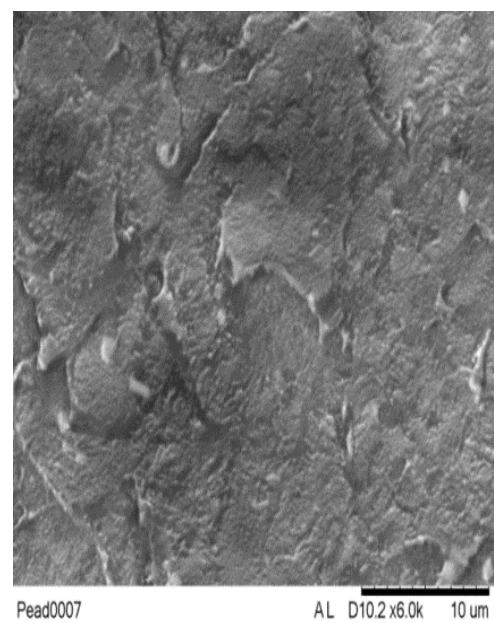

(f)

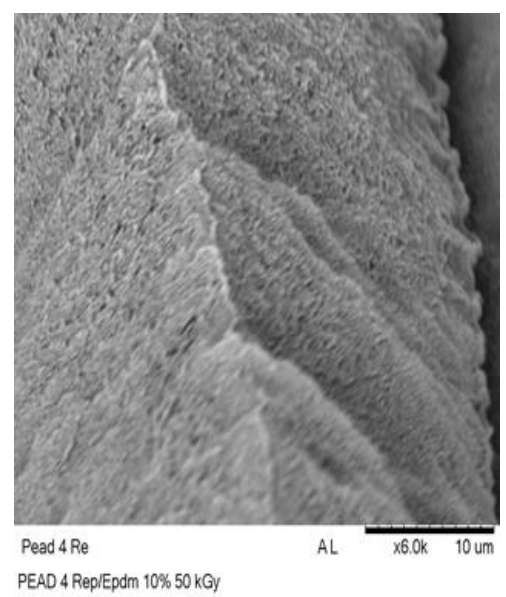

(i)

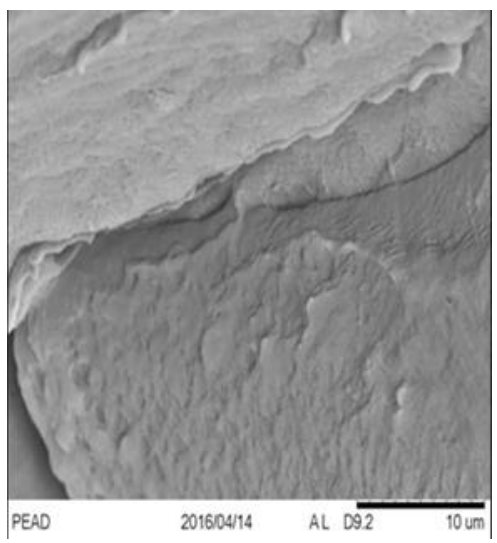

FIGURA 44 - Micrografias obtidas por microscopia eletrônica de varredura para as blendas: (a,b,c) PEAD 4ํㅡㄹ Reciclagem / 1, 5 e $10 \%$ de EPDM não irradiada , (d,e,f) irradiadas com dose de $50 \mathrm{kGy},(\mathrm{g}, \mathrm{h}, \mathrm{i})$ irradiadas com dose de 100 kGy 


\section{CONCLUSÕES}

A partir da discussão dos resultados, pode-se concluir que:

O PEAD reprocessado por quatro vezes é um produto que já apresenta a tendência a degradação, apesar do processo termomecânico também promover a reticulação. No entanto, nesse nível de reciclagem, muitas características físicas e químicas são semelhantes às do PEAD virgem como o grau de cristalinidade e alguns parâmetros mecânicos como resistência ao impacto, módulo de flexão, tensão máxima de flexão e tensão em $100 \%$ de deformação. A morfologia da superfície fraturada do PEAD reciclado não mostrou-se alterada em relação ao PEAD virgem.

As blendas formadas pelo PEAD reciclado e EPDM puro apresentaram interação em termos de compatibilidade e miscibilidade. $O$ aumento da concentração do elastômero promoveu a diminuição do grau de cristalinidade e também aumentou o tamanho do cristalito, efeito promovido pela co-cristalização de cada um dos componentes, o que pode explicar a sua alta interação e miscibilidade sem o uso de outros agentes. Com o aumento da concentração de EPDM, as blendas tornaram-se mais maleáveis e com resistência ao impacto, mas suportam menor tensão. As blendas guardam semelhante morfologia da superfície fraturada em relação ao PEAD reciclado.

O processo de irradiação gama permitiu obter blendas reticuladas, embora o processo de degradação concorrente seja evidente. A reticulação induzida por radiação é notória no PEAD, porém na blenda, o elastômero parece apresentar suscetibilidade aos efeitos da radiação. É evidente o aumento dos parâmetros mecânicos em relação às blendas não irradiadas, principalmente nas amostras com baixa concentração do elastômero; alguns parâmetros mecânicos de amostras com baixa concentração de EPDM apresentaram maior desempenho do que até mesmo o PEAD virgem. $O$ processo de irradiação não promoveu mudanças na morfologia das blendas. 


\section{TRABALHOS FUTUROS}

Com esse trabalho pôde-se obter blendas poliméricas que conjugam compatibilidade/miscibilidade de componentes com alto desempenho mecânico promovido pelo processo de irradiação, o que vem a configurar uma alternativa na busca de soluções industriais. Com o material obtido é possível analisar uma redução de custos atendendo as necessidades de empresas principalmente de pequeno e médio porte, sem que haja grande dispêndio financeiro para a sua obtenção em termos de aquisição de aditivos e aplicação de processos mais elaborados e de alto custo.

O presente trabalho abriu distintas possibilidades para 0 seu desenvolvimento científico e tecnológico:

- Investigar o processo de co-cristalização entre os componentes da mistura PEAD/EPDM;

- $\quad$ Propor modelo estatístico da mistura considerando os fatores que influenciam nos parâmetros mecânicos, físicos e químicos da blenda;

- $\quad$ Estudar o comportamento de blendas de PEAD/EPDM na condição da matriz polimérica de PEAD por reciclagem secundária, considerando outros parâmetros (p. ex. pigmentação e outros agentes nucleantes, outras composições). 


\section{REFERÊNCIAS BIBLIOGRÁFICAS}

1 COLTRO, L.; GASPARINO, B.F.;QUEIROZ,G.C.; Reciclagem de materiais plásticos: A importância da identificação correta. Polímeros: Ciência e Tecnologia, v.18, n. 2, p.119-125, 2008.

2 SHIBAO,F.Y; MOORI, R.G.; SANTOS,M.R. A logística reversa e a sustentabilidade empresarial. Seminários em Administração. Setembro de 2010 .Disponívelem:<http://www.ead.fea.usp.br/semead/13semead/resultado/trabalhos PDF/521. pdf -521>.Acesso em: 09 novembro de 2014.

3 COSTA, H. M.; RAMOS, V.D.; ANDRADE, M. C.; LESSA, M. D. Cinética de Cristalização Não-isotérmica de Resíduos de Polietileno de Alta Densidade (PEAD). Polímeros, v. 24, n. 4, p. 521-528, 2014.

4 MANCINI, S. D.; NOGUEIRA, A. R.; KAGOHARA, D.A.; SCHWARTZMAN, J.A.S.; MATOS, T.; ROSA, A.H. - Influência do Tipo de Coleta (Comum ou Seletiva) na Reciclagem de Filmes de Poliolefinas Pós-consumo. Polímeros: Ciência e Tecnologia, v. 18, n. 4, p. 289-296, 2008.

5 BRASKEM. Setor Petroquímico. Estimativa da Produção do Eteno. Disponível em: <http://www.braskem.com.br/o-setor-petroquimico.> Acesso em: 20 novembro de 2015.

6 LANXESS. Press Releases. Estimativa da Produção de EPDM. Disponível em: < http://lanxess.com.br/pt/imprensa/news. $>$ Acesso em 22 novembro. 2015.

7 ASSOCIAÇÃO BRASILEIRA DE NORMAS TÉCNICAS. NBR 10.004: Resíduos Sólidos - Classificação. Rio de Janeiro: 2004.

8 ALZERRECA, M.; PARIS, M.; BOYRON, O.; ORDITZ, D.; LOUARN, G.; CORREC, O. Mechanical properties and molecular structures of virgin and recycled HDPE polymers used in gravity sewer systems. Polymer Testing, v.46, p. 1- 8, 2015.

9 CANEVALORO JÚNIOR, S. V. Ciência dos Polímeros. In: Degradação. São Paulo: Art Liber, 2006. p.122.

10 IUPAC - International Union of Pure and Applied Chemistry. Conceito sobre Blendas . Disponível <http://www.iupac.org/goldbook/P04736.pdf> Acesso em: 23 de junho de 2016. 
11 PEREZ, I.S.B.; MANRICH, S.; MANRICH, S. Efeito da Adição de Diferentes Copolímeros em Blendas HDPE/HIPS Pós-Consumo: Morfologia de Fases e Propriedades Térmicas. Polímeros: Ciência e Tecnologia, v. 18, n.3, p. 207-214, 2008.

12 BARRA, G.M.O.; ROEDER,J.; SOLDI, V.; PIRES, A.T.N.; AGNELLI, J.A.M. Blendas de Poliamida 6/Elastômero: Propriedades e Influência da Adição de Agente Compatibilizante. Polímeros: Ciência e Tecnologia, v. 13,n. 2, p. 94-101, 2003.

13 CAMERON,G.G.; QURESHI, M.Y.; TAVERN, S.C. Blends of immiscible Compatibilized with block copolymer : A spin -label study. Journal Euro Polymers, v. 32, p. 587- 591, 1996.

14 ABIPLAST, Associação Brasileira da Indústria do Plástico. Perfil 2014 Indústria brasileira de transformação de material plástico- São Paulo, 2014. Disponível em: <http://www.abiplast.org.br / publicacoes_tecnicas>. Acesso em: 20 de maio de 2015.

15 PEACOCK, A. J. Handbook of polyethylene: structures, properties and applications. In: Morphology and Crystallization of Polyethylene. New York: Marcel Dekker Inc, 2000. p. 67.

16 WIEBECK, H.; HARADA, J. Plásticos de Engenharia. São Paulo: Artiliber, 2005. cap.2. Polietileno de ultra-alto peso molecular-PEUAPM. p.37.

17 UNIVERSO DA QUÍMICA, Polímeros uma nova óptica; 2014. Disponível em:<http://universechemistry.blogspot.com.br/2014/10/polimeros-uma-novaoptica.html>. Acesso em: 22 de maio de 2015.

18 COUTINHO, F. M. B.; MELLO, I. L.; SANTA MARIA, L. C.Polietileno: Principais tipos, propriedades e aplicações. Polímeros: Ciência e Tecnologia, v. 13, n. 1, p. 1-13, 2003.

19 FERREIRA, R.L.R.; SANTANA, R.M.C. Estudo comparativo da influência da razão de sopro nas propriedades de filmes tubulares de PEBD e PEAD. Polímeros, v. 25, n. 1, p. 83-93, 2015.

20 SINFRÔNIO,F.S.M. Avaliação Termoanalítica da Reciclagem de Polietileno e Polietileno Tereftalato Usando Micro e Mesoporosos. 2006. (Tese Doutoramento). Universidade Federal da Paraíba Centro de Ciências Exatas e da Natureza, Departamento de Química , Programa de Pós-graduação em Química. Paraiba. 
21 CERCENA, R. Preparação, Caracterização,Propriedades Mecânicas e Térmicas de Sistemas EPDM/ CAULIM. 2013. (Tese Doutorado). Universidade Federal de Santa Catarina, Florianópolis.

22 STELESCU, M.D.; AIRINEI, A.; GRIGORAS, C. Use of Differential Scanning Calorimetry (DSC) in the Characterization of EPDM/PP Blends. International Journal Thermophysics, v. 31, p. 2264-2274, 2010.

23 DAMAZIO, D.; DUTRA, R.C.L.; DINIZ, M.F.; MATTOS, E. C.; Determinação por FT-IR de Transmissão e Reflexão (UATR) de Etileno e Propileno em EPDM. Polímeros, v. 24, n. 6, p. 703-710, 2014.

24 AZEVEDO, J. B.; CHAVEZ, M.A.; RABELLO, M.S. Efeito de Reticulante na Morfologia e Propriedades Físico-Mecânicas de Espumas Poliméricas Obtidas com EVA e EPDM. Polímeros, v. 20, p. 407-414, 2010.

25 SATORI SEAL. Estrutura molecular do EPDM. Disponivel em < http:// http://www.satoriseal.com/technical/technical_articles/compound_identification_in_ quality_control.htm >. Acesso em: 20 de janeiro de 2014 .

26 SPINACÉ, M. A. S.; PAOLI, M. A. A Tecnologia da reciclagem de polímeros. Química. Nova, v. 28, p. 65-72, 2005.

27 AMERICAN SOCIETY FOR TESTING AND MATERIALS - ASTM. Standards Relating to Recycling and Use of Recycled Plastics. ASTM D5033- 90, 1991.

28 CANDIAN, L. M.; DIAS , A. A. Estudo do Polietileno de alta densidade para uso em elementos estruturais. Cadernos de Engenharia de Estruturas, v. 11, n. 51, p. 1-16, 2009.

29 SAMDANI, G. Chemical treatment devulcanizes rubber crumbs for recycling. Chemical Engineering, n. 102, p. 17-19, 1995.

30 INSTITUTO DO PVC. O fluxograma esquemático da reciclagem mecânica. Disponivel em < http:// www.institutodopvc.org/publico/index.php.pdf > Acesso em: 20 de outubro de 2014.

31 UTRACKI, L.A.; WALSH, D.J.; WEISS, R.A. Multiphase Polymers: Blends and lonomers. In: Polymer Alloys, Blends, and lonomers. Washington: American Chemical Society, 1989. p. 2-3.

32 SIQUEIRA, D.F .; BRUNS, R.E .; NUNES, S.P. Compatibilização e Otimização de Blendas Poliméricas. Polímeros: Ciência eTecnologia, v. 3, p.15-19, 1993. 
33 ITO, E.N.; PESSAN, L.A.; HAGE JR. E.; COVAS, J.A. Análise do Desenvolvimento Morfológico da Blenda Polimérica PBT/ABS durante as Etapas de Mistura por Extrusão e Moldagem por Injeção. Polímeros: Ciência e Tecnologia, v. 14, n. 2, p. 83-92, 2004.

34 SCOTT,C.E.; MACOSKO,C.W. Morphology development during the initial stages of polymer-polymer blending. Polymer, v. 36, p. 461-470, 1995.

35 HANAFY,G.M.; MADBOULY, S.A.; OUGYZAWA, Y.; INOUE, T. Effect of shear history on the morphology and coarsening behaviour of polycarbonate /poly(styrene-co-acrylonitrile) blend. Polymer, v. 46, p. 705- 712, 2005.

36 AKCELRUD,L. Fundamentos das Ciências dos Polímeros. In: Estrutura e Propriedades. São Paulo: Manole, 2007. p. $19-27$.

37 LIMA. J. Comportamento de fases de soluções binárias e ternárias de Poli (Etileno - co- Álcool Vinílico), Poli (Metacrilato de Metila) e Dimetilformamida. 2008. (Tese Doutorado).Universidade Estadual de Campinas, Campinas.

38 QUENTAL, A.C; CARVALHO, F.P.; TADA, E. S.; FELISBERTI, M. I. Blendas de PHB e seus copolímeros: miscibilidade e compatibilidade. Química Nova, v. 33, n. 2, p. 438-446, 2010.

39 CASTRO, R. E. N. ; SALAS, J. C. I.; TOLEDO, E.A.; RUBIRA , A. F. ; MUNIZ, E. C. Estudo da Cristalização e miscibilidade de blendas constituídas de PEO e PVC. In Anais do CONGRESSO BRASILEIRO DE ENGENHARIA E CIÊNCIA DOS MATERIAIS, 14, São Pedro, SP, 2000.

40 WELLEN, R. M.R.; RABELLO, M.S. Redução da Velocidade de Cristalização a Frio do PET na Presença de Poliestireno. Polímeros: Ciência e Tecnologia, v. 17, n. 2, p. 113-122, 2007.

41 PASSADOR, F.R.; PESSAN, L.A.; Estado de Mistura e Dispersão da Fase Borrachosa em Blendas PVC/NBR. Polímeros: Ciência e Tecnologia, v. 16, n. 3, p. 174-181, 2006.

42 MUNARO, M. Desenvolvimento de blendas de polietileno com desempenho aperfeiçoado para utilização no setor elétrico. 2007.(Tese Doutorado). Universidade do Paraná, Curitiba.

43 MELO, T.J.A.; CARVALHO, L.H. Propriedades Mecânicas e Morfologia de uma Blenda Polimérica de PP/HIPS Compatibilizada com SEBS. Polímeros: Ciência e Tecnologia, v. 10, n. 2, p. 82-89, 2000. 
44 OLAYO , R.; MANZUR , A.; LLMAS , J. H.; ESCOBAR , A. Effect of EPDM on the mechanical properties of blends of high and low density polyethylene. Polymer Bulletin, v. 41, p. 99-105, 1998.

45 STELESCU, D. M.; AIRINEI, A .; HOMOCIANU , M .; FIFERE , N.; TIMPU , D.; AFLORI , M. Structural characteristics of some high density polyethylene/EPDM blends. Polymer Testing, v. 32 , p. 187-196 , 2013.

46 KADI, A.A.; BRAHIMI, B.; BOUSMINA, M.Polymer Blends for Enhanced Asphalt Binders. Polymer Engineering and Science, v. 36, n. 12, p. 1724$1733,1996$.

47 VRANGES, N.; REK, VESNA. Effect of EPDM on Morphology, Mechanical Properties, Crystallization Behavior and Viscoelastic Properties of iPPpHDPE Blends. Macromolecular Symposia, v. 258, p. 90-100, 2007.

$48 \mathrm{KIM}$, J. Y.; CHUN, B. C. Effect of high density polyethylene addition and testing temperature on the mechanical and morphological properties polypropylene/ethylene-propylene diene terpolymer binary blend. Journal of Materials Science, v. 35, p. 4833 - 4840, 2000.

49 CHAPIRO, A. Radiation Chemistry of Polymers. Radiation Research Supplement, v. 4, p. $179-191,1964$.

50 O'DONNELL, J.H., SANGSTER,D.F. Principles of radiation chemistry. London: Edward Arnold Publishers, p. 8-21, 1970.

51 CLOUGH, R.L. High - energy radiation and polymers: A review of commercial processes and emerging applications. Nuclear Instruments and Methods in Physics Research B, v. 185, p. 8-33, 2001.

52 SILVERMAN, J.Basic Concepts of Radiation Processing. Radiation Physics and Chemistry, v. 9, p. 1-15, 1977.

53 CLELAND, M.R.; PARKS, L.A.; CHENG, S. Applications for radiation processing of materials. Nuclear Instruments and Methods in Physics Research B , v. 208, p. 66-73, 2003.

54 MARTIN, S.R.S. Recuperação/Reciclagem de Compostos de Borrachas Butílica e Halobutílica por meio de Radiação Ionizante. 2013.(Tese Doutorado). Instituto de Pesquisas Energéticas e Nucleares, São Paulo.

55 ADEM, E.; AVALOS-BORJA, M.; CARRILO, D.; VASQUEZ, M.; SANCHES, E.; CARREON, M. P. e BURILLO, G. Crosslinking of recycled polyethylene by gamma 
and electron beam irradiation. Radiation Physics and Chemistry, v. 53, n. 1/6, p. 171-176, 1998.

56 SUAREZ, J. C. M.; MANO, E. B.; PEREIRA, R. A .Thermal behavior of gammairradiated recycled polyethylene blends. Polymer Degradation and Stability, v. 69 , p. $217-222,2000$.

57 SUAREZ, J. C. M.; MANO, E. B.;Characterization of degradation on gammairradiated recycled polyethylene blends by scanning electron microscopy. Polymer Degradation and Stability, v. 72, p. 217-221, 2001.

58 ÖZDEMIR, T. Gamma irradiation degradation/modification of 5-ethylidene 2norbornene (ENB)-based ethylene propylene diene rubber (EPDM) depending on ENB content of EPDM and type/content of peroxides used in vulcanization. Radiation Physics and Chemistry, v. 77, p. 787-793, 2008.

59 DAVENAS, J.; STEVENSON, I.; CELETTE, N.; CAMBON, S.; GARDETTE, J. L.; RIVATON, A.; VIGNOUD, L . Stability of polymers under ionising radiation: The many faces of radiation interactions with polymers, Nuclear Instruments and Methods in Physics Research, v. 191 p. 653-661, 2002.

60 ZAHARESCU, T. Irradiation Effects on Ethylene-Propylene Elastomers in an Aqueous Environment, Polymer Testing, v. 15, p. 69-73, 1996.

61 HACIOGLU, F.; ÖZDEMIR, T., ÇAVDAR, S.; USANMAZ, A. Possible use of EPDM in radioactive waste disposal: Long term low dose rate and short term high dose rate irradiation in aquatic and atmospheric environment, Radiation Physics and Chemistry, v. 83, p.122-130, 2013.

62 ZEID, M. M. A.; RABIE, S. T.; NADA, A. A.; KHALIL, A. M; HILAL, R. H. Effect of Gamma Irradiation on Ethylene Propylene Diene Terpolymer Rubber Composites. Nuclear Instruments and Methods in Physics Research B., v. 266, n. 1, p. 111-116, 2008.

63 SHIN, B. S.; SEO, D.K.; KIM, H.B.; JEUN, J.P.; KANG, P.H. A study of the thermal and mechanical properties of electron beam irradiated HDPE/EPDM blends in the presence of triallyl cyanurate. Journal of Industrial and Engineering Chemistry., v. 18, p. 526-531, 2012.

64 JIA, S.; ZHANG, Z.; WANG, Z.; ZHANG, X.; DU, Z. A study of y -radiationcrosslinked HDPE/EPDM composites as flame retardants. Polymer International, v. 54 , p. 320-326, 2005. 
65 MOHAMED, M.A.; SHALTOUT, N.A.; EL MILIGY.The effect of gamma irradiation and particle size of $\mathrm{CaCO} 3$ on the properties of HDPE/EPDM blends, Arabian Journal of Chemistry, v. 4, p. 71-77, 2011.

66 BRASKEM. Produtos, Folhas de dados. In Portal Braskem. Disponível em: < http:/ www.braskem.com.br >. Acesso em : 29 de maio de 2014.

67 LANXESS. Produtos, Folha de dados. In Portal LANXESS. Disponível em: < http:/ www.lanxess.com.br >. Acesso em: 06 de junho de 2014.

68 ALCÂNTARA,R.L.;CARVALHO,L.H.;RAMOS,S.L.M.S.Propriedades Mecânicas de Resíduos Plásticos Urbanos da Região Nordeste. I- Influência das Condições de Processamento. Polímeros: Ciência e Tecnologia, v. 5, p. 42-47,1995.

69 ANNUAL BOOK OF ASTM STANDARDS. Standard Test Method for Tensile Properties of Plastics. ASTM D-638, 2014.

70 ANNUAL BOOK OF ASTM STANDARDS. Standard Test Methods for Flexural Properties of Unreinforced and Reinforced Plastics and Electrical Insulating Materials. ASTM D-790,2015.

71 ANNUAL BOOK OF ASTM STANDARDS.Standard Test Methods for Determining the Izod Pendulum Impact Resistance of Plastics. ASTM D-790, 2010.

72 BABETTO, A. C.; CANEVALORO, S. V. Degradação de Polipropileno durante múltiplas extrusões. Polímeros: Ciência e Tecnologia, v. 10, n. 2, p. 90-99, 2000.

73 XINDA CORP. Produtos. In XINDA. Disponível em: <http:/ www.xinda copr.com/ products/ Co-Kneader>. Acesso em: 20 de setembro de 2015.

74 CANEVALORO JR, S. V. Ciência dos Polímeros. In:Comportamento Mecânico dos Polímeros. São Paulo: Art Liber, 2006. p.191.

75 MOTHÉ, C. G.; AZEVEDO, A. D. Análise Térmica de Materiais. São Paulo, SP: ieditora, 2002.

76 ANNUAL BOOK OF ASTM STANDARDS. Standard Test Method for RubberCompositional Analysis by Thermogravimetry (TGA). ASTM D-6370, 2014.

77 PADILHA, A. F. Materiais de Engenharia ,Microestrutura e Propriedades. In: Determinação da estrutura cristalina. Curitiba: Hemus, 3.ed, 2000. p. 89- 101. 
78 ANNUAL BOOK OF ASTM STANDARDS. Standard Test Method for Transition Temperatures and Enthalpies of Fusion and Crystallization of Polymers by Differential Scanning Calorimetry. ASTM D- 3418, 2015.

79 STRÖMBERG, E.; KARLSSON, S. The Design of a Test Protocol to Model the Degradation of Polyolefins During Recycling and Service Life. Journal of Applied Polymer Science, v. 112, p. 1835-1844, 2009.

80 SANTOS, P.M.; CARDOSO, M.A.G.; KHOURI, S.; JUNIOR, A.R.P.; UEHARA, M.; SAKANE, K.K. Utilização da microespectroscopia infravermelha (FT-IR) para teste de algoritmos estatísticos na diferenciação dos micro-organismos Candida albicans, Candida dubliniensis e Candida parapsilosis. Revista Brasileira de Engenharia Biomédica, v. 28, n. 4, p. 398-409, 2012.

81 ANNUAL BOOK OF ASTM STANDARDS. Standard Test Method for Rubber, Raw - Determination of Gel, Swelling Index, and Dilute Solution Viscosity. ASTM D-2765, 2011.

82 DEDAVID, B. A.; GOMES, C.I.; MACHADO, G. MICROSCOPIA ELETRÔNICA DE VARREDURA. Aplicações e preparação de amostras :Materiais Poliméricos, metálicos e semicondutores. Porto Alegre, RS: EDIPUCRS, 2007.

83 SILVERSTEIN, R.M., BESSLER, G.C., MORRILL, T.C. Identificação Espectrométrica de Compostos Orgânicos. In;Espectrometria no infravermelho. Rio de Janeiro: Guanabara, 1979. p.65.

84 SILVERSTEIN, R.M., BESSLER, G.C., MORRILL, T.C. Identificação Espectrométrica de Compostos Orgânicos. In:Espectrometria no infravermelho. Rio de Janeiro: Guanabara, 1979. p.75-76.

85 RABELLO, M. Aditivação de Polímeros. In: Estabilizantes. São Paulo: Artliber, 2000. p. 43-46.

86 SILVERSTEIN, R.M., BESSLER, G.C., MORRILL, T.C. Identificação Espectrométrica de Compostos Orgânicos. In;Espectrometria no infravermelho. Rio de Janeiro: Guanabara, 1979. p.127.

87 MOSS, S.; ZWEIFEL, H. Degradation and Stabilization of High Density Polyethylene During Multiple Extrusions. Polymer Degradation and Stability, v. 25, p. 217-245, 1989.

88 DIVYA, V. C.; PATTANSHETTI, V.V.; SURESH, R.; SAILAJA, R.R.N. Development and characterisation ofHDPE/EPDM-g-TMEVS blends for mechanical and morphological properties for engineering applications. Journal of Applied Polymer Science, v. 130, p. 352-358, 2013. 
89 CONTAT-RODRIGO, L., RIBES-GREUS, A., IMRIE, C.T. Characterization by Thermal Analysis of High Density Polyethylens/Polypropylene Blends with Enhanced Biodegradability. Journal of Applied Polymer Science, v. 86, p. $174-185,2002$.

90 SCHEIRS, J., BIGGER, S.W., BILLINGHAM, N.C.Effect of Chromium on the Oxidative Pyrolysis of Gas-phase High-density Polyethylene as Determined by Dynamic Thermogravimetry. Polymer Degradation and Stability, v. 38, p. 139145, 1992.

91 KABORANI, A. Thermal Properties of Composites Made of Heat-treated Wood and Polypropylene. Journal of Composite Materials, v. 43, p. 2599-2607, 2009.

92 CHRISSAFIS, K., PARASKEVOPOULOS, K.M., STAVREV, S.Y., DOCOSLIS, A., VASSILIOU, A., BIKIARIS, D.N. Characterization and thermal degradation mechanism of isotactic polypropylene/carbon black nanocomposites. Thermochimica Acta, v. 465, p. 6 -17, 2007.

93 CAMACHO, W.; KARLSSON, S. Assessment of Thermal and Thermo-oxidative Stability of Multi-extruded Recycled PP, HDPE and a Blend Thereof. Polymer Degradation and Stability, v. 78, p. 385-391, 2002.

94 MELO,R.P.,AGUIAR,V.O., MARQUES, M.F.V. Silane Crosslinked Polyethylene from Different Commercial PE's: Influence of Comonomer, Catalyst Type and Evaluation of HLPB as Crosslinking Coagent. Materials Research, v. 18, m. 2, p. $313-319,2015$.

95 BIELIŃSKI, D.M., ŚLUSARSKI, L., WLOCHOWICZ, A., ŚLUSARCZYK, C., DOUILLARD, A. Some Aspects of Isotactic Polypropylene Crystallization in an Ethylene-Propylene-Diene Rubber Matrix. Polymer International, v. 44, p. 161173, 1997.

96 SILVA, A.L.N., TAVARES, M.I.B., POLITANO, D.P., COUTINHO, F.M.B., ROCHA, M.C.G. Polymer Blends Based on Polyolefin Elastomer and Polypropylene. Journal of Applied Polymer Science, v. 66, p. 2005-2014, 1997.

97 GINIC-MARKOVIC, M., CHOUDHURY, N.R., DIMOPOULOS, M., WILLIAMS, D.R.G., MATISONS, J. Characterization of Elastomer Compounds by Thermal Analysis. Thermochimica Acta, v. 316, p. 87-95, 1998.

98 JANIGOVÁ, I.,CHODÁK, I., CHORVÁTH, I. The Influence of Crosslinking on Isothermal Crystallization of LDPE Filled with Silica. European Polymer Journal, v. 28, n. 12, p. 1547-1552,1992.

99 PHILLIPS, P.J., KAO, Y.H. Crystallinity in Chemically Crosslinked Low Density Polyethylenes: 2. Crystallization Kinetics. Polymer, v. 27, p. 1679-1686, 1986. 
100 CHENG, S.Z.D., Handbook of Thermal Analysis and Calorimetry Applications to Polymers and Plastics, Series Ed. Gallacher, P. K. v. 3, p. 281282, Elsevier, Amsterdam, 2002.

101 GUPTA, A.K., RANA, S.K., DEOPURA, B.L. Crystallization Behavior of HighDensity Polyethylene/Linear Low-Density Polyethylene Blend. Journal of Applied Science, v. 44, p. 719-726, 1992.

102 CALLISTER JR., W.D. Ciência e Engenharia de Materiais, uma introdução. In: Características, Aplicações e o Processamento dos Polímeros. Rio de Janeiro: LTC, 5.ed, 2002. p. 327-337.

103 SINGH, A. Irradiation of polyethylene: Some aspects of crosslinking and oxidative degradation. Radiation Physics and Chemistry, v. 56, p. $375-380$, 1999.

104 CANEVAROLO JR, S. V. Técnicas de Caracterização de Polímeros. In: HAGE JÚNIOR, E. Resistência ao Impacto (Ed.) São Paulo: Art Liber, 2004. p. 363 